\title{
Atmospheric Pitting Corrosion Studies of AA7075-T6 Under Electrolyte Droplets
}

\section{THESIS}

Presented in Partial Fulfillment of the Requirements for the Degree Master of Science in the Graduate School of The Ohio State University

\author{
By \\ Mark Stephen Thomson \\ Graduate Program in Materials Science and Engineering
}

The Ohio State University

2016

Master's Examination Committee:

Dr. Gerald Frankel, Advisor

Dr. Jenifer Locke 
Copyright by

Mark Stephen Thomson

2016 


\begin{abstract}
Pitting corrosion of AA7075-T6 was investigated in situ by Scanning Kelvin Probe (SKP) and in exposures in outdoor settings by application of droplets containing $\mathrm{MgCl}_{2}$ and $\mathrm{NaCl}$. Initial droplet volumes of 3, 6 and $9 \mu \mathrm{L}$ were used, and salt concentrations were selected at $0.1,0.25,0.5$ and $1 \mathrm{M}$ for $\mathrm{MgCl}_{2}$, and 0.25, 0.6 (3.5 $\mathrm{wt} \%$ ), and $1 \mathrm{M}$ for $\mathrm{NaCl}$. Analysis for all tests was conducted by optical microscope and optical profilometer.

Within the droplets studied by SKP, single regions of sustained pitting attack formed with preference at the edge of the droplets due to shortened distance of oxygen diffusion. The pits at the sustained attack sites formed anodes with supporting cathodic reactions at the surrounding sample surface. As the pits grew, the cathodic region was observed to expand, leading to elevated potentials measured at the center of the droplets. Droplets with greater initial volume formed larger areas of contact with the sample surface leading to accelerated corrosion attack.

Comparison of samples exposed for various lengths of time outdoors to those tested in the lab displayed different corrosion behaviors for $\mathrm{MgCl}_{2}$ and $\mathrm{NaCl}$ droplets. $\mathrm{MgCl}_{2}$ droplets experienced similar pitting in the lab and outdoors. However, $\mathrm{NaCl}$ experienced more aggressive pitting attack on samples exposed outdoors. Outdoor tests for $\mathrm{NaCl}$ also underwent attack along the entire perimeter of the droplets. A mechanism is proposed for this attack.
\end{abstract}


Overall, sustained pitting attack is observed along groups of surface particles oriented along the rolling direction. In many cases, pitting led to the formation of a secondary droplet at the periphery of the primary droplet. A mechanism is proposed for the pitting behavior of AA7075-T6 under the studied electrolyte droplets, as well as a new mechanism for the formation of secondary droplets. 


\section{Dedication}

To my mom and dad, Linda and Steve, for supporting me much longer than I'm sure they expected, and with few complaints.

To my sisters, Kim and Lori, because you always have to include your siblings.

And to Veronica, for giving me the support and push I needed to get to the finish. 


\section{Acknowledgments}

First and foremost, I would like to thank my advisor, Dr. Gerald Frankel, for providing me with the opportunity to work with him and the wonderful people in the Fontana Corrosion Center. His patience, assistance and motivation were major contributions to my completion of this work. I would also like to thank Dr. Jenifer Locke for participating on the committee for my thesis defense.

I would like to acknowledge funding for this project was provided by the Office of the Secretary of Defense.

Last, I would like to thank all of the current and former students of the Fontana Corrosion Center that I had the privilege to work alongside with. Their assistance and willingness to answer my questions were of tremendous help, but more importantly, I could not have asked for a better group of people to spend this time with. 


\section{Vita}

Ohio State University
of Materials Science, The Ohio State
University

\section{Fields of Study}

Major Field: Materials Science and Engineering 


\section{Table of Contents}

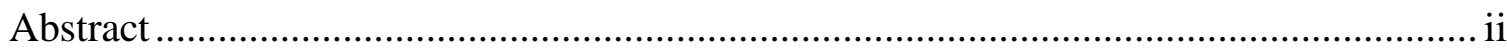

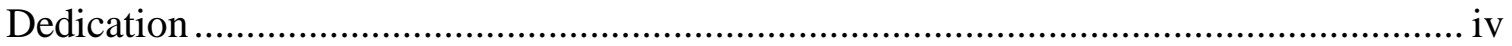

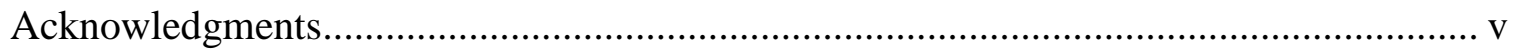

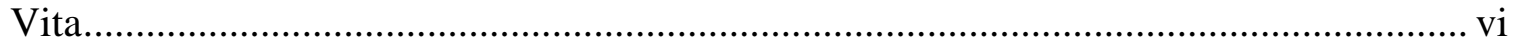

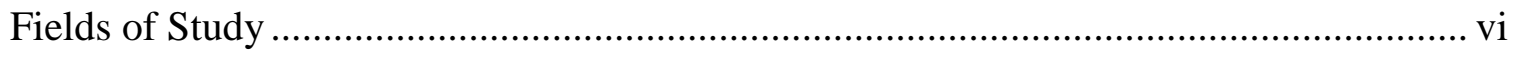

Table of Contents ............................................................................................... vii

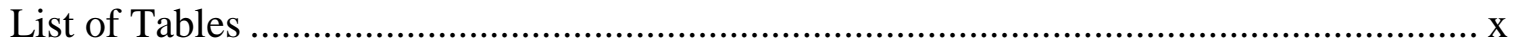

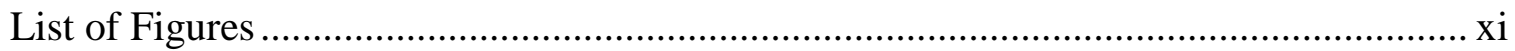

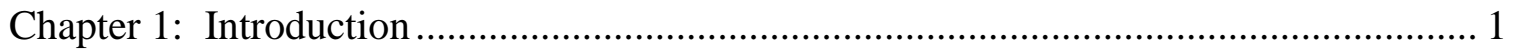

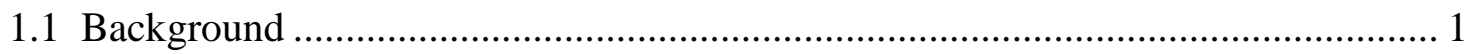

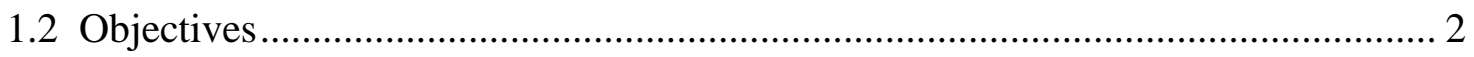

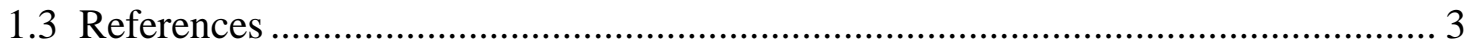

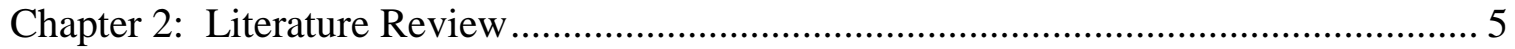

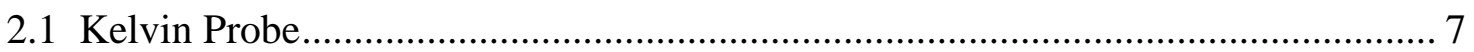

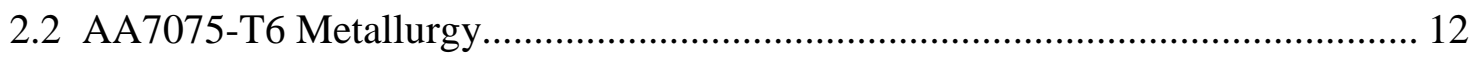

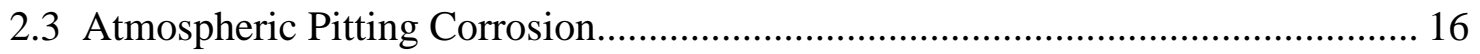




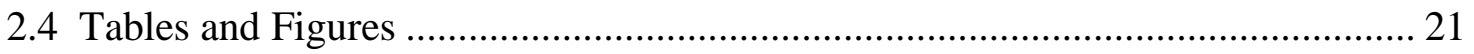

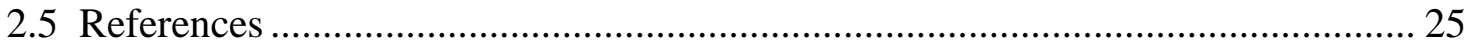

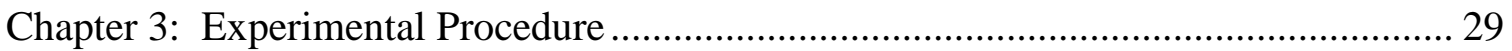

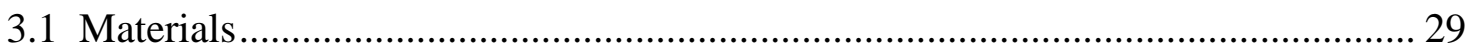

3.2 Scanning Kelvin Probe Droplet Testing.......................................................... 30

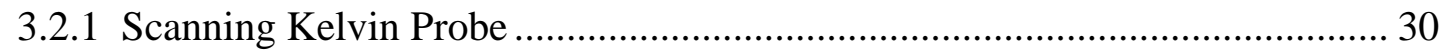

3.2.2 Tests of Droplet Varying Volume and Concentration................................... 30

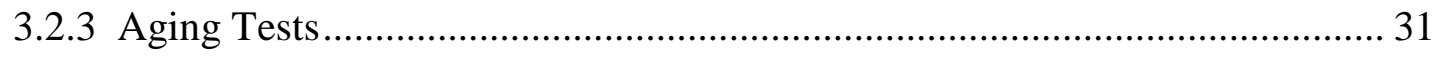

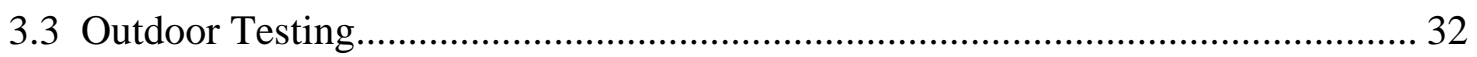

3.4 Stereomicroscope Droplet Study.................................................................... 32

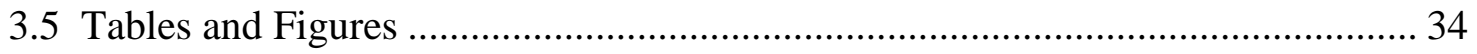

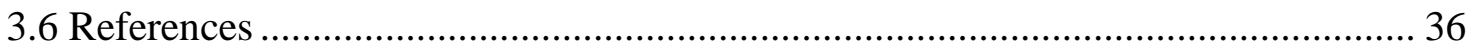

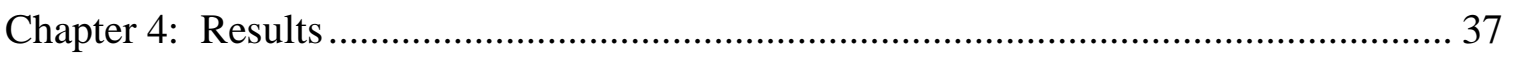

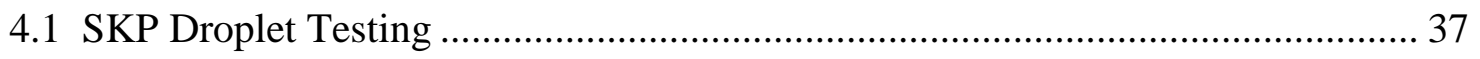

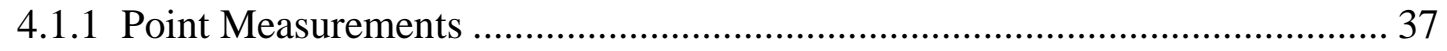

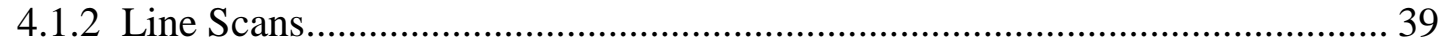

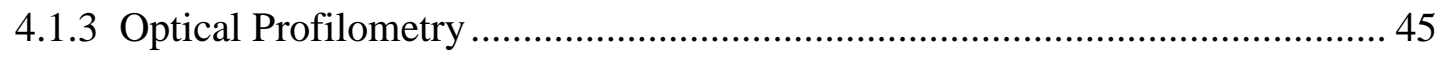

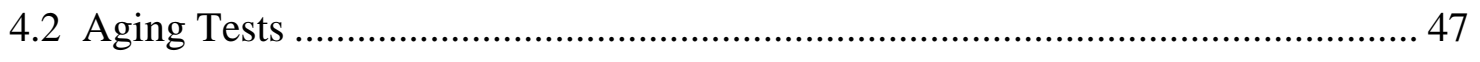

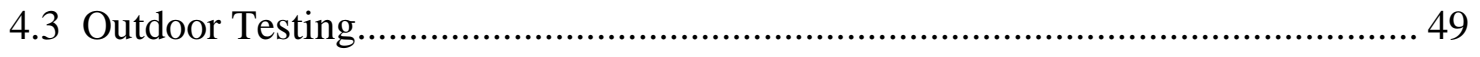


4.4 Stereomicroscope Droplet Study......

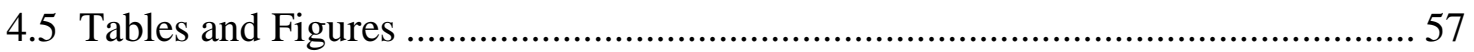

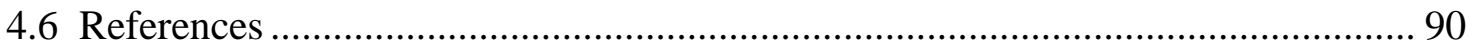

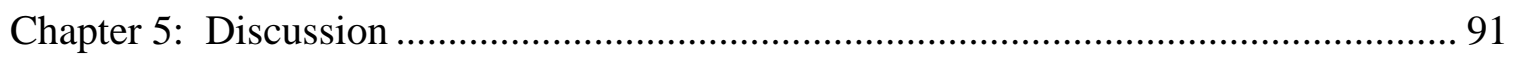

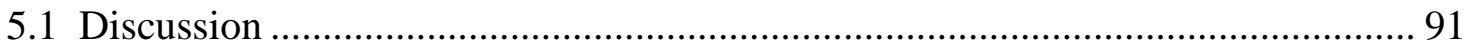

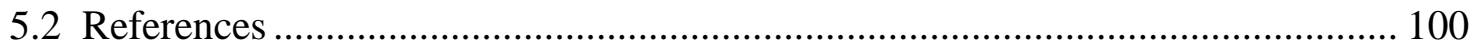

Chapter 6: Conclusions and Future Work............................................................ 101

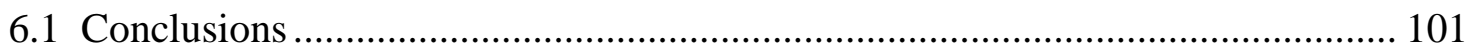

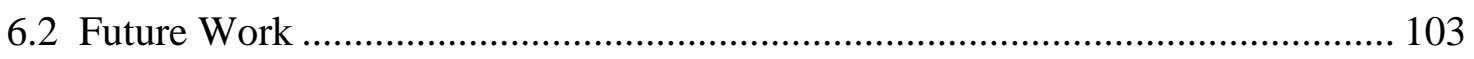

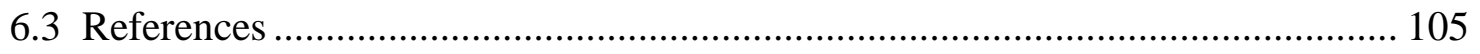

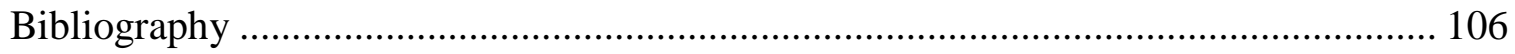




\section{List of Tables}

Table 3.1. Composition of AA7075 in agreement with ASTM B211............................ 34 Table 3.2. Typical temperature and relative humidity of Columbus, OH between July 11 and August 8, data retrieved from NOAA. ............................................................. 34 


\section{List of Figures}

Figure 2.1. Contact potential difference of two metals when in close proximity and when connected by a wire. 21

Figure 2.2. Position of electrically connected Scanning Kelvin probe tip relative to electrolyte droplet and test sample. Probe tip maintains fixed distance relative to surface of droplet. Based on ref ${ }^{13}$. Reproduced with permission of The Electrochemical Society.

Figure 2.3. a) Sample of waveform collected by SKP. b) Absolute value for processed waveform obtained in figure 'a' . Reproduced with permission of Elsevier.

Figure 2.4. Schematic diagram of KP and data acquisition setup utilizing off-nulling technique with height control. ${ }^{7}$ Reproduced with permission of Elsevier.

Figure 3.1. Photos of the SKP setup used. a) Overall setup. b) SKP chamber. 35 Figure 4.1. Potential profiles for $\mathrm{MgCl}_{2}$ droplet tests recorded with SKP for droplets with initial volumes of 3, 6 and $9 \mu \mathrm{L}$, and initial $\mathrm{MgCl}_{2}$ concentrations of $0.1 \mathrm{M}$ (top left), 0.25 $\mathrm{M}$ (top right), $0.5 \mathrm{M}$ (bottom left) and $1 \mathrm{M}$ (bottom right).... 57 Figure 4.2. Potential profiles for $\mathrm{NaCl}$ droplet tests recorded with SKP for droplets with initial volumes of 3, 6 and $9 \mu \mathrm{L}$, and initial $\mathrm{NaCl}$ concentrations of $0.25 \mathrm{M}$ (top left), 3.5 wt\% (top right) and $1 \mathrm{M}$ (bottom)...... 58 
Figure 4.3. Representative example of secondary droplet formation found under $6 \mu \mathrm{L}$ droplet of 3.5 wt\% NaCl. a) Pit initiation observed after 2 hours. b) Pit growth at 6 hours. c) Secondary droplet initiation at 12 hours. d) Secondary droplet growth after 20 hours.59 Figure 4.4. Highest points observed during line scans of droplets. Results for $\mathrm{NaCl}$

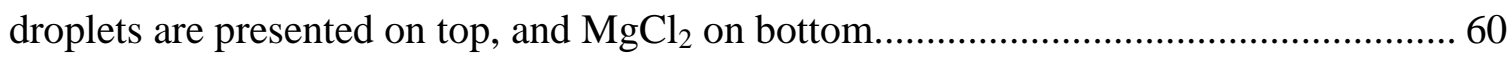
Figure 4.5. Comparison of droplet profile obtained by SKP line scan and droplet profile calculated based on measured height and diameter, as well as assumption that it behaved as a spherical cap. 62 Figure 4.6. Droplet experiment that experienced formation of a bulge in the droplet over the pitting region. On top, an image of the droplet as observed in the SKP is presented, as well as a dashed line representing the path of the line scan. On bottom, the profile obtained by the line scan is shown, with the bulge of interested found on the right side of the droplet.

Figure 4.7. Chloride concentration profiles of droplets derived from the known starting chloride content and the volume calculated from the diameter and observed droplet height. a) Droplets with initial $\mathrm{MgCl}_{2}$ concentration of $0.5 \mathrm{M}$. b) Droplets with initial volume of $9 \mu \mathrm{L}$ and varied $\mathrm{MgCl}_{2}$ concentration. c) Droplets with initial $\mathrm{NaCl}$ concentration of $3.5 \mathrm{wt} \%$. d) Droplets with initial volume of $9 \mu \mathrm{L}$ and varied $\mathrm{NaCl}$ concentration.

Figure 4.8. Potential profile obtained by SKP line scan across droplet of $0.1 \mathrm{M} \mathrm{MgCl}_{2}$ with initial volume of $9 \mu \mathrm{L}$ after 20 hour test in SKP chamber. 65 
Figure 4.9. Secondary droplet formation on $0.25 \mathrm{M} \mathrm{MgCl}_{2}$ droplet with initial volume of $9 \mu \mathrm{L}$ after 20 hour test in SKP chamber. On top is an image recorded of the droplet in the chamber with the path of the line scan shown. On bottom, the potential and height profiles are shown as obtained from the line scan. 66 Figure 4.10. A droplet of $0.1 \mathrm{M} \mathrm{MgCl}_{2}$ with initial volume of $6 \mu \mathrm{L}$ with a region of sustained pitting near the edge is shown as seen in the SKP on top, with a line identifying the path of the line scan. The resulting height and potential profiles are shown on the bottom.

Figure 4.11. Droplet of $3.5 \mathrm{wt} \% \mathrm{NaCl}$ with initial volume of $6 \mu \mathrm{L}$ studied during interval line scans. Sustained pitting occurred near the edge, seen behind the SKP probe tip in the image. The path of the line scans is shown by the dashed arrow. 68 Figure 4.12. On top, the potential profile against time measured by SKP at the center of the droplet shown in Figure 4.11. On bottom, potential profiles recorded during line scans by SKP performed after 5, 10, 15 and 20 hours 69 Figure 4.13. Optical microscope images of representative examples of behavior under droplets in SKP tests. a) Droplet of $3.5 \mathrm{wt} \% \mathrm{NaCl}$ with initial volume $6 \mu \mathrm{L}$. b) Droplet of 0.5 $\mathrm{M} \mathrm{MgCl}_{2}$ with initial volume $6 \mu \mathrm{L}$. Regions consistently observed are identified in both images. 70

Figure 4.14. Pitting volume and maximum pit depth of sustained pitting attack regions for droplets of $\mathrm{NaCl}$ studied in SKP. Pit volume shown on top, maximum pit depth shown on bottom. Data displaced for sets at matching initial droplet volume. 
Figure 4.15. Pitting volume and maximum pit depth of sustained pitting attack regions for droplets of $\mathrm{MgCl}_{2}$ studied in SKP. Pit volume shown on top, maximum pit depth shown on bottom. Data displaced for sets at matching initial droplet volume. 73

Figure 4.16. Diameter of droplets measured during aging experiments. 74

Figure 4.17. Volume of pits measured during aging experiments.............................. 75

Figure 4.18. Maximum depth of pits measured during aging experiments. .................. 76 Figure 4.19. Temperature and RH measured for the four weeks outdoor tests were conducted in Dublin, OH between July 11, 2015 and August 8, 2015.Data obtained from ref ${ }^{6}$ 77

Figure 4.20. Corrosion behavior of droplets of $0.5 \mathrm{M} \mathrm{MgCl}_{2}$ with initial volume $6 \mu \mathrm{L}$. Tests conducted in the lab are shown on the left, tests conducted outdoors shown on the right. Lengths of exposure were one day (top), four days (middle) and seven days (bottom)

Figure 4.21. Corrosion behavior of droplets of $3.5 \mathrm{wt} \% \mathrm{NaCl}$ with initial volume $6 \mu \mathrm{L}$. Tests conducted in the lab are shown on the left, tests conducted outdoors shown on the right. Lengths of exposure were one day (top), four days (middle) and seven days (bottom)

Figure 4.22. Comparison of pitting results for $\mathrm{MgCl}_{2}$ droplet tests conducted in the lab with those tested outdoors. Pitting depth shown on top, pitting volume shown on bottom. Data at each time interval displaced to separate weeks during which outdoor tests were conducted. 80 
Figure 4.23. Comparison of pitting results for $\mathrm{NaCl}$ droplet tests conducted in the lab with those tested outdoors. Pitting depth shown on top, pitting volume shown on bottom. Data at each time interval displaced to separate weeks during which outdoor tests were conducted.

Figure 4.24. Images recorded for droplet described in Example 1............................. 83

Figure 4.25. Images recorded for droplet described in Example 2.............................. 84 Figure 4.26. a) OM image of secondary droplet region from Example 2 after rinsing with DI water and ethanol. b) OM image of secondary droplet region after several minutes in the ultrasonicator. c) Secondary droplet region analyzed by optical profilometer. The secondary droplet regions are identified in the figures Figure 4.27. Images recorded for droplet described in Example 3. Initiation of secondary droplet identified. 86 Figure 4.28. a) OM image of secondary droplet region from Example 3 after rinsing with DI water and ethanol. b) OM image of secondary droplet region after several minutes in the ultrasonicator. c) Secondary droplet region analyzed by optical profilometer. 87 Figure 4.29. Images recorded for droplet described in Example 4. Initiation of secondary droplet identified. 88 Figure 4.30. a) OM image of secondary droplet region from Example 4 after rinsing with DI water and ethanol. b) OM image of secondary droplet region after several minutes in the ultrasonicator. c) Secondary droplet region analyzed by optical profilometer. 89 


\section{Chapter 1: Introduction}

\subsection{Background}

Aluminum alloy AA7075-T6 is a material of importance in the aerospace industry, experiencing widespread use in the construction of aircraft frames. ${ }^{1}$ The high strength to density ratio of the alloy is a primary characteristic of its appeal. A consequence of the alloying and processing necessary for the strengthening is the formation of second phase (intermetallic) particles. Intermetallic particles are the primary feature involved in the localized corrosion of aluminum alloys. ${ }^{2}$ Aluminum and its alloys possess a high activity that promotes the formation of an oxide film that prevents uniform corrosion, however this passive layer can experience breakdown in unfavorable conditions, commonly in the presence of chloride ions, that can lead to pitting attack. ${ }^{3}$ In AA7075-T6, the intermetallic particles interact galvanically with the surrounding matrix, leading to pitting attack of the matrix. ${ }^{4}$ Atmospheric corrosion leading to localized corrosion can cause preferential sites for crack initiation in 7075-T6, making it an important issue to study.

Testing of atmospheric corrosion, and more specifically atmospheric pitting corrosion, is largely done by long-term exposure tests, which necessarily are very time consuming, or cabinet exposure tests such as B117. ${ }^{5}$ In the laboratory, methods for testing atmospheric corrosion often fail to recreate conditions experienced in the field, as 
well as behaviors experienced in field exposures. ${ }^{6}$ One method of accelerated lab testing that has been utilized to attempt to better simulate field conditions is with the use of thin electrolyte layers or droplets. ${ }^{7-11}$ While these tests often provide more realistic conditions, they can be difficult to analyze, particularly measuring the corrosion potential by immersing a reference electrode beneath the electrolyte layer. Scanning Kelvin Probes (SKP) have been shown to be effective tools in measuring the corrosion potential while also not interfering with corrosion processes taking place. ${ }^{12-14}$

\subsection{Objectives}

The objective of this work is to investigate the corrosion behavior of AA7075-T6 under electrolyte droplets and how it is influenced by droplet morphology, electrolyte, concentration, and humidity by in situ analysis with a Scanning Kelvin Probe. Analysis is done as well by post-test characterization of the pitting behavior by optical microscopy and profilometry. By better understanding these relationships, the effectiveness of accelerated lab testing in simulation of atmospheric pitting corrosion can be evaluated and improved upon. 


\subsection{References}

1. J. E. Hatch, A. Aluminum, and M. American Society for: 'Aluminum : properties and physical metallurgy'; 1984, Metals Park, Ohio, American Society for Metals.

2. N. Birbilis and R. G. Buchheit, JOURNAL- ELECTROCHEMICAL SOCIETY, 2005, 152(4), B140-B151.

3. G. S. Frankel, Journal of the Electrochemical Society, 1998, 145(6), 2186-2198.

4. E. Lunarska, E. Trela, and Z. Szklarska-Smialowska, Corrosion Corrosion, 1987, 43(4), 219-228.

5. D. B. Blucher, J. E. Svensson, and L. G. Johansson, Journal of the Electrochemical Society, 2003, 150(3), B93-B98.

6. C. Leygraf and T. E. Graedel: 'Atmospheric corrosion'; 2000, New York, WileyInterscience.

7. U. R. Evans: 'An introduction to metallic corrosion'; 1982, London; Metals Park, Ohio, E. Arnold ; American Society for Metals.

8. S. Hastuty, A. Nishikata, and T. Tsuru, Corrosion Science, 2010, 52(6), 20352043.

9. $\quad$ S. C. Morton and G. S. Frankel, Materials and Corrosion-Werkstoffe Und Korrosion, 2014, 65(4), 351-361.

10. J. F. Li, B. Maier, and G. S. Frankel, CS Corrosion Science, 2011, 53(6), 21422151. 
11. T. Tsuru, K. I. Tamiya, and A. Nishikata, Electrochimica Acta, 2004, 49(17-18), 2709-2715.

12. M. Stratmann, K. T. Kim, and H. Streckel, Zeitschrift Fur Metallkunde, 1990, 81(10), 715-725.

13. M. Stratmann and H. Streckel, Corrosion Science, 1990, 30(6-7), 697-714.

14. M. Stratmann, H. Streckel, K. T. Kim, and S. Crockett, Corrosion Science, 1990, 30(6-7), 715-734. 


\section{Chapter 2: Literature Review}

Providing a high strength to weight ratio, AA7075-T6 has served as an important material of construction in the aerospace industry, primarily used in aircraft frames. ${ }^{1}$ It is also, however, susceptible to various forms of localized corrosion attack, including pitting, intergranular corrosion, and crevice corrosion. ${ }^{2}$ This susceptibility, in consideration of the important roles the alloy is commonly used in, makes better understanding of the corrosion mechanisms occurring, particularly in atmospheric conditions, an important goal. Accelerated lab testing is not always successful in recreating behaviors that may be found in atmospheric corrosion, so it is necessary to develop a new way to more accurately represent atmospheric conditions. ${ }^{3}$ One promising technique that has emerged is by the study of corrosion beneath thin electrolyte layers or droplets, particularly using a Scanning Kelvin Probe (SKP). ${ }^{4-7}$ The SKP provides a noncontact way of measuring corrosion potential beneath an electrolyte droplet in situ. This is an important capability when dealing with thin electrolyte layers, as other techniques which require immersion in the electrolyte to measure potential can interfere with the corrosion behavior. It is necessary to understand the mechanism by which SKP performs to properly apply them in studying corrosion. 
This literature review will start with start with a discussion of the theory and operation of SKPs, and then will cover AA7075-T6 metallurgy, followed by atmospheric pitting corrosion. Providing a high strength to weight ratio, AA7075-T6 has served as an important material of construction in the aerospace industry, primarily used in aircraft frames. ${ }^{1}$ It is also, however, susceptible to various forms of localized corrosion attack, including pitting, intergranular corrosion, and crevice corrosion. ${ }^{2}$ This susceptibility, in consideration of the important roles the alloy is commonly used in, makes better understanding of the corrosion mechanisms occurring, particularly in atmospheric conditions, an important goal. Accelerated lab testing is not always successful in recreating behaviors that may be found in atmospheric corrosion, so it is necessary to develop a new way to more accurately represent atmospheric conditions. ${ }^{3}$ One promising technique that has emerged is by the study of corrosion beneath thin electrolyte layers or droplets, particularly using a Scanning Kelvin Probe (SKP). ${ }^{4-7}$ The SKP provides a noncontact way of measuring corrosion potential beneath an electrolyte droplet in situ. This is an important capability when dealing with thin electrolyte layers, as other techniques which require immersion in the electrolyte to measure potential can interfere with the corrosion behavior. It is necessary to understand the mechanism by which SKP performs to properly apply them in studying corrosion.

This literature review will start with start with a discussion of the theory and operation of SKPs, and then will cover AA7075-T6 metallurgy, followed by atmospheric pitting corrosion. 


\subsection{Kelvin Probe}

The Kelvin Probe is a tool that was first shown to be valid for investigation of corrosion by Stratmann and Streckel in $1990,{ }^{8-10}$ and was used in other research capacities prior to that. This section will provide a discussion of the theory upon which Kelvin probes operate, as well as the operation of SKP to measure corrosion potential beneath thin electrolyte layers. The Kelvin Probe provides a means of performing non-contact measurements of the contact potential difference between two electrically connected metals electrically connected and separated by a thin air gap. The principles behind this measurement are shown in Figure 2.1. ${ }^{11}$ The review of the principles of SKP operation presented in this section is derived from a combination of publications

reviewed. ${ }^{5,7,11,12}$ On the left side of Figure 2.1, the work function of the sample and the probe tip, $\Phi_{\mathrm{s}}$ and $\Phi_{\mathrm{p}}$, are presented relative to vacuum. Upon electrically connecting the two via a wire, the Fermi levels of the sample and probe become equal, the right of Figure 2.1. From this, the contact potential difference, or Volta potential, can be calculated as shown by Equation 1, where $V_{C D P}$ is the contact potential difference.

$$
V_{C P D}=\left(\phi_{P}-\phi_{S}\right) / e
$$

In a general SKP setup, the probe, made of a stainless steel with a tip diameter not larger than $300 \mu \mathrm{m}$ and which will be vibrating vertically, is electrically connected to the sample of interest and placed above the sample surface as shown in Figure 2.2. ${ }^{13}$ The probe and sample now form a capacitor 
with the relationship given in Equation 2, where $C$ is the capacitance, $\varepsilon$ is the dielectric constant, $\varepsilon_{0}$ the permittivity of free space, $A$ the area of the probe tip, $d_{0}$ the mean distance between the probe and the sample. $\Delta d$ the amplitude of vibration of the tip, $\omega_{1}$ the vibration frequency of the probe tip, and $t$ is the time.

$$
C=\varepsilon \varepsilon_{0} \frac{A}{D}=\varepsilon \varepsilon_{0} \frac{A}{d_{0}+\Delta d \sin \left(\omega_{1} t\right)}
$$

From this relationship, it can be seen that the vibration of the probe relative to the sample surface induces an alternating current in their electrical connection, identified as $i_{A C}$ and related as shown in Equation 3.

$$
i_{A C}=\frac{d Q}{d t}=\frac{d\left(V_{C P D} \cdot C\right)}{d t}=V_{C P D} \frac{\partial C}{\partial t}=V_{C P D}\left(\varepsilon \varepsilon_{0} \cdot A \cdot \Delta d \cdot \omega_{1}\right) \frac{\cos \left(\omega_{1} t\right)}{\left(d_{0}+\Delta d \cdot \sin \left(\omega_{1} t\right)\right)^{2}}
$$

By assuming $d_{0} \gg \Delta d$, and assuming the average capacitance, $C_{0}=\frac{\varepsilon \varepsilon_{0} A}{d_{0}}$, the above can be simplified to what is shown in Equation 4.

$$
i_{A C}=\varepsilon \varepsilon_{0} \cdot A \cdot V_{C P D} \cdot \frac{\Delta d}{d_{0}{ }^{2}} \cdot \omega_{1} \cos \left(\omega_{1} t\right)=C_{0} \cdot V_{C P D} \cdot \frac{\Delta d}{d_{0}} \omega_{1} \cos \left(\omega_{1} t\right)
$$

By taking what has been shown and applying a backing potential, designated as $V_{\mathrm{B}}$, and incorporating a high impedance $\mathrm{I} / \mathrm{V}$ converter, with impedance $R$, to measure the resultant current, the relationships in Equations 5 and 6 can be determined, where $i(t)$ is the current measured and $V_{K P}$ is the potential measured by the SKP.

$$
\begin{gathered}
i(t)=\frac{d Q(t)}{d t}=\left(V_{C P D}+V_{B}\right) \cdot \frac{d C(t)}{d t} \\
V_{K P}=R C_{0} \cdot\left(V_{B}+V_{C P D}\right) \cdot \frac{\Delta d}{d_{0}} \cdot \omega_{1} \cos \left(\omega_{1} t\right)
\end{gathered}
$$


By adjusting the applied backing potential, $V_{B}$, so that the output potential, $V_{K P}$, goes to zero, the Volta potential can be determined as $-V_{B}=V_{C P D}$. Difficulties can arise from this nulling technique due to noise in the signal being readily observed when the backing potential is accurately offsetting the Volta potential. ${ }^{11}$, ${ }^{12}$ In order to avoid this noise, an off-null technique, which is the technique used by the SKP utilized in this work, has been previously developed. Application of this method also provides for control of the probe height in order to maintain a constant mean distance between the probe tip and the sample surface, which can provide valuable information regarding surface topography. This feature is shown in Figure 2.2 as the probe tip remains at a fixed distance from the surface of a droplet as it undergoes evaporation.

The setup for the SKP used with the off-null technique is shown in Figure 2.3. ${ }^{7}$ This technique requires the backing potential be sinusoidal with a frequency of $\omega_{2}$. This produces a voltage relationship as shown in Equation 7. In this study an AC backing potential $V_{B}=1 \mathrm{~V}$ with a frequency of $\omega_{2}=10 \mathrm{~Hz}$ is applied, a resultant measured current of $I_{K P}$ is observed, shown by Equation 8 .

$$
\begin{gathered}
V=V_{B} \sin \left(\omega_{2} t\right)+V_{C P D} \\
I_{K P}=\frac{d Q}{d t}=\frac{d V}{d t} \cdot C+V \cdot \frac{d C}{d t} \\
=\left(C V_{B} \omega_{2} \sin \left(\omega_{2 t}\right)\right)+\left(V_{B} \sin \left(\omega_{2} t\right)+V_{C P D}\right)\left(\varepsilon \varepsilon_{0} \cdot A \cdot \omega_{1} \frac{\Delta d}{d_{0}^{2}} \cos \left(\omega_{1} t\right)\right)
\end{gathered}
$$


If it can be assumed that $\omega_{2} \ll \omega_{1} \frac{\Delta d}{d_{0}^{2}}$, which it can in this case as the vibrational frequency of the probe tip is $\omega_{1}=1 \mathrm{kHz}$, then the left term can be ignored and the potential observed by the SKP, $V_{K P o f f}$, can be calculated as shown in Equation 9.

$$
\begin{aligned}
& V_{K P_{\text {off }}}=R \cdot\left(V_{B} \sin \left(\omega_{2} t\right)+V_{C P D}\right)\left(\varepsilon \varepsilon_{0} \cdot A \cdot \omega_{1} \frac{\Delta d}{d_{0}{ }^{2}} \cos \left(\omega_{1} t\right)\right) \\
& =R \cdot C_{0} \cdot\left(V_{B} \sin \left(\omega_{2} t\right)+V_{C P D}\right) \cdot \omega_{1} \cdot \frac{\Delta d}{d_{0}} \cdot \cos \left(\omega_{1} t\right)
\end{aligned}
$$

The observed potential, $V_{K P o f f}$, is a modulation of $\omega_{1}$ and $\omega_{2}$, and by multiplying this with the backing potential, a waveform can be generated. The waveforms are then analyzed to inspect shape and order, allowing for the calculation of a scaling factor, $k$. In the case shown in Figure 2.3a and b, it is known that $\mathrm{V}_{\mathrm{CPD}}>0$ and $\left|\mathrm{V}_{\mathrm{CPD}}\right|<\left|\mathrm{V}_{\mathrm{B}}\right|$. The relationship between $\mathrm{V}_{\mathrm{CPD}}, \mathrm{V}_{\mathrm{B}}$, and the scaling factor, $k$, and the maxima of the waveform is given by Equation 10, which can be rearranged to give $k$, shown in Equation 11. ${ }^{7}$

$$
\begin{gathered}
k \cdot\left(\max _{1}\left(V_{K P}\right)+\max _{2}\left(V_{K P}\right)\right)=\left|V_{B}+V_{C P D}\right|+\left|-V_{B}+V_{C P D}\right|=2 V_{B} \\
k=\frac{2 V_{B}}{\max _{1}\left(V_{K P}\right)+\max _{2}\left(V_{K P}\right)}
\end{gathered}
$$

The scaling factor is related to the distance between the probe and the sample, and is used to keep that distance constant.

In the first studies to validate the use of the SKP in corrosion studies, Stratmann and Streckel ${ }^{8,9}$ were able to show that the corrosion potential of a metal surface under a thin electrolyte layer is related to the measured Volta potential as shown in Equation 12., 9 


$$
E_{\text {Corr }}=\left\{\frac{W_{R e f}}{F}-\chi_{E l}-\varepsilon_{1 / 2}^{\text {Standard }}\right\}+\Delta \Psi_{E l}^{R e f}
$$

In the equation, $E_{C o r r}$ is the corrosion potential, $F$ is the Faraday constant, $W_{R e f}$ is the work function of the probe, $\chi_{E I}$ is the electrolyte surface potential, $\varepsilon_{1 / 2}^{\text {Standard }}$ is the half-cell potential of the reference standard, and $\Delta \Psi_{E l}^{R e f}$ is the Volta potential between the probe and the electrolyte surface. Knowing that $\varepsilon_{1 / 2}^{\text {Standard }}$ is constant, the surface potential does not change substantially between electrolytes and is small, and that the work function of the probe remains mostly constant as long as environment is stable, it can be assumed that the Volta potential, which is the value measured by the SKP, is directly proportional to the corrosion potential. This was shown to be true by measuring the corrosion potential beneath a thin electrolyte layer with the SKP and measuring the corrosion rate by monitoring the oxygen partial pressure in the chamber and finding that the results were consistent with one another. ${ }^{9}$ By calibrating the SKP against a known reference, commonly saturated $\mathrm{CuSO}_{4}$ in a $\mathrm{Cu}$ cup, it can be assumed that the potential measured under electrolyte layers is consistent with the local corrosion potential. The potential can then be monitored at a point relative to time, or the probe can be scanned across a region to provide a potential profile. 


\subsection{AA7075-T6 Metallurgy}

The 7xxx series of aluminum alloys are considered to be the strongest aluminum alloys, primarily used in the aircraft and transportation industry due to their high strength to density ratio. ${ }^{1}$ The primary alloying elements for the series are zinc, copper and magnesium, which contribute to strength primarily by precipitation hardening through heat treatment. ${ }^{14}$ In this section, the influence of alloying elements on the alloy microstructure, particularly the formation of intermetallic particles, and how this affects the localized corrosion susceptibility is discussed. The pitting mechanism for aluminum alloys is also reviewed.

AA7075 is the most commonly used of the 7xxx series, and one of the most extensively studied 7xxx alloys due to its applications in the aerospace industry. ${ }^{15}$ For the 7075 alloy, peak strength is achieved by the T6 temper, ${ }^{16}$ a process of solution treating and artificial aging. The process promotes the growth of secondary phase particles that strengthen the alloy. The microstructure of 7075T6 has been found to have a large variety of the secondary phase particles, which are divided into three classifications: precipitates, constituent particles, and dispersoids. ${ }^{17}$ The precipitates contribute the strength of the alloy. Some of the precipitates that have been identified include $\mathrm{Mg}_{2} \mathrm{Al}_{3}, \mathrm{Al}_{2} \mathrm{Cu}$, and $\mathrm{Al}_{32} \mathrm{Zn}_{49}$, but the most important precipitates are considered to be $\eta$ and $\eta^{\prime}$, which are considered to be the primary contributors to the alloy strength. ${ }^{16}$ Precipitates $\eta$ and $\eta^{\prime}$, phases of $\operatorname{MgZn}_{2}$, form in solute-rich GP zones at temperatures below the 
GP zone solvus by the process presented in Equation $11 .{ }^{18}$ The precipitates are considered metastable $\left(\eta^{\prime}\right)$ and stable $(\eta)$.

$$
\text { Supersaturated Solid Solution } \rightarrow \text { GP zones } \rightarrow \eta^{\prime} \rightarrow \eta
$$

The largest of the secondary particles to form are the constituent particles, on the order of tens of microns, and consist of compositions such as $\mathrm{Al}_{2} \mathrm{CuMg}$ (identified as the S-phase), $\mathrm{Al}_{7} \mathrm{Cu}_{2} \mathrm{Fe}, \mathrm{Al}_{3} \mathrm{Fe}$, and $(\mathrm{Al}, \mathrm{Cu})_{6}(\mathrm{Fe}, \mathrm{Cu}) .{ }^{17}$ Formed during solidification and unable to be dissolved in the following thermomechanical processing, constituent particles typically align and break up during rolling and extruding, and remain unaffected by additional heat treatment. The alloyingelement rich nature of these particles many times causes them to possess electrochemical behavior that is very different from the matrix material. The final category of secondary phase particles is dispersoids, which contribute to grain size control and influence recrystallization, are found to be homogenously distributed. Dispersoids are commonly composed of intermetallics, identified to include $\mathrm{Al}_{3} \mathrm{Ti}, \mathrm{Al}_{3} \mathrm{Zn}, \mathrm{Al}_{6} \mathrm{Mn}$, and $\mathrm{Al}_{20} \mathrm{Cu}_{2} \mathrm{Mn}_{3} .{ }^{17}$

Independently, the three main alloying elements have been studied to determine their respective effects on the electrochemical behavior of 7xxx series alloys. Although the addition of Mg has been shown to not have an effect on the breakdown potential of aluminum, it was observed to dissolve preferentially to aluminum, increasing the aluminum concentration in pits and therefore possibly increasing repassivation potential. ${ }^{19}$ Contrary to this, aluminum is found to dissolve preferentially to both $\mathrm{Cu}$ and $\mathrm{Zn}$, however the influences on the 
breakdown potential by the two alloying elements are opposite. ${ }^{20} \mathrm{Zn}$ has been found to decrease the pitting and passivation potentials, while also promoting aluminum dissolution kinetics in pits. ${ }^{19} \mathrm{Cu}$ was found to increase pitting and passivation potentials. In addition, increasing $\mathrm{Cu}$ concentration in 7xxx series alloys was observed to decrease polarization resistance, leading to an increased corrosion rate. ${ }^{21}$

More specifically to AA7075-T6, the contribution of the secondary phase particles to the corrosion behavior has been studied in addition to effects of the alloying elements alone. The broad variety in composition of the particles listed above, specifically constituent particles, has been found to produce a wide range of corrosion potentials, subsequently forming galvanic couples with the surrounding Al matrix. ${ }^{22,23}$ Generally, particles containing $\mathrm{Mg}$ are anodic relative to the alloy, and particles containing $\mathrm{Cu}, \mathrm{Fe}$, and $\mathrm{Mn}$ are cathodic. ${ }^{22}$ In the case of a particle that is anodic relative to the surrounding matrix, dissolution of the particle is found to occur while the matrix provides reduction of oxygen, forming a pit. For particles that are cathodic to the matrix, the surrounding matrix is observed to dissolve in a trenching fashion as reduction of oxygen takes place at the cathodic particle. The secondary phase particles are observed across exposed surfaces of 7075-T6 and subsequently these forms of localized attack are both seen to take place simultaneously at many sites on the surface during lab tests.

The pitting mechanism for aluminum alloys shares many similarities to that observed in stainless steels. ${ }^{2}$ Aluminum alloys are susceptible to pitting 
corrosion in media that is near neutral $\mathrm{pH}$, making pitting a concern in many environments that it would typically be exposed to. ${ }^{24}$ Commonly, chloride ions are involved in the localized passive layer breakdown at the onset of pitting, although the mechanism by which it does so is not entirely understood. ${ }^{1}$ Once pitting has initiated, propagation takes place as dissolution of aluminum in the anodic pit is balanced by cathodic reactions occurring on the surface outside of the pit, commonly by oxygen reduction. Hydrolysis within the pit produces aluminum hydroxides and hydrogen ions, leading to the acidification of the pit, catalyzing further dissolution. ${ }^{24}$ In addition to the corrosion being driven by the micro-galvanic cell formed between the anodic pit and the cathodic surface outside of it, self-corrosion can take place within the pit by the reaction shown in Equation $12^{25}$.

$$
\mathrm{Al}+3 \mathrm{H}_{2} \mathrm{O} \rightarrow \mathrm{Al}(\mathrm{OH})_{3}+3 / 2 \mathrm{H}_{2} \uparrow
$$

The evolution of hydrogen bubbles by the reduction of $\mathrm{H}^{+}$helps to push the aluminum hydroxide formed out of the pit, where it commonly forms a white, gellike precipitate over the pit. $^{24}$ Precipitate formation can eventually lead to blocking ions from diffusing in and out of the pit, slowing down or stopping the pitting process.

Mechanical deformation incurred during polishing has been shown to develop an active layer at the outermost surface of 7075-T6 that exhibits chemical properties differing from those of the bulk material. ${ }^{26,27}$ The thin surface layer has a lower breakdown potential than the bulk material, resulting in passive layer 
breakdown and accelerated dissolution. The surface layer has a different microstructure from the bulk material, composed of nano-grains absent of hardening precipitates and with elevated $\mathrm{Zn}$ concentrations at the grain boundaries. These active grain boundaries undergo attack triggering the by dissolution of the nano-grains. Identification of the active surface layer and its dissolution is important to the study of 7075-T6 corrosion as it can influence the observed results in many test methods that require polishing. Fortunately, it was determined that the active surface layer can be entirely removed by etching in $1 \mathrm{M}$ $\mathrm{NaOH}$ solution at $60^{\circ} \mathrm{C}$ for 90 seconds, followed by immersion in $70 \% \mathrm{HNO}_{3}$ for 30 seconds, leaving unmodified bulk material exposed. ${ }^{28}$

\subsection{Atmospheric Pitting Corrosion}

Atmospheric corrosion is identified as attack to metals exposed to atmospheric environments. ${ }^{3}$ In this section, the atmospheric pitting process and its contributing factors are discussed, as well as the techniques utilized to study and simulate atmospheric pitting corrosion conditions and behaviors in the lab. This type of corrosion is dependent on many atmospheric conditions, most notably humidity, temperature, and pollutants present. Thin moisture layers can develop at sufficient humidity or by other direct means such as rain, and combined with pollutants from the atmosphere, the conditions of the resulting electrolyte layer can be favorable to the promotion of atmospheric corrosion. The thin nature of the films provides opportunities for different reactions to take place at the surface 
than those that are observed when metals are submerged in liquid. Most notably, this allows for readily available oxygen for diffusion to the surface, as well as limited convection of the solution. ${ }^{4}$

In aluminum and aluminum alloys, the strong tendency to form an oxide layer prevents uniform attack. Under sufficiently aggressive conditions, particularly in the presence of $\mathrm{Cl}^{-}$ions, localized breakdown of the passive layer can occur. ${ }^{29}$ In atmospheric corrosion, sustained levels of humidity are critical to maintain the electrolyte layer, however fluctuations of the humidity also play an important role in the chemistry of the thin film. While the presence of ions in the electrolyte layer is necessary for attack to initiate, it is also important that they be present in sufficient concentration. A droplet of salt solution on the surface of an aluminum sample may not have the necessary $\mathrm{Cl}^{-}$concentration to initiate attack, but at appropriate humidity, the droplet will undergo evaporation resulting in an increase of salt concentration until the activities of water in the droplet and the water in air are in equilibrium. ${ }^{30}$ The elevation of $\mathrm{Cl}^{-}$concentration could then be sufficient to promote breakdown of the passive layer and subsequently promote pitting attack.

The combination of high humidity and atmospheric salts make marine environments ideal for atmospheric pitting corrosion by this mechanism. ${ }^{31}$ For AA7075-T6, exposure in sites of varied atmospheric composition, samples tested in coastal atmospheres suffered much greater loss of mechanical properties than those exposed to industrial or industrial-coastal atmospheres. ${ }^{32}$ In exposure tests 
performed in northern and eastern Australia, pitting attack was found to be the primary form of corrosion for samples of 7075-T6, with the most aggressive corrosion taking place at coastal sites. ${ }^{33}$ Coastal regions have been shown to deposit both $\mathrm{MgCl}_{2}$ and $\mathrm{NaCl}^{34}$ At humidity values equal to or greater than the critical relative humidities of these salts (35\% RH for $\mathrm{MgCl}_{2}$ and $75 \% \mathrm{RH}$ for $\mathrm{NaCl}^{34}$ ) salt solutions are able to form on a sample surface. ${ }^{34}$ It is also important to note that although deposition rates of salts decrease with distance from the shore, it has been shown that they can remain elevated for a considerable distance from the shore. ${ }^{35}$ Duncan and Ballance looked at dry chloride deposition rates at sites in New Zealand of varying distance from the ocean, and found that chloride deposition rates as high as $10 \%$ of those observed at the shore could be found as far as $52 \mathrm{~km}$ from the ocean. ${ }^{35}$

While the unique conditions of atmospheric corrosion under thin electrolyte layers has been known, finding ways to monitor what is happening under the thin layers and droplets has proven to be a challenge. One early experiment to give a glimpse of the behavior of atmospheric corrosion was the Evans drop. ${ }^{36}$ Using phenolphthalein, which turns pink in elevated $\mathrm{pH}$, to identify cathodic zones, and ferricyanide, which turns blue where iron salts are present, to identify anodic zones, droplets of $\mathrm{KCl}$ on mild steel were studied. At the start of the experiment, beneath the droplet oxygen is consumed by reduction as cathodic and anodic sites are present across the surface. Eventually, oxidation becomes the dominant reaction at the center of the droplet and oxygen reduction dominates 
towards the edge of the droplet. This is a result of the shorter diffusion path for oxygen to the surface near the edges, forming a differential aeration cell, a type of behavior not observed in typical lab tests requiring immersion. While observing the $\mathrm{pH}$ in this scenario provides good information, it does not form a full picture of what is happening under thin electrolyte layers. The primary obstacle has typically been in the immersion of a reference electrode in the electrolyte layer. While methods had been developed to successfully measure the potential under thin layers, they had the drawback of interfering with oxygen diffusion or introduction of contaminant ions. ${ }^{30,37}$ This problem was solved with the proven application of a Kelvin Probe, allowing for in situ measurement of corrosion potential beneath a thin electrolyte layer in a manner that is non-contact. ${ }^{38}$

Utilizing the SKP, Maier et al. were able to study the pit initiation behavior on SS304 under droplets of varying initial volume and electrolyte concentration by monitoring the shape of and potential beneath the center of the droplets. ${ }^{13}$ Furthering this technique, Morton et al. studied the pitting behavior of AA7075-T6 under $\mathrm{NaCl}$ containing inhibitors. ${ }^{39}$ This study found the formation of a secondary droplet at the periphery of the initial droplets, under which accelerated corrosion attack took place by the large-scale separation of the anode beneath the secondary droplet and the cathode beneath the primary droplet. A mechanism was proposed for the creation of the secondary droplets. The diffusion of ions away from edge pits is restricted, leading to a local acidic environment caused by cation hydrolysis. The local acidity promotes further pitting attack in the area. The high concentration of ions generated by this pitting attack 
promotes deliquescence in the region, forming the secondary droplet. Secondary droplet formation was associated with a large jump in the potential observed at the droplet center, caused by the proposed large scale cathode/anode separation. Analysis at the end of the tests by scanning the SKP probe tip in a line across the droplet and secondary droplet did not observe this same drastic potential increase though, and this was attributed to evaporation of the droplet caused by a drop in humidity from opening the chamber to adjust the sample.

The phenomenon and mechanism of secondary droplet formation are investigated in the present study, in addition to the influence of initial droplet parameters including volume, electrolyte, and electrolyte concentrations. The impact of humidity cycling and time of exposure are also undetermined and key components to better understanding how this form of accelerated lab test can be representative of the atmospheric pitting behavior and are therefore considered here. 


\subsection{Tables and Figures}

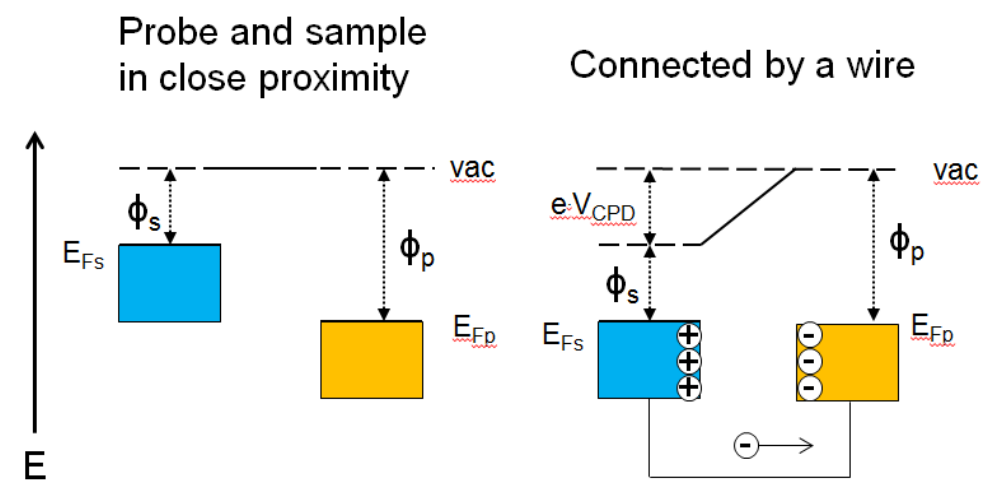

Figure 2.1. Contact potential difference of two metals when in close proximity and when connected by a wire. 


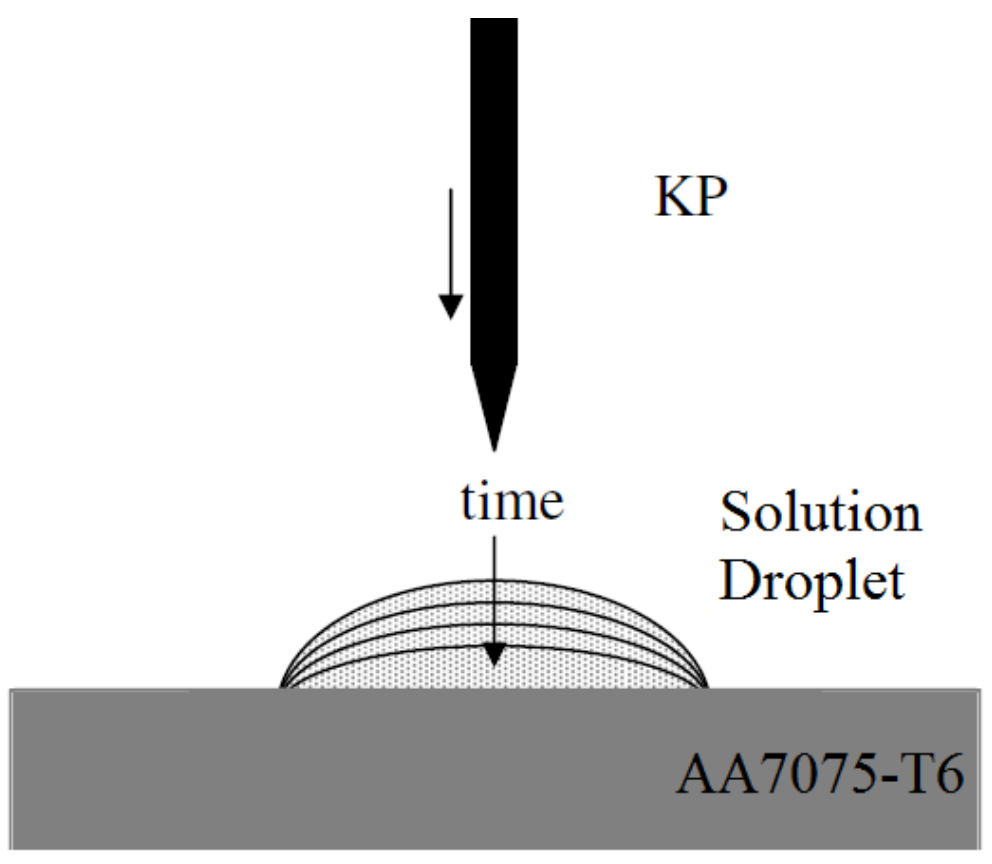

Figure 2.2. Position of electrically connected Scanning Kelvin probe tip relative to electrolyte droplet and test sample. Probe tip maintains fixed distance relative to surface of droplet. Based on ref ${ }^{13}$. Reproduced with permission of The Electrochemical Society. 

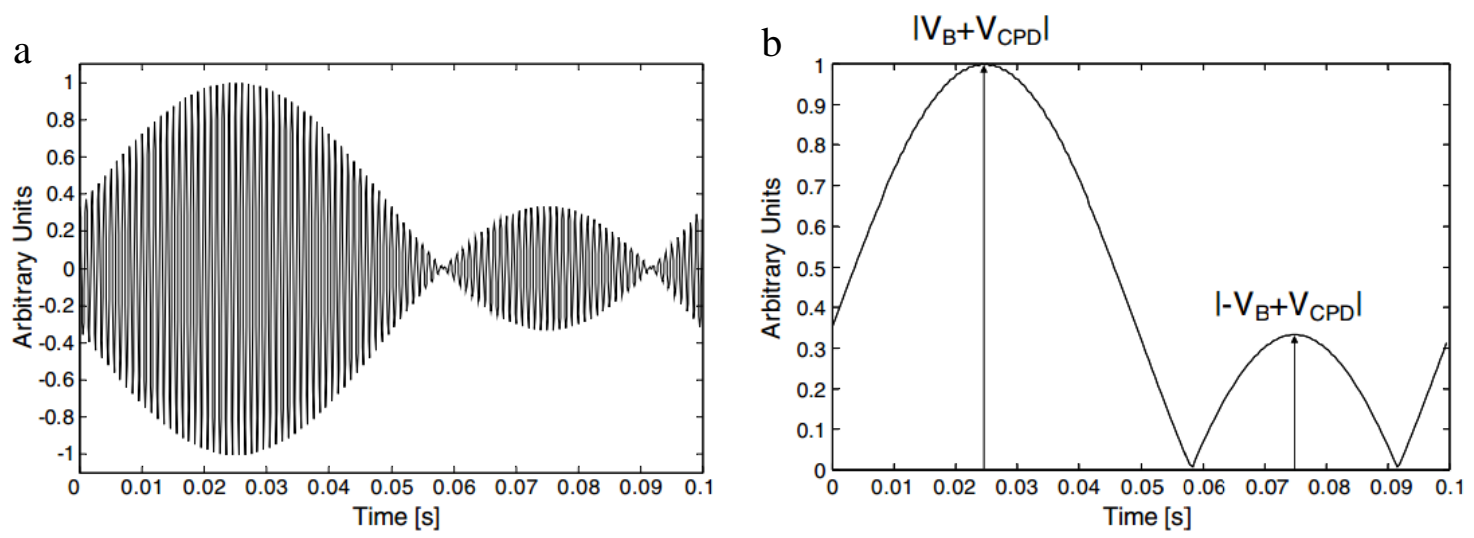

Figure 2.3. a) Sample of waveform collected by SKP. b) Absolute value for processed waveform obtained in figure 'a'. ${ }^{7}$ Reproduced with permission of Elsevier. 


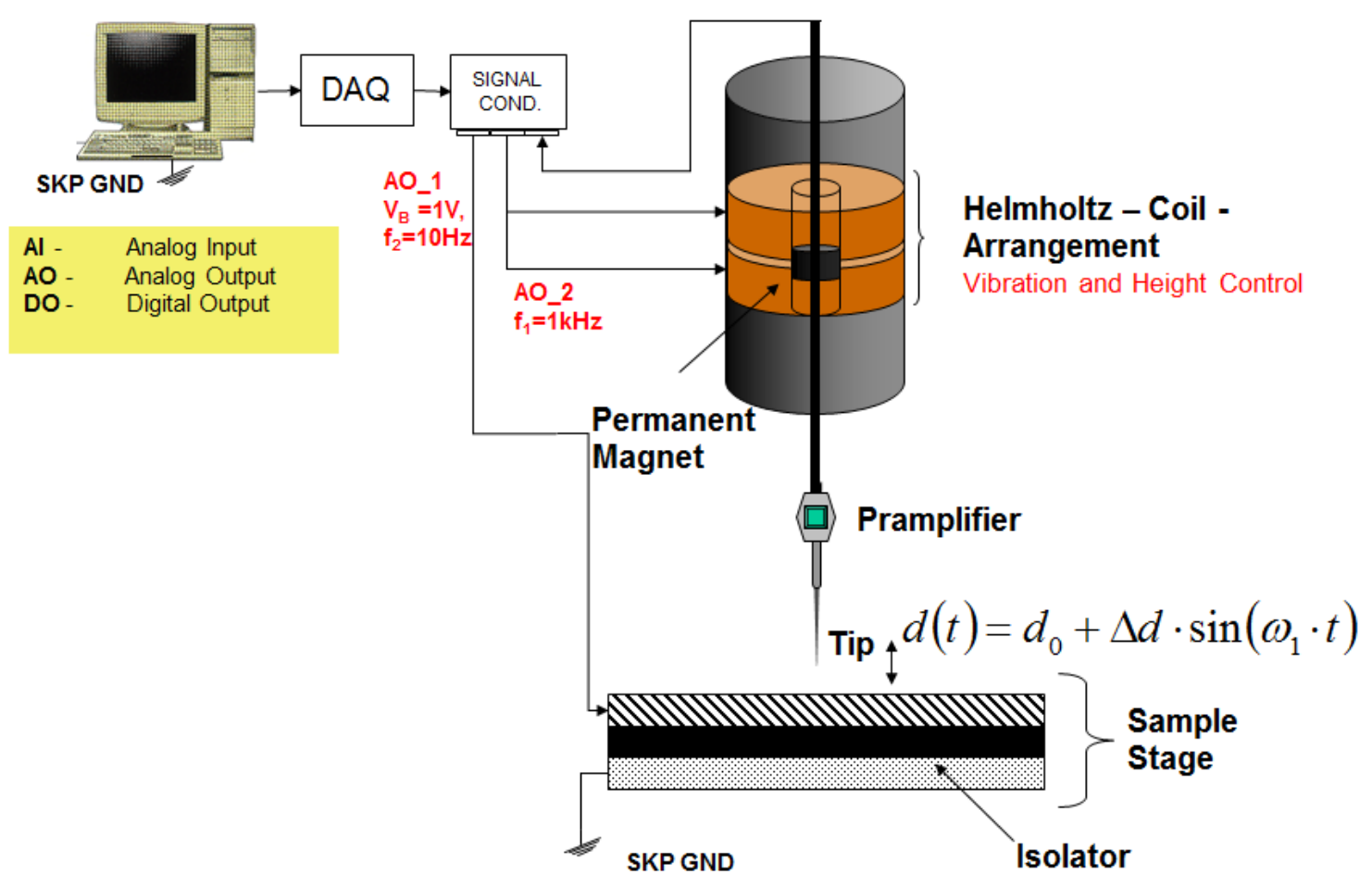

Figure 2.4. Schematic diagram of KP and data acquisition setup utilizing off-nulling technique with height control. ${ }^{7}$ Reproduced with permission of Elsevier. 


\subsection{References}

1. J. E. Hatch, A. Aluminum, and M. American Society for: 'Aluminum : properties and physical metallurgy'; 1984, Metals Park, Ohio, American Society for Metals.

2. Q. Meng, 2003.

3. C. Leygraf and T. E. Graedel: 'Atmospheric corrosion'; 2000, New York, WileyInterscience.

4. S. Hastuty, A. Nishikata, and T. Tsuru, Corrosion Science, 2010, 52(6), 20352043.

5. B. S. Maier: 'Electrochemical studies under thin electrolyte layers using a Kelvin Probe', Ohio State University, Columbus, Ohio, 2010.

6. J. F. Li, B. Maier, and G. S. Frankel, CS Corrosion Science, 2011, 53(6), 21422151.

7. G. S. Frankel, M. Stratmann, M. Rohwerder, A. Michalik, B. Maier, J. Dora, and M. Wicinski, Corrosion Science, 2007, 49(4), 2021-2036.

8. M. Stratmann and H. Streckel, Corrosion Science, 1990, 30(6-7), 681-696.

9. M. Stratmann and H. Streckel, Corrosion Science, 1990, 30(6-7), 697-714.

10. M. Stratmann, H. Streckel, K. T. Kim, and S. Crockett, Corrosion Science, 1990, 30(6-7), 715-734.

11. M. Wicinski, Kelvin Probe: The Vibrating Capacitor Technique, WicinskiWicinski GbR.

12. G. S. Frankel, MSE 7818 Notes. Spring 2015. 
13. B. Maier and G. S. Frankel, J Electrochem Soc Journal of the Electrochemical Society, 2010, 157(10), C302-C312.

14. J. R. Davis, Metals Handbook, Desk Edition (2nd Edition), ASM International.

15. F. Andreatta, H. Terryn, and J. H. W. de Wit, Electrochimica Acta, 2004, 49(17/18).

16. I. J. Polmear: 'Light alloys : metallurgy of the light metals'; 1996, New York; Toronto, J. Wiley \& Sons.

17. N. Birbilis and R. G. Buchheit, JOURNAL- ELECTROCHEMICAL SOCIETY, 2005, 152(4), B140-B151.

18. M. Chemingui, M. Khitouni, K. Jozwiak, G. Mesmacque, and A. Kolsi, Materials \& Design, 2010, 31(6), 3134-3139.

19. I. L. Muller and J. R. Galvele, CS Corrosion Science, 1977, 17(12), 995-1007.

20. I. L. Muller and J. R. Galvele, CS</cja:jid> Corrosion Science, 1977, 17(3), 179,191-189,193.

21. Q. J. Meng and G. S. Frankel, Journal of the Electrochemical Society, 2004, 151(5), B271-B283.

22. M. Gao, Metallurgical and Materials Transactions. A, Physical Metallurgy and Materials Science, 1998, 29(4), 1153-1160.

23. R. Buchheit and L. Sandia National, Journal of the Electrochemical Society, 1995, 142(11), 3994-3996.

24. C. Vargel: 'Corrosion of Aluminium'; 2004, Amsterdam; Boston, Elsevier. 
25. M. C. Reboul, T. J. Warner, H. Mayet, and B. Baroux, Aluminium Alloys: Their Physical and Mechanical Properties, Pts 1-3, 1996, 217, 1553-1558.

26. Z. Zhao and G. S. Frankel, CS Corrosion Science, 2007, 49(7), 3064-3088.

27. Z. Zhao and G. S. Frankel, CS Corrosion Science, 2007, 49(7), 3089-3111.

28. Z. Zhao, 2006.

29. G. S. Frankel, Journal of the Electrochemical Society, 1998, 145(6), 2186-2198.

30. R. P. V. Cruz, A. Nishikata, and T. Tsuru, Corrosion Science, 1998, 40(1), 125139.

31. D. A. Jones: 'Principles and prevention of corrosion'; 1996, Upper Saddle River, NJ, Prentice Hall.

32. S. Hu, S. Sun, A. Guo, X. Jia, and Y. Geng, Corrosion, 2011, 67(10).

33. B. S. Smith, E. J. Duxbury, B. T. Moore, S. Defence, and C. Technology Organization, 1997.

34. Y. Tsutsumi, A. Nishikata, and T. Tsuru, Journal of the Electrochemical Society, 2006, 153(7), B278-B282.

35. J. R. Duncan and J. A. Ballance: 'Marine salts contribution to atmospheric corrosion'; 1988, Porirua, BRANZ.

36. U. R. Evans: 'An introduction to metallic corrosion'; 1982, London; Metals Park, Ohio, E. Arnold ; American Society for Metals.

37. S. Ito, M. Yabumoto, H. Omata, and T. Murata: 'ATMOSPHERIC CORROSION OF STAINLESS STEELS A2 - FROMENT, MICHEL', in 'Passivity of Metals and Semiconductors', 637-642; 1983, Elsevier. 
38. M. Stratmann, K. T. Kim, and H. Streckel, Zeitschrift Fur Metallkunde, 1990, 81(10), 715-725.

39. S. C. Morton and G. S. Frankel, Materials and Corrosion-Werkstoffe Und Korrosion, 2014, 65(4), 351-361. 


\section{Chapter 3: Experimental Procedure}

\subsection{Materials}

Samples used in these experiments were composed of rolled plate AA7075-T651

produced to meet ASTM B211 ${ }^{1}$, obtained with $6 \mathrm{~mm}$ thickness and cut into squares of 3 cm x $3 \mathrm{~cm}$. The samples were abraded with SiC paper, progressing through grits of 120, 240, 400, 600 and 800, in ethanol. Removal of the previously identified surface layer ${ }^{2}$ was then performed by etching the samples in $1 \mathrm{M} \mathrm{NaOH}$ solution at $60^{\circ} \mathrm{C}$ for 45 seconds, followed by pickling in $70 \% \mathrm{HNO}_{3}$ for 10 seconds and finally rinsing with ethanol. This etching process is consistent with that used in previous work. ${ }^{3}$ After etching, samples were stored in a desiccator until use, at which point they were rinsed with ethanol and DI water, and then dried with filtered, pressurized air.

Samples were typically stored in the desiccator for 3-7 days prior to use in testing. In the experiments, droplets were produced from solutions containing either $\mathrm{MgCl}_{2}$ in concentrations of $0.1,0.25,0.5$ and $1 \mathrm{M}$, or $\mathrm{NaCl}$ in concentrations of $0.25 \mathrm{M}, 0.6 \mathrm{M}$ (3.5\% by weight), and $1 \mathrm{M}$. 


\subsection{Scanning Kelvin Probe Droplet Testing}

\subsubsection{Scanning Kelvin Probe}

The Scanning Kelvin Probe (SKP) utilized in these experiments was a product of Wicinski-Wicinski GbR (Dusseldorf, Germany). The overall setup of the SKP is shown in Figure 3.1a, and a closer image of the testing chamber is shown in Figure 3.1b. The SKP design permitted $\mathrm{x}$ - and $\mathrm{y}$-axis control on a sample stage, as well as $\mathrm{z}$-axis control of the probe height. LabVIEW software was used for control and data acquisition. Software memory would exceed capacity if data acquisition was permitted to run for two days or longer, therefore testing duration had to be limited to within one day. The probe tip was $200 \mu \mathrm{m}$ in diameter and made of stainless steel 304L. Air was bubbled through saturated $\mathrm{KCl}$ solution and flowed continuously into the SKP chamber to obtain a relative humidity $(\mathrm{RH})$ of $85 \%$, which is the equilibrium $\mathrm{RH}$ for saturated $\mathrm{KCl}$ solution. A 2 megapixel USB digital microscope within the chamber was used for collecting images of samples every minute during tests.

Prior to testing, the RH was increased to $85 \%$ and calibration of the SKP was performed on a copper cup $1 \mathrm{~cm}$ in diameter filled with saturated $\mathrm{CuSO}_{4}$, known to have a potential of $320 \mathrm{mV}$ SCE.

\subsubsection{Tests of Droplet Varying Volume and Concentration}

For droplet tests, a single droplet of one of the previously described solutions was deposited on a polished sample, which was then placed on the stage in the pre-humidified SKP chamber. Droplets of 3, 6 and $9 \mu \mathrm{L}$ were tested for each solution composition, and 
every condition was repeated a minimum of four times. The stage and head were maneuvered to bring the probe tip above the center of the droplet. Measurement of the height and potential at that point was then initiated, recording both points in one second intervals for 20 hours. During the tests, the distance between the probe tip and the droplet surface remained fixed, allowing for change of the droplet height to be observed. After 20 hours, a line scan was performed across the diameter of the droplet, as well as across other areas of interest when necessary. The images of the droplet recorded with the digital microscope provided a time lapse of the droplet behavior.

After measurements in the SKP were completed, the samples were rinsed with DI water and ethanol, and the corrosion product was removed by immersion for 1 minute in a solution of $1.5 \mathrm{~L}$ DI water, $150 \mathrm{~mL} \mathrm{H}_{3} \mathrm{PO}_{4}$, and $30 \mathrm{~g} \mathrm{CrO}_{3}$ at $80^{\circ} \mathrm{C}$. Samples were then immersed in ethanol and placed in an ultrasonicator for several minutes to remove any caps over pits. Images were recorded under an optical microscope after both stages of cleaning. Samples were then analyzed using a Contour GT-K1 optical profilometer to measure pitting dimensions.

\subsubsection{Aging Tests}

To investigate the influence of time spent in the desiccator after active surface layer removal, tests were performed on samples of increasing age relative to date of etching. In these experiments, samples were prepared in the same manner described previously, however they were either used immediately after etching, or after aging in the desiccator for 1-6 days. Tests were repeated at least four times for samples at each age. A 
droplet of $9 \mu \mathrm{L} 3.5 \% \mathrm{NaCl}$ was placed on the sample, which was then placed in the SKP chamber at $85 \%$ RH for 20 hours. Droplets were chosen to be $9 \mu \mathrm{L}$ to make changes in wetting diameter as large as possible. Samples were then cleaned and imaged by optical microscope in the same manner described in the previous section, and analyzed by optical profilometer.

\subsection{Outdoor Testing}

Outdoor testing was performed using samples prepared as previously described. The samples were exposed in Dublin, OH, with the samples placed under shelter, between the dates of July 11 and August 8, 2015. Typical temperature and humidity behavior for the region during that time frame are provided in Table 3.2. ${ }^{4}$ Tests were started at 17:00 on the dates of July 11, 18, 15, and August 1. For each sample, a $6 \mu \mathrm{L}$ droplet of either $3.5 \% \mathrm{NaCl}$ or $0.5 \mathrm{M} \mathrm{MgCl}_{2}$ was applied. Three samples were exposed for each electrolyte for 1, 4 or 7 days, leading to a total of 18 samples being tested each week. Samples were then cleaned and analyzed under optical microscope and optical profilometer by the same procedure as the lab tests. Control experiments were performed with the same droplet conditions on samples were exposed in the SKP chamber at $85 \%$ RH for 1,4 and 7 days.

\subsection{Stereomicroscope Droplet Study}

Prompted by the results found in the previous experiments, the pitting behavior and secondary droplet formation process were observed using of a digital microscope 
camera. The samples were prepared in the same manner as described above. A $6 \mu \mathrm{L}$ droplet of $3.5 \% \mathrm{NaCl}$ was deposited on the sample surface, which was then placed in a glass chamber. Air bubbled through saturated $\mathrm{KCl}$ flowed through the chamber to maintain a RH of 85\%. The droplet was then observed using a QImaging Go-3 camera mounted to a stereomicroscope, with images captured every 30 seconds for 20 hours. The process of sample cleaning and analysis by optical microscope and optical profilometer was the same as that used for the SKP droplet tests. 


\subsection{Tables and Figures}

Table 3.1. Composition of AA7075 in agreement with ASTM B211.

\begin{tabular}{|c|c|c|c|c|c|c|c|c|c|c|}
\hline Element & $\mathrm{Si}$ & $\mathrm{Fe}$ & $\mathrm{Cu}$ & $\mathrm{Mn}$ & $\mathrm{Mg}$ & $\mathrm{Cr}$ & $\mathrm{Zn}$ & $\mathrm{Ti}$ & Other & $\mathrm{Al}$ \\
\hline $\mathrm{Wt} \%$ & 0.4 & 0.5 & $1.2-2.0$ & 0.3 & $2.1-2.9$ & $0.18-0.28$ & $5.1-6.1$ & 0.2 & 0.15 & Bal. \\
\hline
\end{tabular}

Table 3.2. Typical temperature and relative humidity of Columbus, OH between July 11 and August 8, data retrieved from NOAA. $25^{\text {th }}$ and $75^{\text {th }}$ percentile of collected data ranges presented.

\begin{tabular}{lll}
\hline & $25^{\text {th }_{\%}}$ & $75^{\text {th }_{0}}$ \\
\hline High Temp. $\left({ }^{\circ} \mathrm{C}\right)$ & 28 & 32 \\
Low Temp. $\left({ }^{\circ} \mathrm{C}\right)$ & 17 & 21 \\
High RH (\%) & 84 & 98 \\
Low RH (\%) & 41 & 65 \\
\hline
\end{tabular}



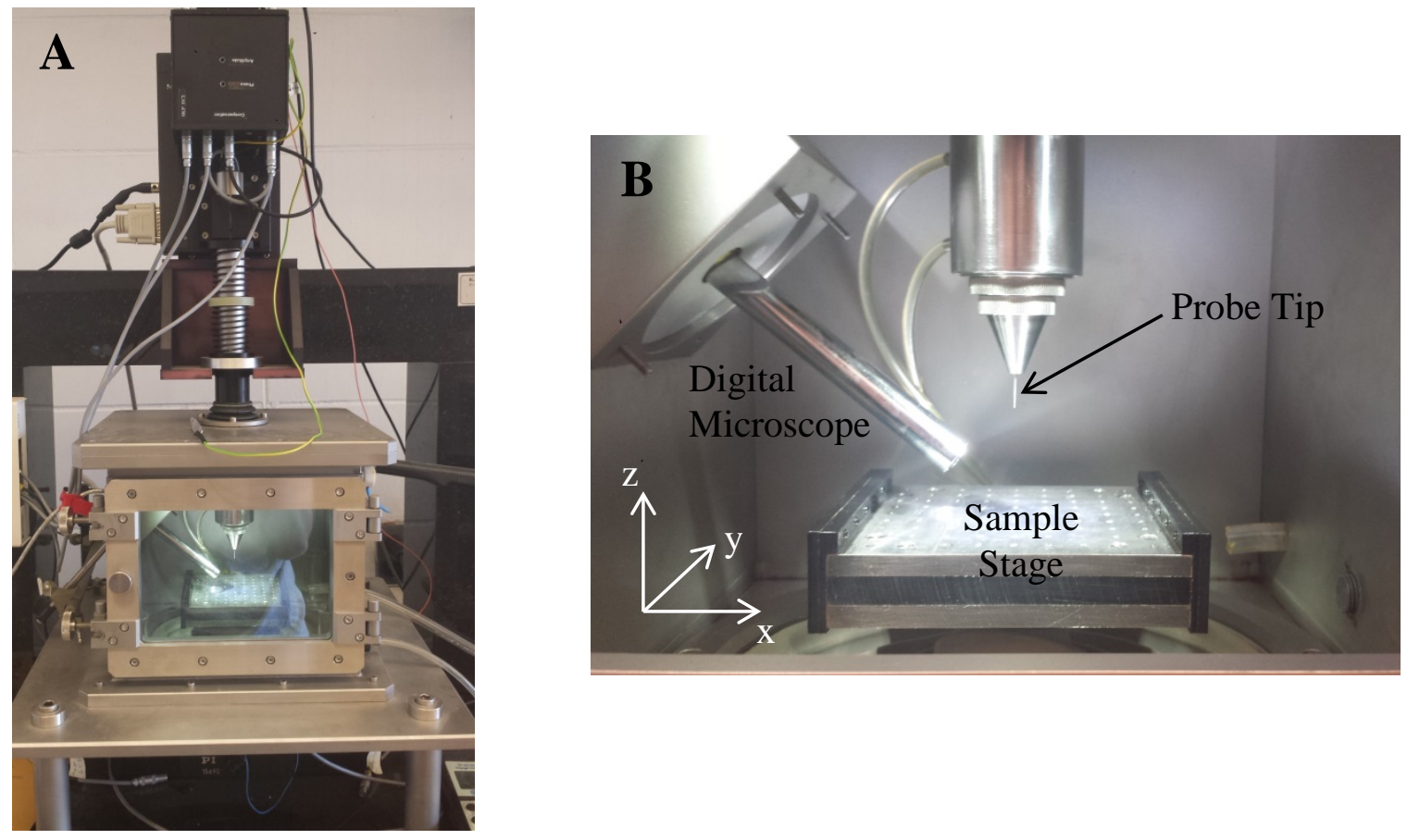

Figure 3.1. Photos of the SKP setup used. a) Overall setup. b) SKP chamber. 


\subsection{References}

1. A. International, ASTM Standard B211-12e1, in Standard Specification for Aluminum and Aluminum-Alloy Rolled or Cold Finished Bar, Rod, and Wire. 2012.

2. Z. Zhao and G. S. Frankel, CS Corrosion Science, 2007, 49(7), 3064-3088.

3. S. C. Morton and G. S. Frankel, Materials and Corrosion-Werkstoffe Und Korrosion, 2014, 65(4), 351-361.

4. Anon. 'National Centers for Environmental Information (NCEI)', [viewed; Available from: http://www.ncdc.noaa.gov/. 


\section{Chapter 4: Results}

\subsection{SKP Droplet Testing}

\subsubsection{Point Measurements}

Potential values were recorded by the SKP during the point measurement tests and representative results are displayed as profiles in Figures 4.1 and 4.2. During the tests, all of the droplets underwent evaporation leading to increased concentration of electrolyte and initiation of pitting. This evaporation period, typically lasting between one and five hours, depending on the initial droplet volume and concentration, was consistently associated with a rapid decrease in potential observed. It is believed that this resulted from the chloride concentration increasing and possibly by pitting initiation. Also during evaporation, only the height of the droplets decreased; the droplet perimeters were pinned at the original positions and did not change. Beyond the initial potential drop, however, the behaviors varied. Under all initial conditions, droplets were observed to experience at least one sustained pitting region, with several tests exhibiting multiple sustained pits within the same pitting region. It appeared that additional pits only formed when the previous pit was no longer active. Only one pit was active at any time. Sustained pitting regions were identified visually as sites of white corrosion product build-up that were discernible by eye. Sustained attack typically occurred within the 
droplets near the edge, though several tests did experience sustained attack closer to the center of the droplets. The identification of sustained pitting regions was limited to visible observation using the digital microscope in the SKP chamber. While the regions were identified to form within the first few hours of the tests, it was not possible to identify the exact moment of pit initiation. These large pits always resulted in the precipitation of a white corrosion product over top of them, initially believed to likely be primarily $\mathrm{Al}(\mathrm{OH})_{3},{ }^{1}$ as well as the evolution of bubbles emanating from the pit area, presumably $\mathrm{H}_{2}$. Later analysis described in Section 4.4 showed that much of what was seen as the white product build-up was actually an agglomeration of $\mathrm{H}_{2}$ micro-bubbles, appearing white because of reflection of light. Many of the tests that experienced stable pitting near the droplet edge also saw outward growth of the droplet edge near the pit, in most cases resulting in the formation of a secondary droplet outside of and connected to the initial droplet, which has been previously observed. ${ }^{2}$ Secondary droplets were observed at least once for all droplet concentrations of both salts but were produced most consistently under 3 and $6 \mu \mathrm{L}$ droplets of $3.5 \mathrm{wt} \%$ and $1 \mathrm{M} \mathrm{NaCl}$. The formation and behavior of these secondary droplets will be discussed later on, but an example of their formation as observed in the SKP chamber is given in Figure 4.3. Build-up of corrosion product, again most visibly hydrogen bubbles, is seen near the edge of the droplet, followed by the initiation and growth of a secondary droplet at this location. Aggressive attack was found to take place beneath these secondary droplets. All of the tests also exhibited smaller pits across the entire surface beneath the droplets, identified during 
optical profilometry, but these pits were much less aggressive than the single or few sustained pits that were established as they were typically less than five microns deep.

Of the potential profiles recorded, several types of behavior were found. For many of the tests, after the initial drop in potential as the droplet volume moved toward equilibrium salt concentration, the potential stabilized and remained steady through the rest of the experiment. For $\mathrm{NaCl}$ droplets, this stable potential was found to be between 800 and $-700 \mathrm{mV}_{\mathrm{SCE}}$, and for $\mathrm{MgCl}_{2}$ between -700 and $-600 \mathrm{mV} \mathrm{VCE}_{\text {SCE }}$ Tests that displayed this behavior were all associated with the sustained pitting taking place at the edge of the droplet. Other tests exhibited elevations in the potential at times after the droplet finished evaporating, or fluctuations of increases and decreases of the observed potential. In tests where the observed potential was changing throughout, a variety of pit behaviors was observed that will be discussed later. However, fluctuations in the potential consistently occurred as changes in the morphology of the corrosion product build-up and bubble agglomeration beneath the droplet were seen taking place.

\subsubsection{Line Scans}

After the point measurement experiments were completed, the SKP was then utilized to perform a line-scan across the center of the droplet starting on the bare sample surface and making sure to scan the entire diameter of the droplet. During the line-scans, the height and potential were recorded at $10 \mu \mathrm{m}$ intervals, providing height and potential profiles of a cross-section of the droplet. The droplet heights for different conditions of concentration, volume and salt cation are shown in Figure 4.4. As expected, droplets with 
higher initial salt concentration saw greater equilibrium droplet thicknesses. Variation in observed droplet heights for droplets of the same starting conditions could be attributed to differences in droplet diameter. The droplets were effectively spherical caps and the droplet profiles had the shape of an arc. Examples of these line scans obtained for droplets with initial concentration of $0.1 \mathrm{M} \mathrm{MgCl}_{2}$ are provided in Figure 4.5. Assuming a perfect spherical cap, the arc radius could be calculated from the width $(W)$ and height $(H)$ of the droplet using Equation $1 .^{3}$

$$
\text { arc radius }=\frac{H}{2}+\frac{W^{2}}{8 H^{2}}
$$

From the calculated arc radius, a perfect arc of the appropriate height and width could be simulated and compared to the observed profile of the droplet height measured by the SKP, permitting the assumption that the droplets behave as spherical caps to be verified. An example of this is shown in Figure 4.6. The assumption was found consistently to be true for droplets except in a few cases where the build-up of product resulted in the formation of bulges. It appeared that the bulges were formed by the hydrogen bubbles, shown later in Section 4.4, extending above the rest of the droplet, such as in the height profile in Figure 4.7. In experiments where this occurred, the bulge was much higher than the expected droplet thickness, and the remainder of the droplet was found to be thinner than was observed for other droplets of the same test conditions, suggesting that more solution was allocated to these regions. For nearly all tests, the droplets behaved as spherical caps, and as such their volumes could be calculated using Equation $2{ }^{3}$ where $H$ is again the height of the droplet, and $a$ is the radius of the dropletsample interface. When calculating the volume, the droplet diameter measured was 
reduced by $200 \mu \mathrm{m}$ to compensate for diameter of the probe tip. As the probe tip approached the droplet edge during line scans, the height of the probe was not at the height of the bare metal surface until it was completely beyond the edge of the droplet. Because the probe had a diameter of $200 \mu \mathrm{m}$, this was not the case until the center of the probe tip was $100 \mu \mathrm{m}$ away from the actual droplet edge. This occurred at both points that the probe was passing the droplet edge, so the measured droplet diameter was 200 $\mu \mathrm{m}$ greater than the actual droplet diameter. With the volume calculated, and the initial chloride content known, the chloride concentrations could be determined as well by dividing the initial chloride content by the calculated droplet volume, Equation 3.

$$
\begin{aligned}
& \text { Volume }=\frac{\pi H}{6}\left(3 a^{2}+H^{2}\right) \\
& {\left[\mathrm{Cl}^{-}\right]=\frac{\text { Init.Chloride content }}{\text { Calc. Vol. }}}
\end{aligned}
$$

From the height data gathered during the point measurements, and assuming the droplet radius remained constant, the chloride concentration of the droplet could be determined through the duration of the experiment. Typical chloride concentration profiles during evaporation and approaching equilibrium are shown in Figure 4.8. In Figure 4.8a and c, the concentration of the droplets relative to time are shown for $0.5 \mathrm{M}$ $\mathrm{MgCl}_{2}$ and $3.5 \mathrm{wt} \% \mathrm{NaCl}$ at each initial droplet volume. For droplets containing $\mathrm{NaCl}$, the initial equilibrium concentration of chloride fell between 3.6 $\mathrm{M}$ and $4.2 \mathrm{M}$, and for $\mathrm{MgCl}_{2}$ it was found in the range of 3.5-4.5 M. For droplets with the highest starting chloride concentration, the equilibrium chloride concentration was found to be higher. This can be seen in Figures 4.8b and d, which show $\mathrm{Cl}^{-}$concentration profiles for $\mathrm{MgCl}_{2}$ and $\mathrm{NaCl}$ respectively, with starting volumes of $9 \mu \mathrm{L}$ and each concentration tested. It is 
possible that the corrosion products that developed increased the volume of the droplets, perhaps by possessing a lower critical relative humidity of deliquescence and absorbing more water from the atmosphere. This would have the most noticeable effect on droplets with the lowest starting concentrations, as they would also have the lowest equilibrium volume, so assuming similar amounts of corrosion product in the first hours of all of the tests would mean a greater addition of volume relative to the equilibrium volume. Also evident in Figure 4.8a and c, the concentration increased faster for smaller droplets, and also reached equilibrium sooner. This was observed for all droplet conditions, and was likely a result of the relationship between the surface area and volume of the droplets. The rate of evaporation is directly related to the ratio of the surface area of a droplet to its volume. ${ }^{4}$ This ratio is greater at smaller initial volumes, leading to the accelerated increase in concentration of smaller droplets. Also, for droplets of the same starting volume, those with higher $\mathrm{MgCl}_{2}$ concentration reached equilibrium concentration fastest, Figure 4.8b. For 6 and $9 \mu \mathrm{L}$ droplets of $\mathrm{NaCl}$, however, equilibrium was found to be achieved fastest for droplets with lower starting salt concentration, seen in Figure 4.8d. It is not clear what causes this discrepancy, but it could be related to the factor causing the much greater equilibrium chloride concentrations in droplets of $\mathrm{MgCl}_{2}$ with greater starting salt concentrations.

For the line-scans performed after the point measurements, in order to avoid altering the droplet by evaporation, the chamber of the SKP was not opened until all measurements were completed. Line scans were restricted to movement along the $\mathrm{x}$-axis direction, however, so in addition to scans over the center of the droplets, scans were also 
performed at different regions on the droplets if necessary to ensure regions of pitting and product build-up were inspected. Due to issues with the SKP, scans were not possible in some instances when the change in droplet height was too steep, as this would cause the probe tip to come into contact with the droplet surface, rendering further measurements inaccurate.

The potential beneath the droplet was steady across regions where no obvious product build-up was observed and elevated outside of the droplet on the bare surface, as shown in Figure 4.9. However, for a variety of corrosion product and droplet formations, the potential profiles exhibited different fluctuations related to the location of the pit and product build-up. In previous work, ${ }^{2}$ the formation of secondary droplets was associated with large-scale separation of the anode in the secondary droplet and the supporting cathodic region observed under the adjoining primary droplet. Such behavior was again observed in this study. Figure 4.10 shows the line scan measurement of a $9 \mu \mathrm{L}$ droplet of $0.25 \mathrm{M} \mathrm{MgCl}_{2}$. Figure 4.10a shows the direction of the line scan, beginning on the bare surface and progressing across the secondary droplet and the primary droplet. The secondary droplet was found to be overlapping considerably with the primary droplet. In Figure 4.10b, it was observed that, far from the secondary droplet, the potential beneath the primary droplet is similar to what would be expected in regions without corrosion product as was shown in Figure 4.9. However a lower potential was observed beneath the secondary droplet, and the potential was elevated beneath the primary droplet near the secondary droplet. This was also observed in previous studies. ${ }^{2}$ Similar behaviors were also found when sustained pitting occurred under the primary droplet without the 
formation of a secondary droplet, as seen in Figure 4.11, showing the results from a $6 \mu \mathrm{L}$ droplet of $0.1 \mathrm{M} \mathrm{MgCl}_{2}$. Again, the region of pitting was found to have a lowered potential relative to the bulk, and the immediate surrounding region was at an elevated potential. The region of bare surface just outside of the droplet near the pit was also at a potential elevated relative to what is expected. Farther away from the pitting region, the potential returned to values expected in regions without pitting. This exhibited the same 50-60 $\mathrm{mV}$ difference between the pitting region and the immediate surrounding area as was seen in cases of secondary droplets. Such behavior contradicts the previously reported results that suggested a larger potential difference was observed in cases of secondary droplet formation. ${ }^{2}$

To observe the development of the regions of potential differences during point measurements, line scans were performed at intervals of five hours during point measurement tests performed under the same conditions as presented, with a $6 \mu \mathrm{L}$ droplet of $3.5 \mathrm{wt} \% \mathrm{NaCl}$. Figure 4.12 shows that a pit near the edge was formed, over which the line scans were performed. Between line scans, the probe was returned to the center of the droplet, and measurement of the potential at that point continued. Results of this test are given in Figure 4.13. In Figure 4.13a, the potential at the center of the droplet is reported. The intervals during which line scans were performed can be observed as breaks in the profile. The accompanying potential profiles obtained from the line scans are shown in Figure 4.13b. In the initial line scan, performed five hours after the start of the test, the potential profile was similar to that shown in Figure 4.9, consistent with the lack of an observed pitting region. In the following potential profiles, recorded at 5, 10, 
15 and 20 hours into the experiment, a region of elevated potential formed and grew laterally, extending beneath the center of the droplet where the probe was located. The extension of the elevated potential region beneath the probe was consistent with the increase of potential observed in the point measurements. This suggests that the fluctuations in potential observed during the other point measurements performed in this study were a result of growth and changes in the shape of the cathodic region surrounding the pitting regions. The failure to observe a lowered potential during the interval line scans suggests that the anodic pit was not below the SKP probe tip as it scanned across the surface.

\subsubsection{Optical Profilometry}

After measurements were completed in the SKP, samples were cleaned and observed by optical microscope and optical profilometer. Certain behavior of the surface beneath the droplet was found to be consistent under all conditions. Examples of representative behavior are shown for $\mathrm{NaCl}$ and $\mathrm{MgCl}_{2}$ droplets in Figure 4.14. As shown in Figure 4.14a, regions of sustained pitting attack were observed in $3.5 \mathrm{wt} \% \mathrm{NaCl}$, with build-up of corrosion product directly on top of and in the immediate vicinity of the pit, identified as region " 1 " in the image. This pitting product was in several cases also observed to be present in the shape of a dome. Beyond this region of corrosion product, an area of clean sample surface was found surrounding the pitting region (region "2”) with a ring of corrosion product build-up along its perimeter. Beyond that the remainder of the area beneath the droplet was found to be covered in a dark corrosion product 
(region”3”). The same regions formed for droplets of $\mathrm{MgCl}_{2}$, Figure 4.14b; however, the product in region " 3 " for these tests was much lighter in color and the product build-up at the edge of the clean region "2" was less noticeable. Across the droplet area, small pits were observed, typically less than $5 \mu \mathrm{m}$ in depth. The small pits were observed to initiate at secondary phase particles, found dispersed in the rolling direction. Regions of sustained pitting appeared to be a series of pits aligned in the rolling direction. However, upon placing the samples in an ultrasonicator for several minutes, corrosion product and material covering the pits was removed and the pits were found to be connected. This single agglomeration of pits was always observed to have grown laterally in the rolling direction. When the sustained pit was oriented such that the nearest droplet edge was parallel to the rolling direction, this resulted in the pits extending parallel to the droplet edge. However when the pit initiated in a region where the rolling direction was perpendicular to the nearest edge, lateral growth of the pit would extend toward the droplet edge. A schematic displaying these pit orientations is presented in Figure 4.15. It was this latter condition, case ' $a$ ' in Figure 4.15, that was found in all tests that developed secondary droplets, with the laterally growing pit extending beneath the secondary droplet region.

Analysis with the optical profilometer allowed for the areas of sustained pitting attack to be characterized. In Figures 4.16 and 4.17, the observed volume of the large pit agglomeration, as well as the maximum depth of the pitting, are presented for all droplet experiment conditions for $\mathrm{NaCl}$ and $\mathrm{MgCl}_{2}$ respectively. For both salts, there was a clear general relationship between increased initial droplet volume and increased pit depth, as 
well as increased pitting volume. This may have been caused by an increase in the available area for cathodic reaction, while the area of the anodic pits stayed roughly the same. It is also possible that because the droplets of larger volume were covering a greater area of the sample, they were also more likely to cover regions susceptible to more aggressive pitting attack. Considering droplets of the same volume but different starting salt concentration, there is no clear trend regarding the pitting depth and pitting volume. In other words, it does not appear that initial droplet concentration had any clear, direct relation to the severity of pitting attack. It seems likely that a combination of factors, such as equilibrium height of the droplet, area of contact, and concentration of chloride ions, were interacting to influence the variations in pitting attack observed between the various droplet conditions.

\subsection{Aging Tests}

For all samples prepared for the droplet tests conducted in this study, samples were etched after polishing to remove the active surface layer, and then placed in a desiccator until use. ${ }^{5}$ During droplet tests in the SKP, droplets of the same initial conditions were found to have different diameters, possibly from variability inherent in the droplet application process, but also possibly a result of differing surface conditions. One possible condition variable could be the in the aging of the oxide layer as the sample sat in the desiccator for increasing times. In order to investigate the influence, if any, of time spent in the desiccator before use on the behavior observed in testing, experiments were conducted on samples at different amounts of time after etching. 
Line scans performed with the SKP after 20 hours in the SKP chamber at 85\% $\mathrm{RH}$, and optical profilometry performed after cleaning the samples, allowed for the droplets, with initial conditions of $9 \mu \mathrm{L}$ and $1 \mathrm{M} \mathrm{NaCl}$, and pitting behaviors to be characterized. The observed diameters of the droplets, recorded from line scans performed by the SKP, are given in Figure 4.18, and the total pitting volumes of the sustained pits and maximum pit depths are given in Figures 4.19 and 4.20, respectively. Droplets tested immediately after etching showed greater wetting of the sample surface, resulting in droplets spreading to a larger diameter. This effect decreased with time after etching, leveling out at three days and beyond, Figure 4.18. This same trend was found for the volume of pitting attack, which also leveled out after three days, Figure 4.19. Although it exhibited more scatter, the maximum pit depth also decreased with increasing time after etching, Figure 4.20 . The depth of pits appears to be sensitive to the aging process due to the decreased droplet area with increased aging time, however this relationship does not appear to be as strong as that found between pitting volume and aging time. These results show that the increased aging after etching influences the droplet diameter, especially immediately after etching. However it is still unclear if it is the less mature oxide layer in these early tests that make the sample susceptible to more aggressive pitting attack, or if it is simply a product of the droplet diameter being greater. The increased droplet diameter is probably the more influential factor. 


\subsection{Outdoor Testing}

For tests conducted outdoors, temperature and humidity data were gathered from a local personal weather station and are presented for each week of the study in Figure 4.21. ${ }^{6}$ The relative humidity was observed to reach a minimum of $46 \%$ for all of the test periods, higher than the critical relative humidity of $\mathrm{MgCl}_{2}$ (35\%) and lower than that of $\mathrm{NaCl}$ (75\%). However, the humidity was found to be higher than $75 \%$ most of the time, as identified by comparison with the dashed lines in the humidity figures. Also of note, substantial amounts of rainfall were observed on some of the days during which outdoor testing took place, most notable on July 12, 14, 19 and 29, and August 3.

Observation of the samples by optical microscope after testing revealed qualitative differences in the behavior of the tests conducted outdoors with those conducted in the SKP chamber in lab. Representative images obtained by optical microscope for each time interval are given in Figures 4.22 and 4.23 for $\mathrm{MgCl}_{2}$ and $\mathrm{NaCl}$, respectively. For $\mathrm{MgCl}_{2}$, there was little difference observed between samples tested in the lab and those tested outdoors for one and four days. For seven days, however, pitting attack under $\mathrm{MgCl}_{2}$ droplets tested in the lab stayed more localized with less lateral growth, while those tested outdoors experienced more lateral growth, with the example shown in Figure 4.22 extending by a series of secondary droplets. Overall, however, optical microscopy did not reveal much difference in the behavior of $\mathrm{MgCl}_{2}$ droplets outdoors versus in the lab.

For $\mathrm{NaCl}$, the corrosion behavior was visibly different in outdoor testing. As seen in Figure 4.23, corrosion behavior appeared similar for tests conducted for one day, but 
after four and seven days corrosion attack formed around the edge of the initial droplet for the outdoor sample. For both time intervals, the basic regions of pitting attack described in Figure 4.14 were observed. In addition to this, attack was seen to propagate outward from the initial droplet edge, along the entire perimeter of the outdoors droplet including the perimeter of secondary droplets. This attack was not observed within the droplet perimeter, suggesting the mechanism providing protection to the bulk of the droplet from aggressive pitting during lab tests was continuing to protect the inner droplet region during outdoor tests. Also, similar to the $\mathrm{MgCl}_{2}$ seven day outdoor test shown in Figure 4.22, $\mathrm{NaCl}$ droplets exposed for four and seven days outdoors that developed secondary droplets exhibited a series of additional secondary droplets forming to extend the pitting region. The lateral growth of the pits in the rolling direction was consistent with that observed in lab testing. However, in the instance shown in Figure 4.23 for seven days outdoors, the secondary droplet behavior differed. Initially, the pit extended in the rolling direction from the initial droplet region to the secondary droplet region, as expected. Beyond this, however, new pits were found to form parallel to the initial pit, but along a new grouping of surface particles. These new pits were also found under secondary droplets that developed off of the initial secondary droplet. It appears that the grouping of particles that the pitting initially extended along terminated and sustained attack moved to a new collection of particles susceptible to attack.

Analysis with the optical profilometer as before allowed for the pitting volume and maximum pit depth to be recorded. These results are given in Figures 4.24 and 4.25. Pit depth and volume were similar for in lab and outdoor conditions for all testing lengths 
of $\mathrm{MgCl}_{2}$, Figure 4.24. For $\mathrm{NaCl}$, however, beyond one day of testing, droplets tested outdoors showed greater pitting volume, and in one instance a pit of greater depth, 115 $\mu \mathrm{m}$, was found. It is clear that the cycling of relative humidity had a much greater influence on the corrosion behavior of the $\mathrm{NaCl}$ droplets than the $\mathrm{MgCl}_{2}$ droplets. The variation of behavior in $\mathrm{NaCl}$ droplets was expected because of the humidity cycling above and below the critical $\mathrm{RH}$ of $\mathrm{NaCl}$. However a greater influence on $\mathrm{MgCl}_{2}$ was anticipated. As the RH dropped, it was expected that the increase in chloride concentration while still remaining wet would accelerate the corrosion process. However, this was clearly not as strong of an influence as anticipated. Also of note, in samples exposed for seven days, the bulk region of the droplet appeared to be slightly lower than the surrounding bare surface, as well as the product-free region formed around the sustained pitting. An example of this is shown in Figure 4.26, which presents the OP analysis of the $\mathrm{MgCl}_{2}$ droplet exposed for seven days shown in Figure 4.22. As seen in the figure, the height of the surface beneath the droplet was lower than that of the surrounding material by several microns. It seems possible that this is indicative of slow but continuous corrosion occurring across the droplet area away from the pit, possibly by continuous metastable pitting or general corrosion. ${ }^{7}$

\subsection{Stereomicroscope Droplet Study}

To better observe the pitting process and the formation of secondary droplets, a series of tests was performed using $6 \mu \mathrm{L}$ droplets of $3.5 \mathrm{wt} \% \mathrm{NaCl}$ on samples prepared the same as those used previously, and observed with a digital microscope camera in a 
chamber of $85 \%$ RH. Images at important points in the tests are provided for the examples provided, however videos are provided for each as supplemental material to this document.

\section{Example 1}

In the first example presented, pitting was observed to take place near the edge of the droplet. Figure 4.27 gives images taken at different intervals during the experiment. After one hour, the pit can be seen just forming near the edge of the droplet. A ring of precipitate build-up is also visible surrounding the pitting region, identifying region "2" that was shown in Figure 4.16, the product-free region. After six hours, a large $\mathrm{H}_{2}$ bubble is located on top of the pit, and several smaller bubbles have migrated to the edge of the product-free region, possibly restricted from moving farther toward the center of the droplet by build-up of corrosion product. At 15 hours, the edge of the product-free region had become more clearly defined and more $\mathrm{H}_{2}$ bubbles had formed. Finally, at 20 hours the hydrogen bubbles were found to extend toward the center of the droplet, following an expansion of the precipitate ring that acted as a boundary of the initial product-free region. It is clear that the grouping of $\mathrm{H}_{2}$ bubbles largely makeup the white formation that was found to be easily visible in tests conducted in the SKP and was used to identify regions where sustained pitting attack was occurring. It was the extension of the hydrogen bubbles beneath the probe tip that was found to correspond to an increase in the observed potential. In this example, the extension of the bubble region appeared to be associated with the outward migration of the precipitate ring. 


\section{Example 2}

As mentioned previously, many of the droplets that experienced sustained pitting attack near the edge of the droplet saw outward growth of the droplet perimeter near the pitting site. In the example shown in Figure 4.28, this extension of the droplet boundary was observed. At four hours, the pit could be seen near the droplet edge, as well as $\mathrm{H}_{2}$ bubbles forming around it and the product-free region. At 10 hours, the product-free region was almost entirely covered by $\mathrm{H}_{2}$ bubbles, and at 12 hours a bulge at the droplet boundary formed. After 16 hours the boundary extension had grown into nearly an entire secondary droplet.

After completing the test, the sample was rinsed with DI water and ethanol and images were taken with the optical microscope, Figure 4.29a. In this image, a large amount of corrosion product was visible near the droplet edge, with some corrosion product visible outside of the primary droplet under the secondary region. After several minutes in an ultrasonicator, it was seen that the corrosion product was covering the pits near the edge, and the lateral pits were seen to extend from beneath the primary droplet region into the secondary region, Figure 4.29b. The morphology of these pits can be seen in greater detail by optical profilometry in Figure 4.29c, the deepest region of the pits extending beyond the initial primary droplet boundary. This suggests that the attack moved laterally at the sustained depth. Therefore, the large volume of pitting found under the secondary droplet was simply a continuation of this growth and not the result of a newly formed highly aggressive site. Also shown in Figure 4.29 are dashed lines on the 
images, used to represent the primary and secondary droplet perimeters. In this example, it can be seen that the primary and secondary droplets formed one contiguous droplet with a shape similar to two circles overlapping.

\section{Example 3}

In the following test, the formation of a distinct secondary droplet at the droplet edge was observed, shown in Figure 4.30. After five hours, sustained pitting attack and $\mathrm{H}_{2}$ bubble formation was observed near the edge of the droplet as in previous tests. At 10 hours, however, a secondary droplet had formed just outside the primary droplet perimeter. At 20 hours, additional $\mathrm{H}_{2}$ bubbles were seen to have formed under the primary droplet, and the secondary droplet had grown. Unlike what was seen in the previous example, the areas of contact of the primary and secondary droplets in this example formed two distinct circles independent of one another. This suggests that the secondary droplet formed entirely outside of the primary droplet perimeter.

As with the previous example, the droplet was analyzed by optical microscope after rinsing with DI water and ethanol, Figure 4.31a. In this image, corrosion product was found beneath the primary droplet, as well as beneath the secondary droplet, however there was a region between the two droplets where no corrosion or products were visible. After ultrasonication, the region was observed again by optical microscope, as well as optical profilometer, Figures $4.31 \mathrm{~b}$ and c. After removal of the corrosion product, it was found that the pit formed under the primary droplet extended laterally into the secondary droplet region but this connection was covered by metal between the edges of the two droplets. The pit appeared to extend beneath the metal surface and reemerged 
beyond the perimeter of the initial droplet. The greatest pit depth was experienced beneath the secondary droplet and at the primary droplet edge with a shallow portion of the pit connecting the two regions.

\section{Example 4}

In the final test presented, failure to maintain the humidity in the chamber occurred early in the test, approximately shortly after 6 hours, dropping beneath the critical relative humidity of $\mathrm{NaCl}$ and causing the growth of $\mathrm{NaCl}$ crystals. Images taken of the pitting region during the test are shown in Figure 4.32. At five and six hours, the build-up of $\mathrm{H}_{2}$ bubbles around the pitting area took place, Figures 4.32a and b. The humidity dropped below the critical $\mathrm{RH}$ of $\mathrm{NaCl}$ and salt crystals were seen to precipitate over the pits after 7.5 hours, Figure 4.32c. It should be noted that no other sites in the droplet precipitated the salt. At 7.5 hours, the chamber leak was closed and humidity began to increase again. After the RH was returned to $85 \%$ at approximately 8 hours, the salt crystals dissolved completely by 8.5 hours, however a region remained where the formation of the salt pushed the droplet boundary out. Pitting took place under this extended region, as suggested by the continued evolution of $\mathrm{H}_{2}$ bubbles in the area, until at 18 hours a new secondary droplet initiated outside of the primary droplet, shown in Figure 4.32e. This secondary droplet grew and is seen to have merged with the primary droplet by 20 hours, Figure 4.32f.

After the test, images were taken by optical microscope after rinsing the sample with DI water and ethanol, and after several minutes in the ultrasonicator, Figures 4.33a and b. Removal of corrosion product by ultrasonicator showed that the pit extended 
laterally beneath the initial bulge left behind by the salt crystals, as well as into the secondary droplet formed at 18 hours. Optical profilometer analysis of the pit, Figure 4.33c, found that the maximum pit depth was found in the region where salt crystals formed. 


\subsection{Tables and Figures}
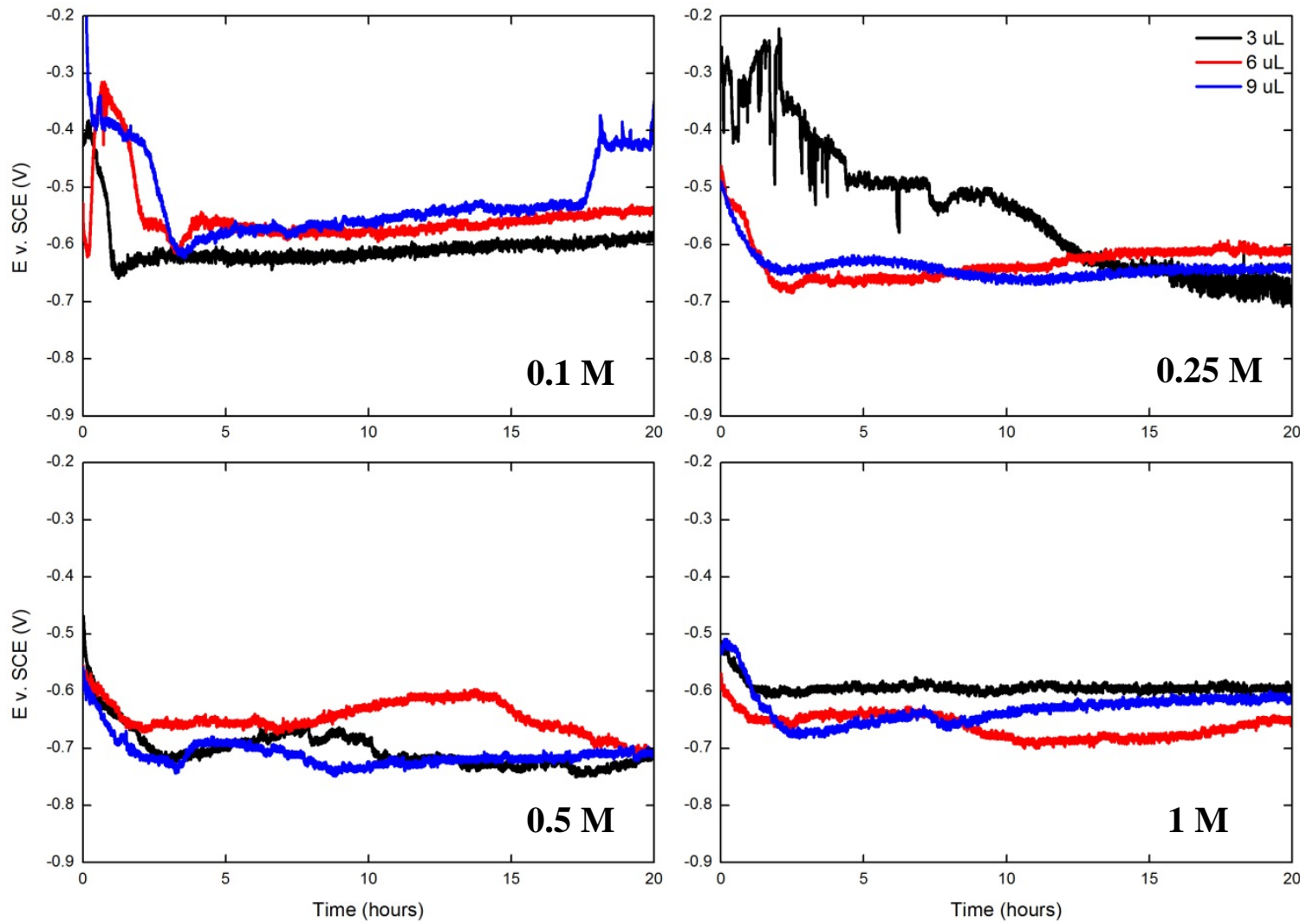

Figure 4.1. Potential profiles for $\mathrm{MgCl}_{2}$ droplet tests recorded with SKP for droplets with initial volumes of 3, 6 and $9 \mu \mathrm{L}$, and initial $\mathrm{MgCl}_{2}$ concentrations of $0.1 \mathrm{M}$ (top left), 0.25 $\mathrm{M}$ (top right), $0.5 \mathrm{M}$ (bottom left) and $1 \mathrm{M}$ (bottom right). 

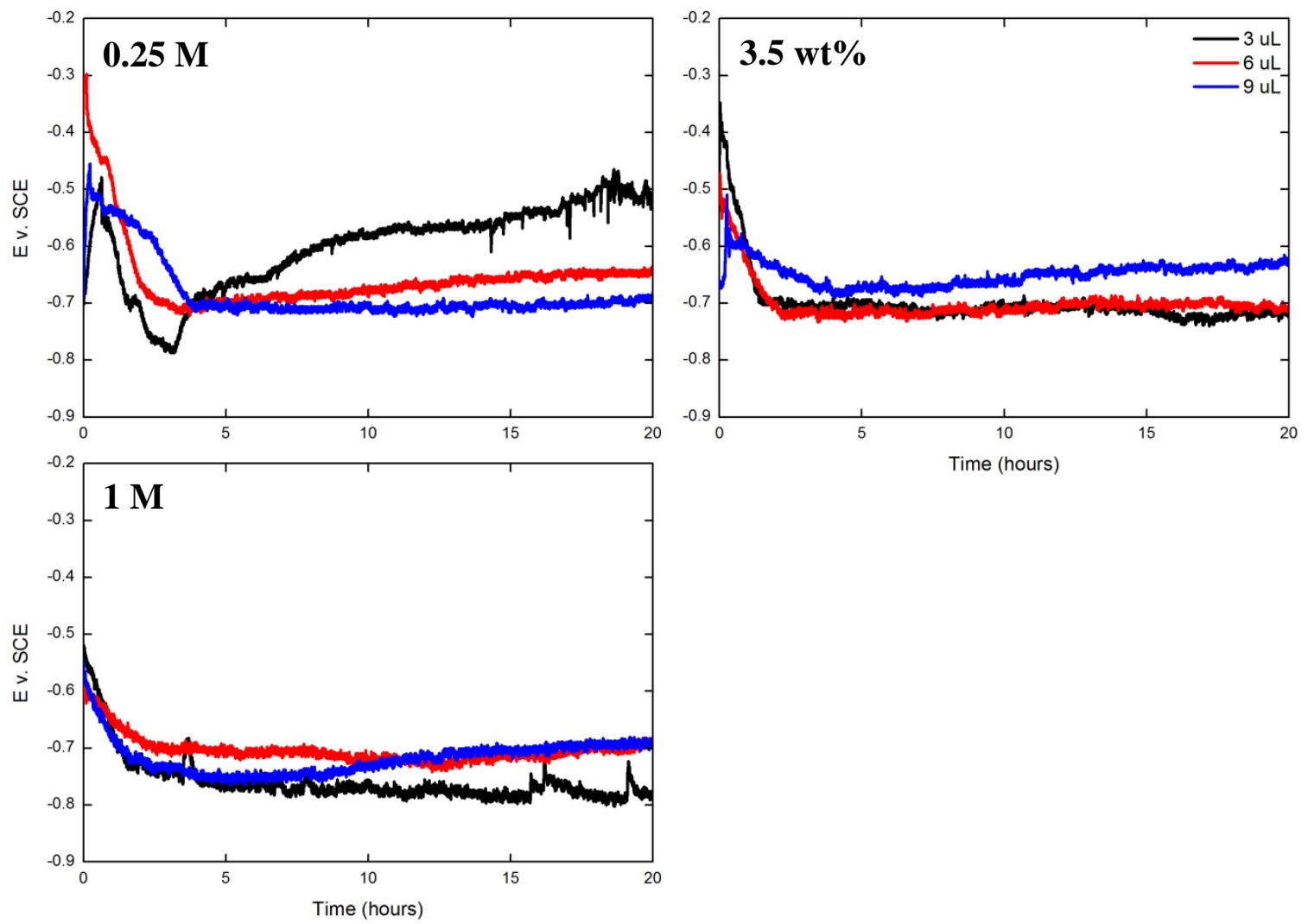

Figure 4.2. Potential profiles for NaCl droplet tests recorded with SKP for droplets with initial volumes of 3, 6 and $9 \mu \mathrm{L}$, and initial $\mathrm{NaCl}$ concentrations of $0.25 \mathrm{M}$ (top left), 3.5 wt\% (top right) and $1 \mathrm{M}$ (bottom). 

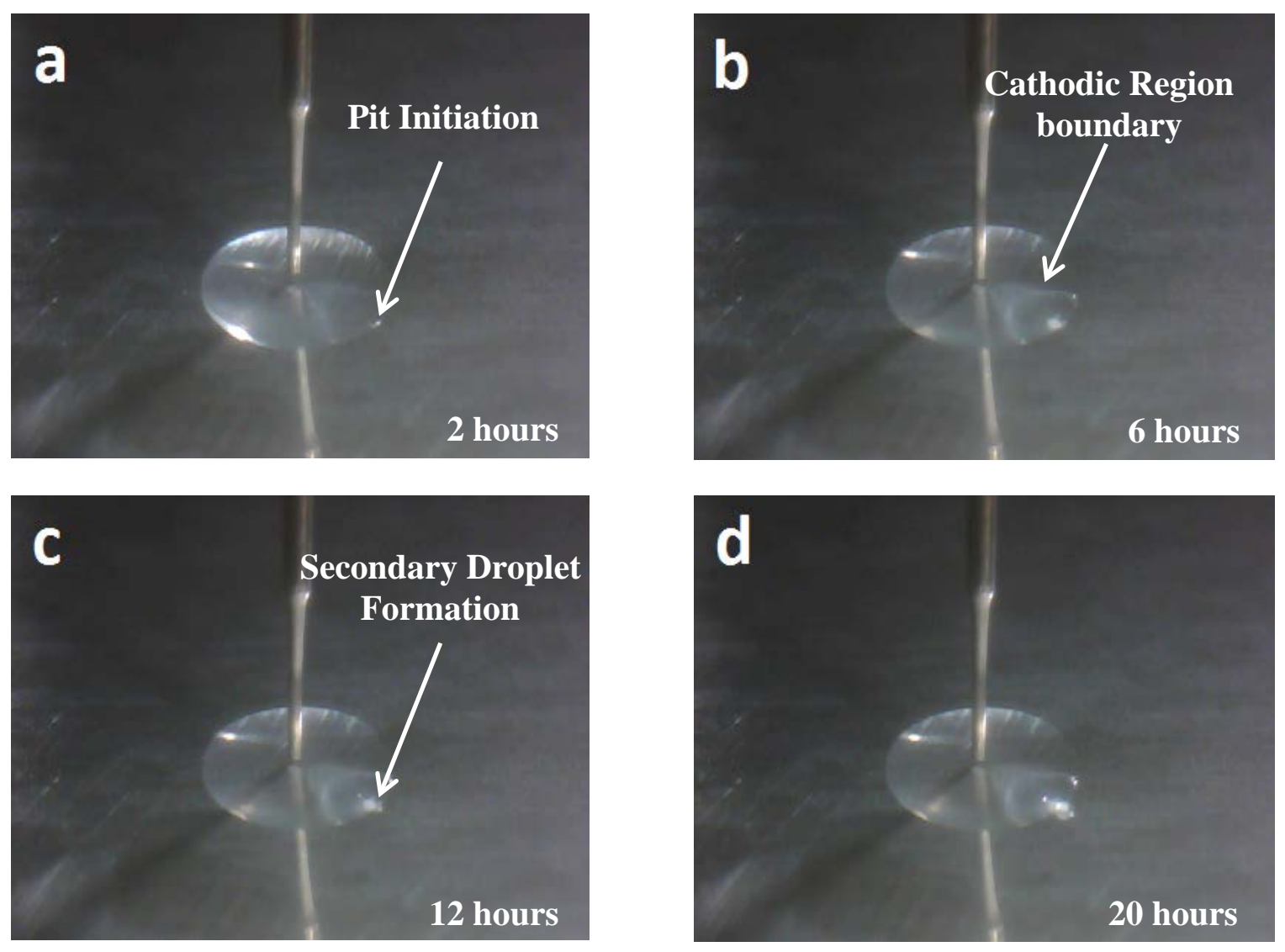

Figure 4.3. Representative example of secondary droplet formation found under $6 \mu \mathrm{L}$ droplet of $3.5 \mathrm{wt} \% \mathrm{NaCl}$. a) Pit initiation observed after 2 hours. b) Pit growth at 6 hours. c) Secondary droplet initiation at 12 hours. d) Secondary droplet growth after 20 hours. 

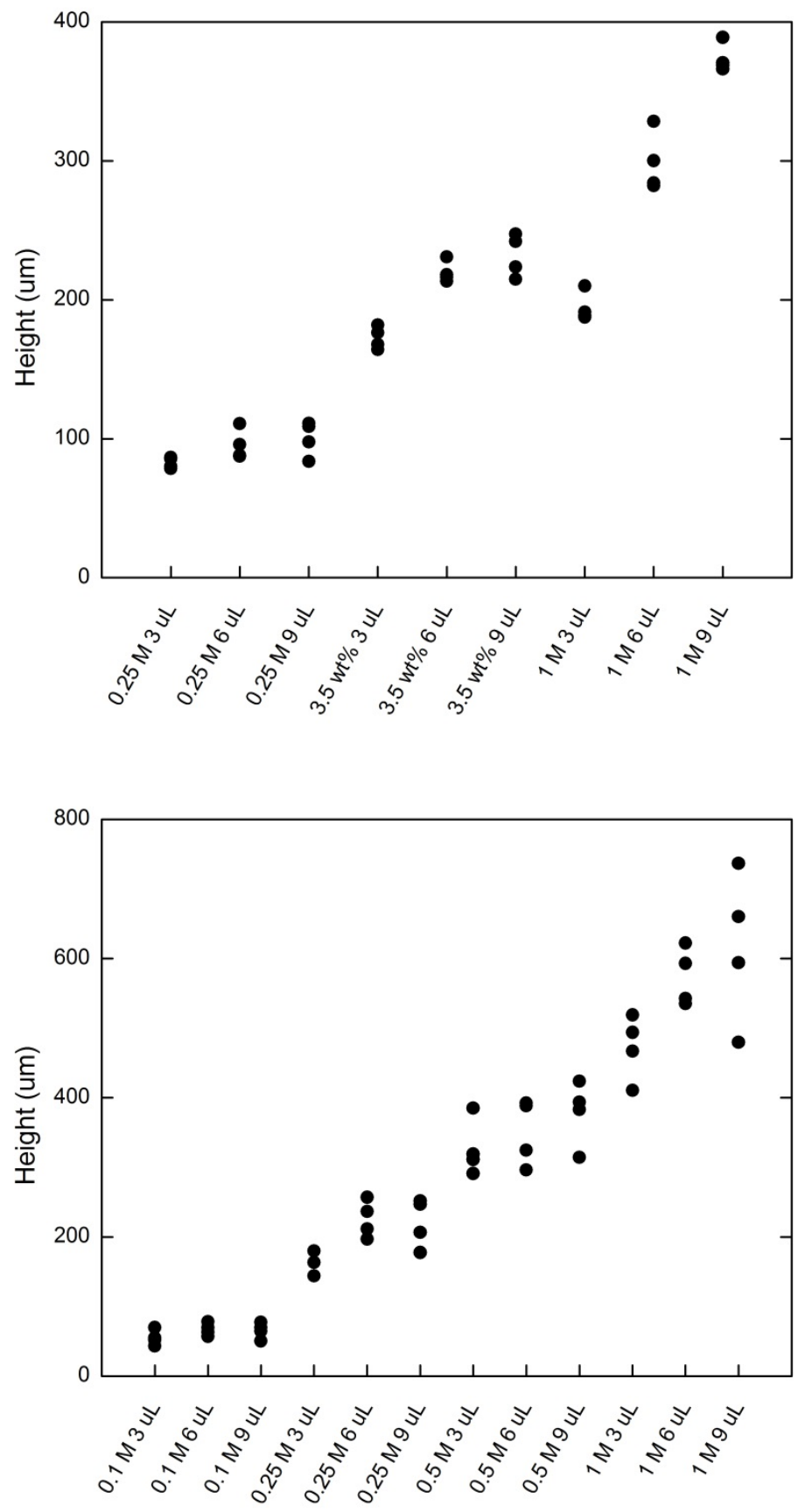

Figure 4.4. Highest points observed during line scans of droplets. Results for $\mathrm{NaCl}$ droplets are presented on top, and $\mathrm{MgCl}_{2}$ on bottom. 


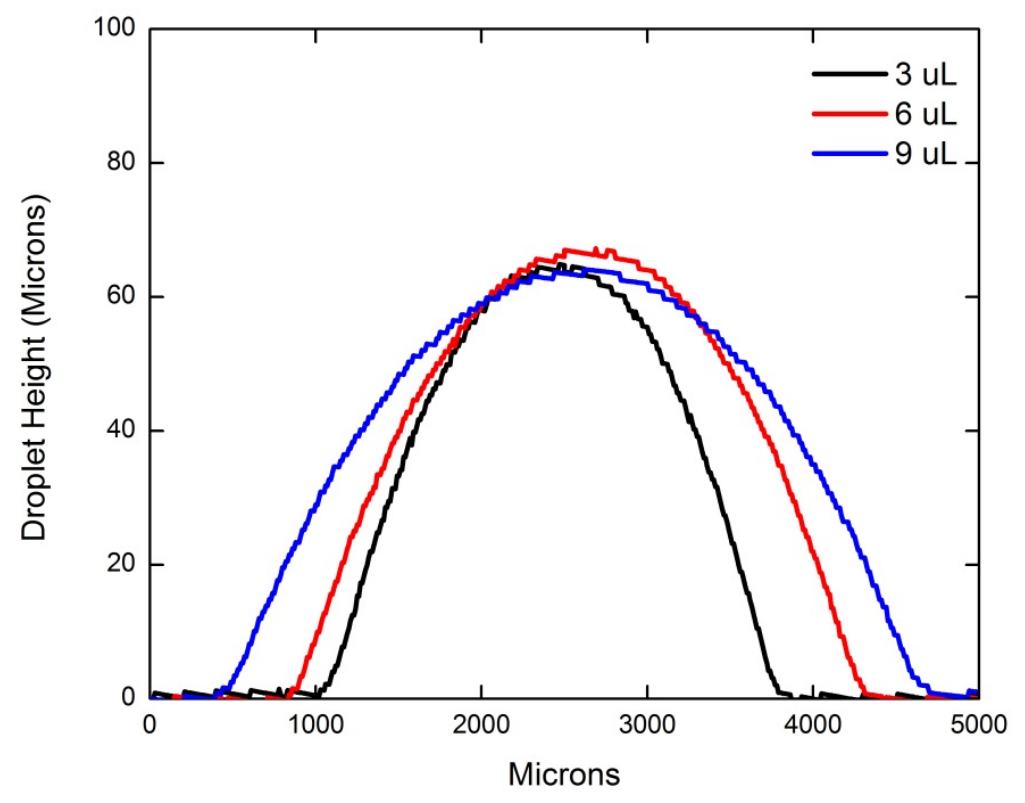

Figure 4.5. Droplet height profiles obtained by line scans for $0.1 \mathrm{M}$ droplets of $\mathrm{MgCl}_{2}$ at initial volumes of 3, 6 and $9 \mu \mathrm{L}$. 


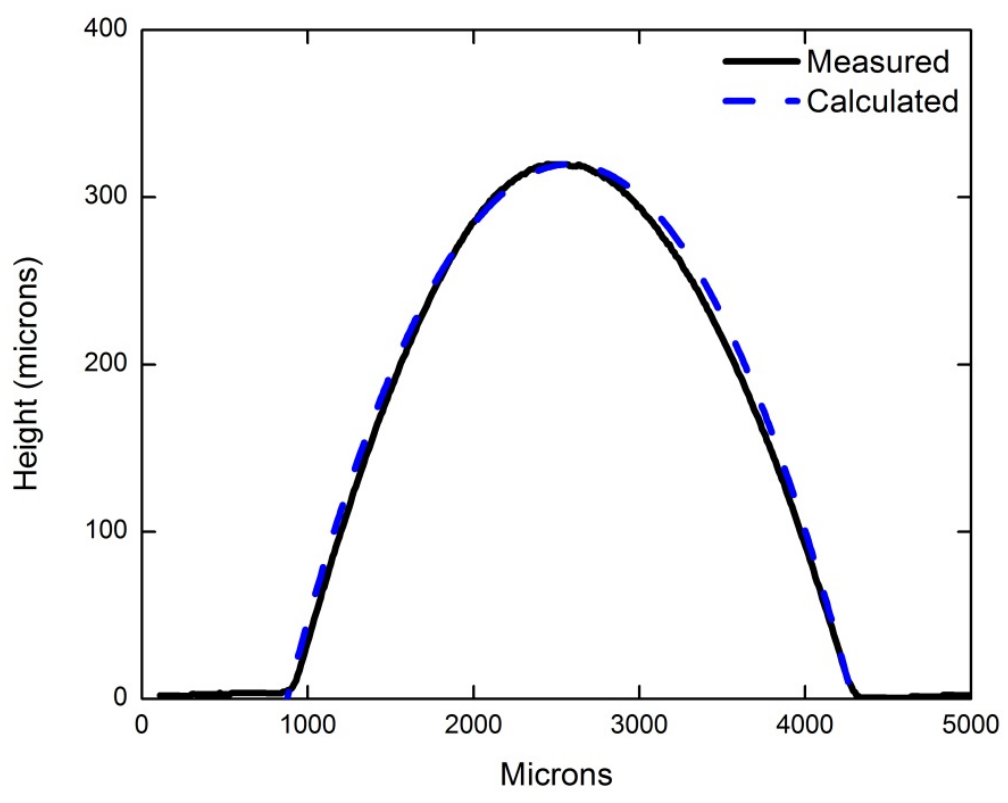

Figure 4.6. Comparison of droplet profile obtained by SKP line scan and droplet profile calculated based on measured height and diameter, as well as assumption that it behaved as a spherical cap. 

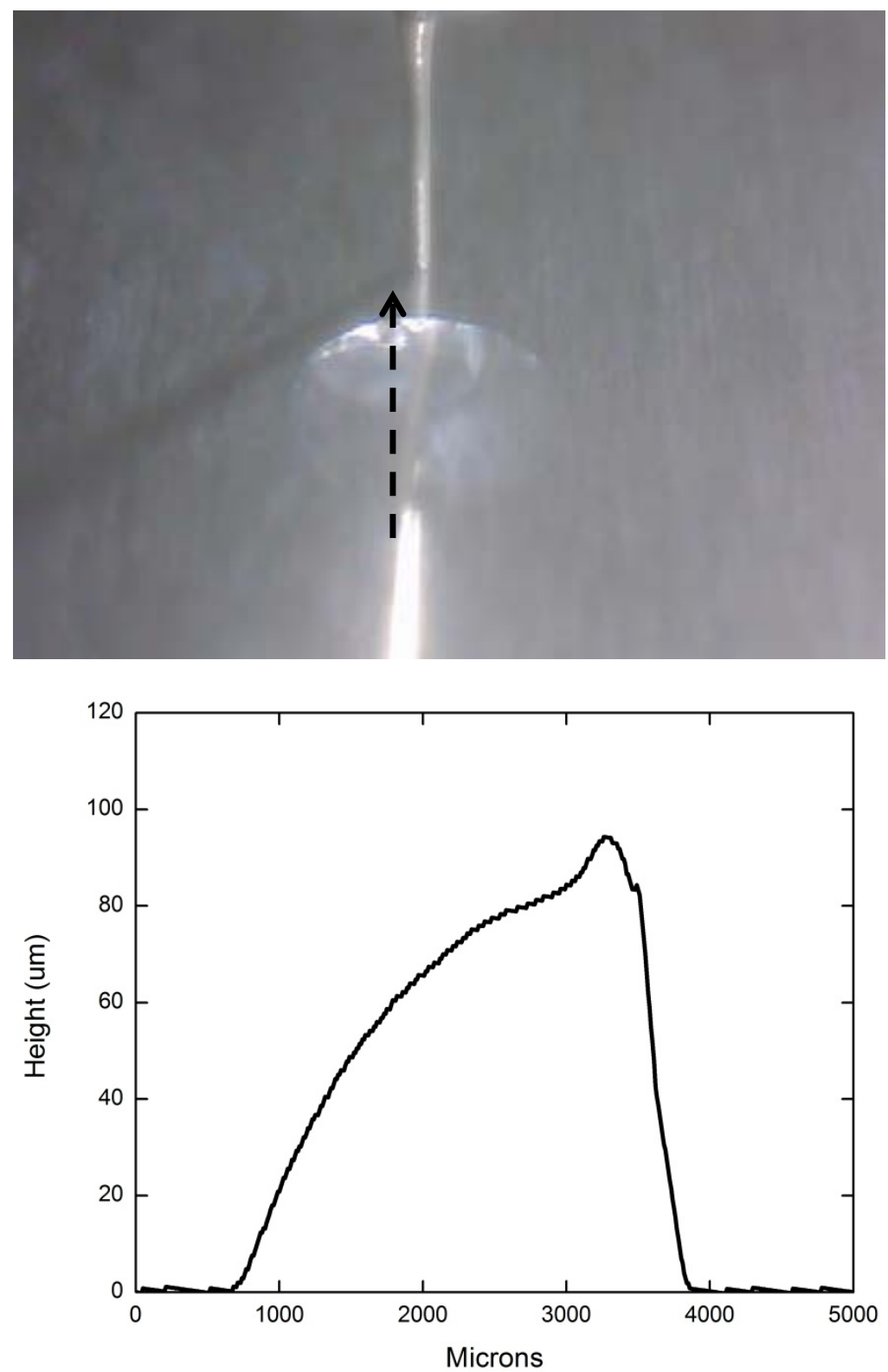

Figure 4.7. Droplet experiment that experienced formation of a bulge in the droplet over the pitting region. On top, an image of the droplet as observed in the SKP is presented, as well as a dashed line representing the path of the line scan. On bottom, the profile obtained by the line scan is shown, with the bulge of interested found on the right side of the droplet. 

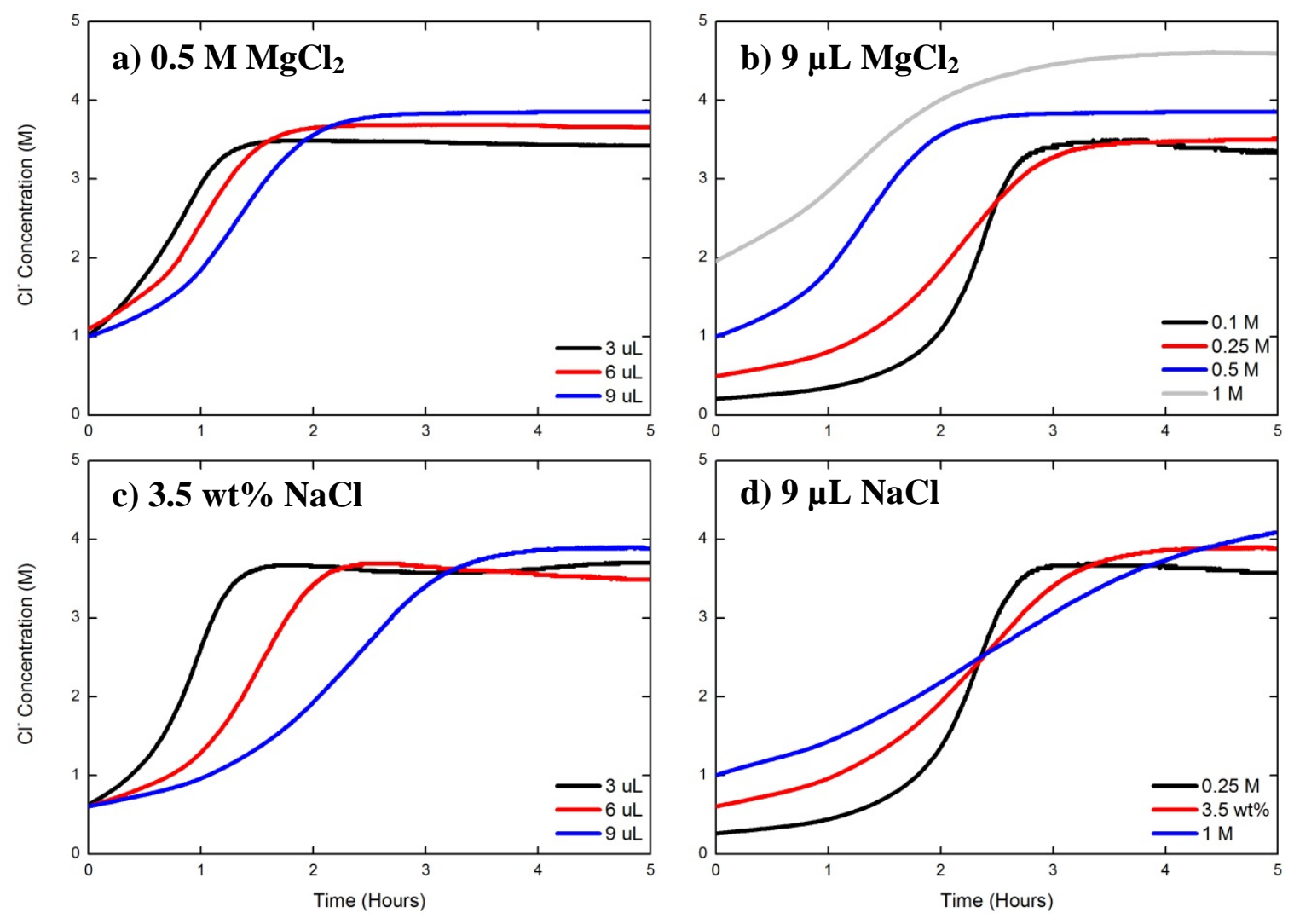

Figure 4.8. Chloride concentration profiles of droplets derived from the known starting chloride content and the volume calculated from the diameter and observed droplet height. a) Droplets with initial $\mathrm{MgCl}_{2}$ concentration of $0.5 \mathrm{M}$. b) Droplets with initial volume of $9 \mu \mathrm{L}$ and varied $\mathrm{MgCl}_{2}$ concentration. c) Droplets with initial $\mathrm{NaCl}$ concentration of $3.5 \mathrm{wt} \%$. d) Droplets with initial volume of $9 \mu \mathrm{L}$ and varied $\mathrm{NaCl}$ concentration. 


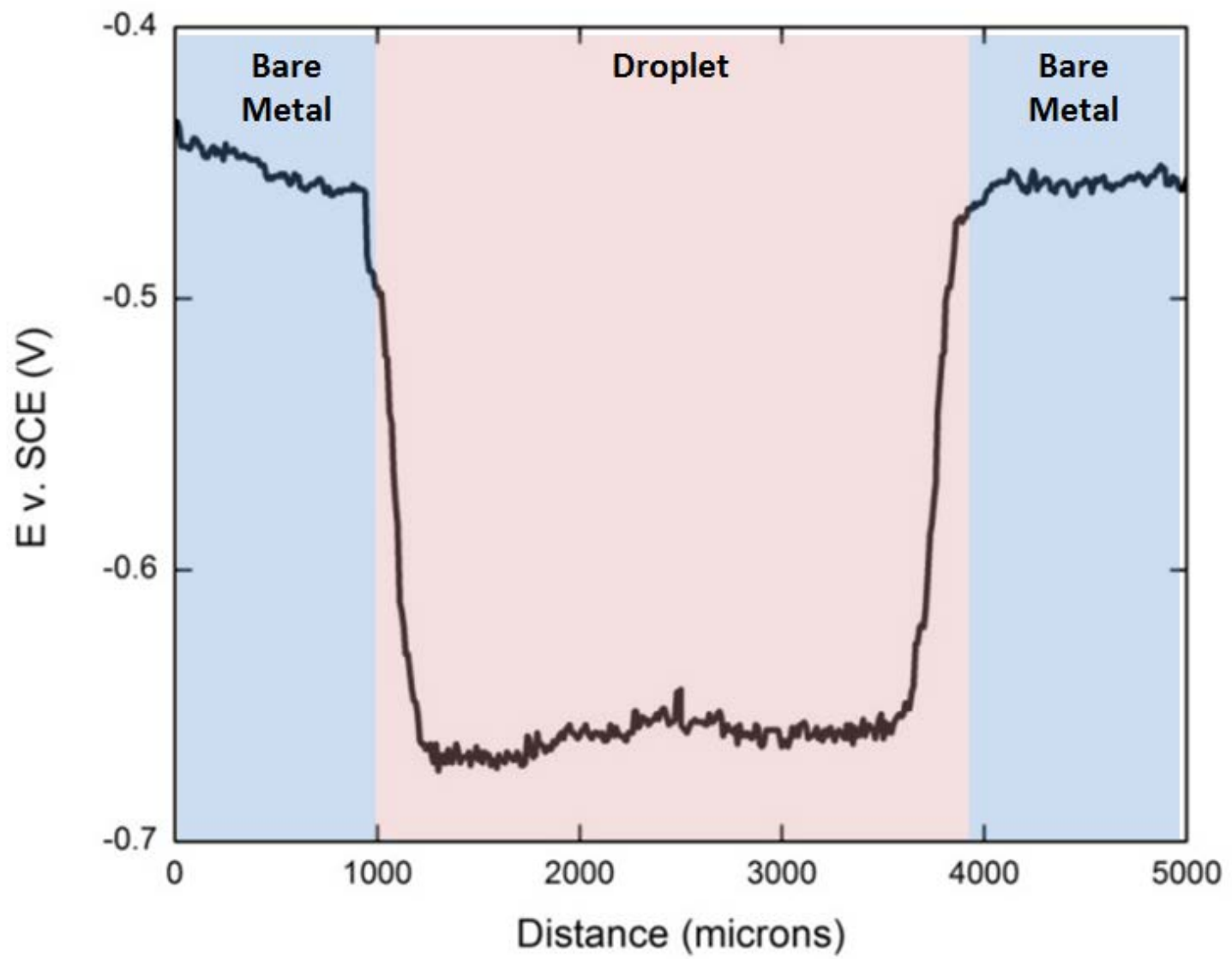

Figure 4.9. Potential profile obtained by SKP line scan across droplet of $0.1 \mathrm{M} \mathrm{MgCl}_{2}$ with initial volume of $9 \mu \mathrm{L}$ after 20 hour test in SKP chamber. 

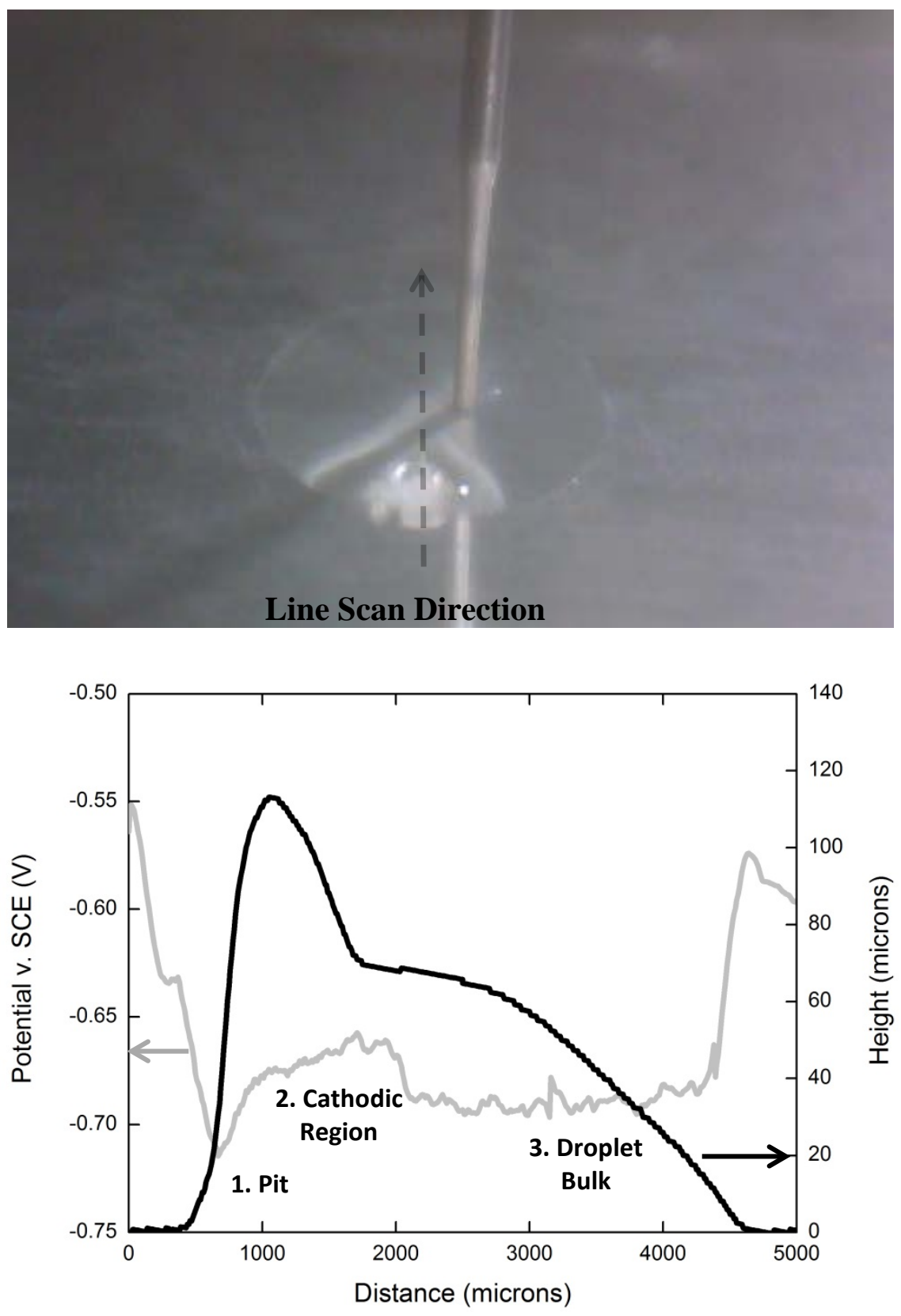

Figure 4.10. Secondary droplet formation on $0.25 \mathrm{M} \mathrm{MgCl}_{2}$ droplet with initial volume of $9 \mu \mathrm{L}$ after 20 hour test in SKP chamber. On top is an image recorded of the droplet in the chamber with the path of the line scan shown. On bottom, the potential and height profiles are shown as obtained from the line scan. 

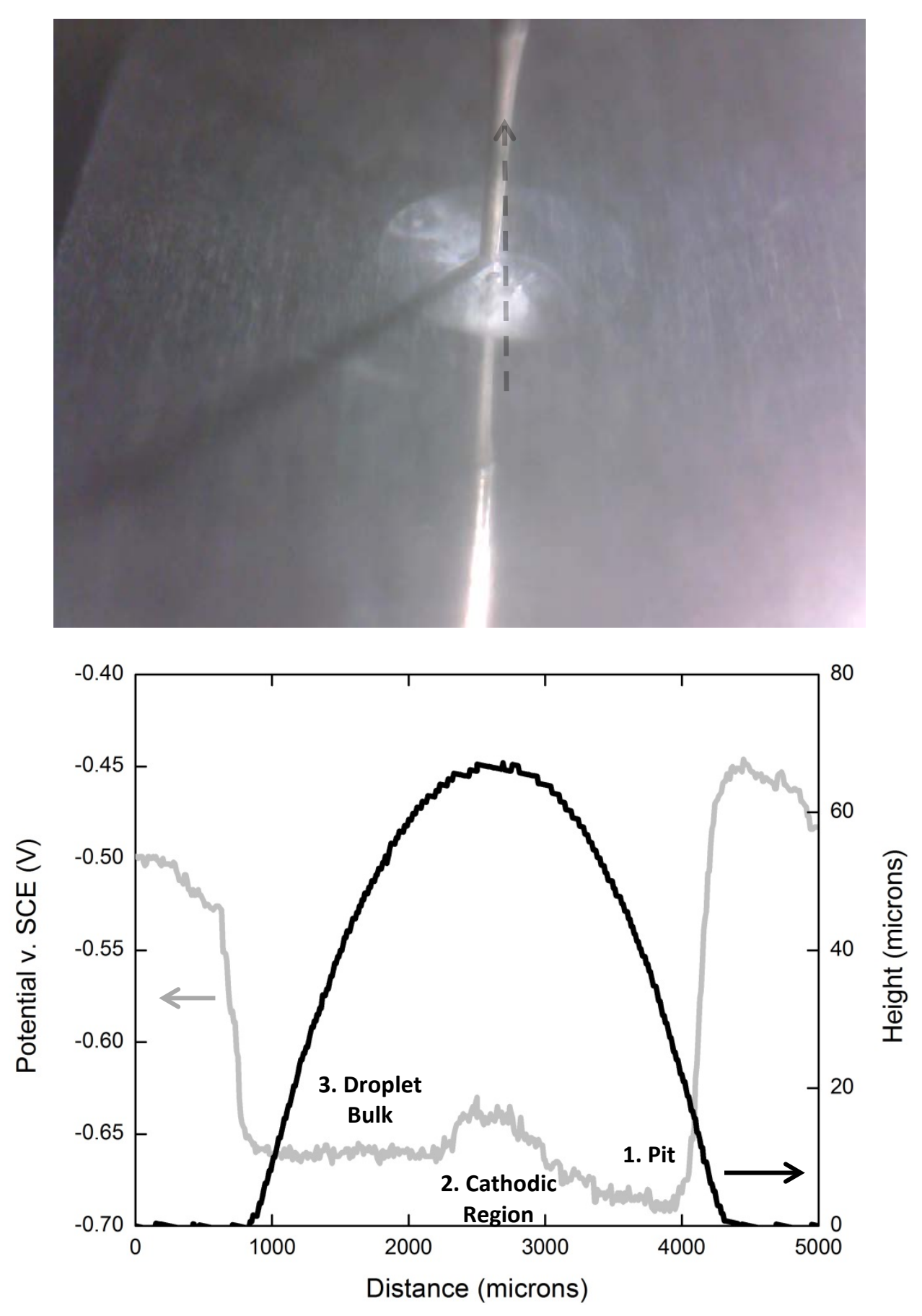

Figure 4.11. A droplet of $0.1 \mathrm{M} \mathrm{MgCl}_{2}$ with initial volume of $6 \mu \mathrm{L}$ with a region of sustained pitting near the edge is shown as seen in the SKP on top, with a line identifying the path of the line scan. The resulting height and potential profiles are shown on the bottom. 


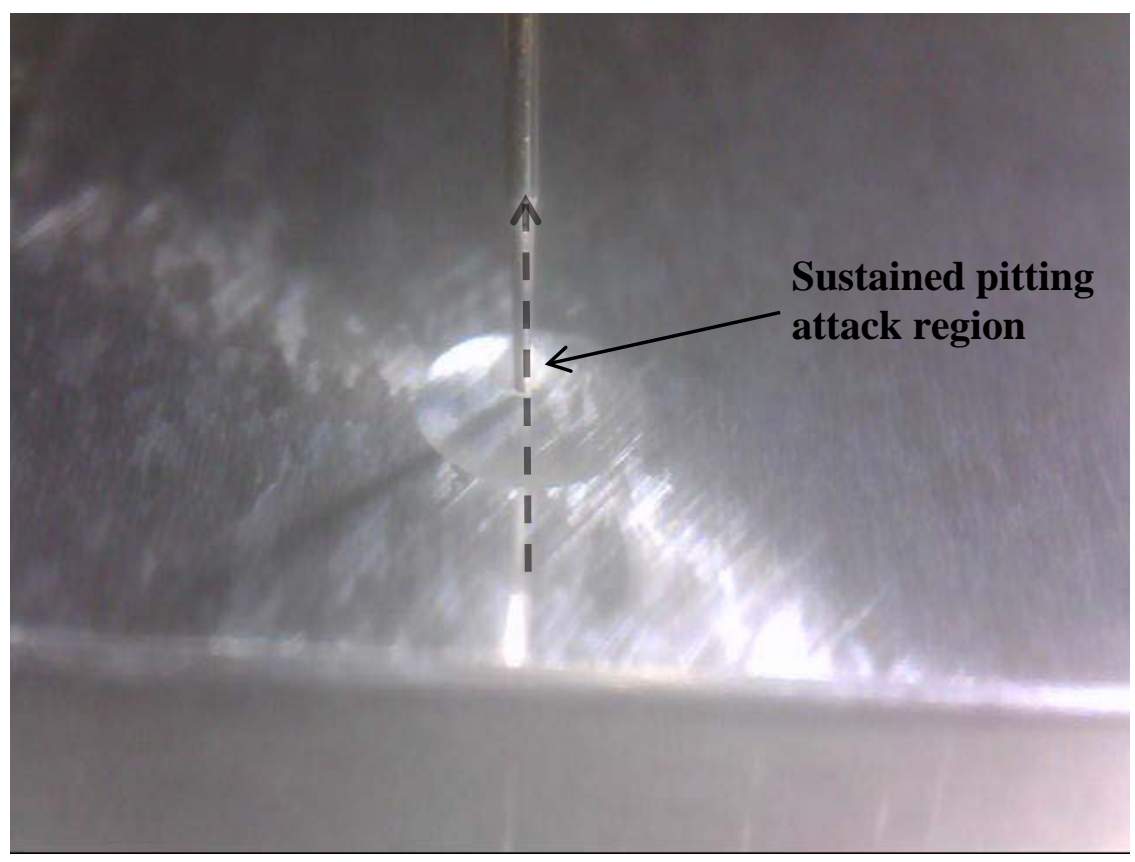

Figure 4.12. Droplet of $3.5 \mathrm{wt} \% \mathrm{NaCl}$ with initial volume of $6 \mu \mathrm{L}$ studied during interval line scans. Sustained pitting occurred near the edge, seen behind the SKP probe tip in the image. The path of the line scans is shown by the dashed arrow. 

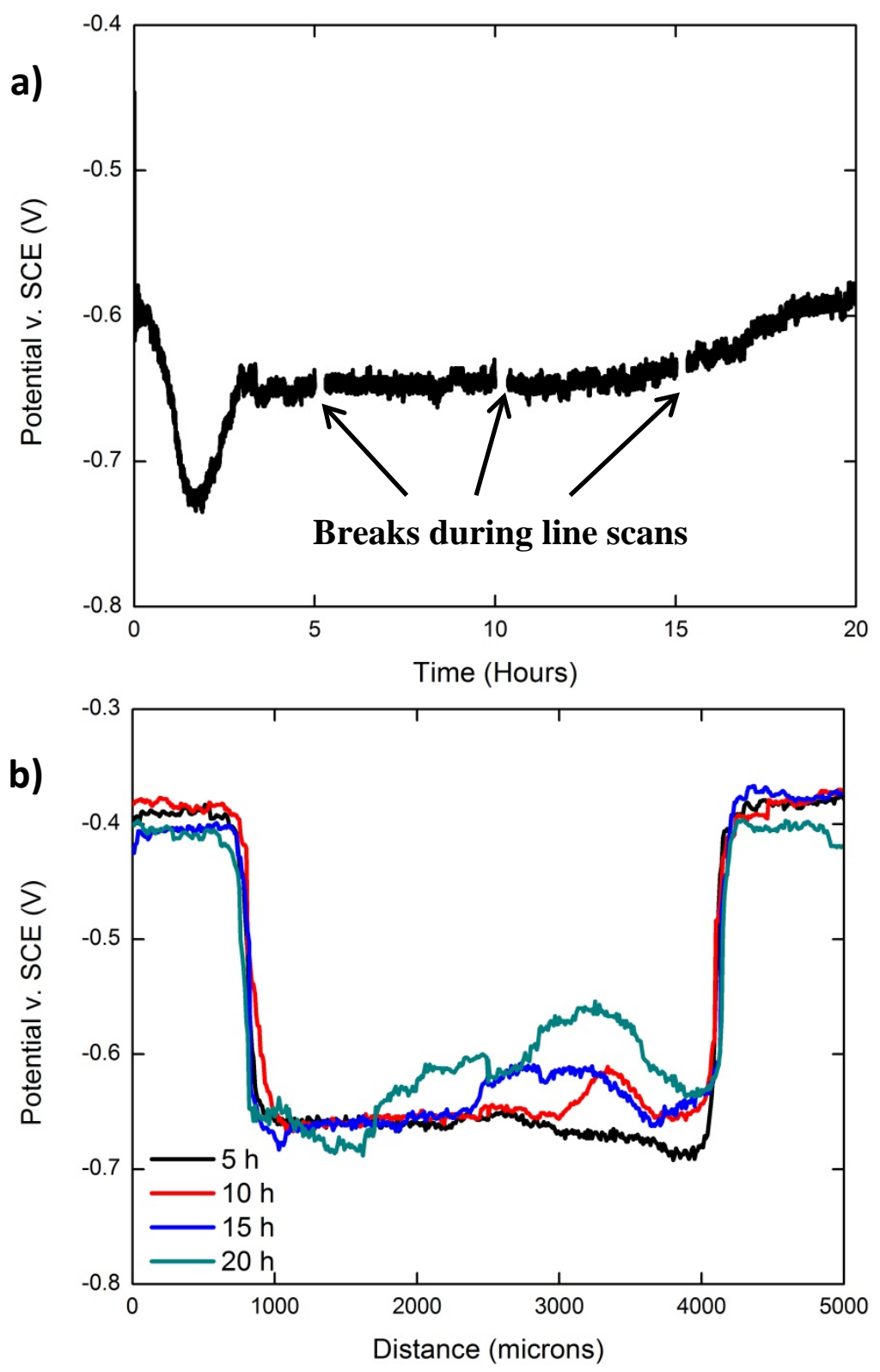

Figure 4.13. On top, the potential profile against time measured by SKP at the center of the droplet shown in Figure 4.11. On bottom, potential profiles recorded during line scans by SKP performed after 5, 10, 15 and 20 hours. 


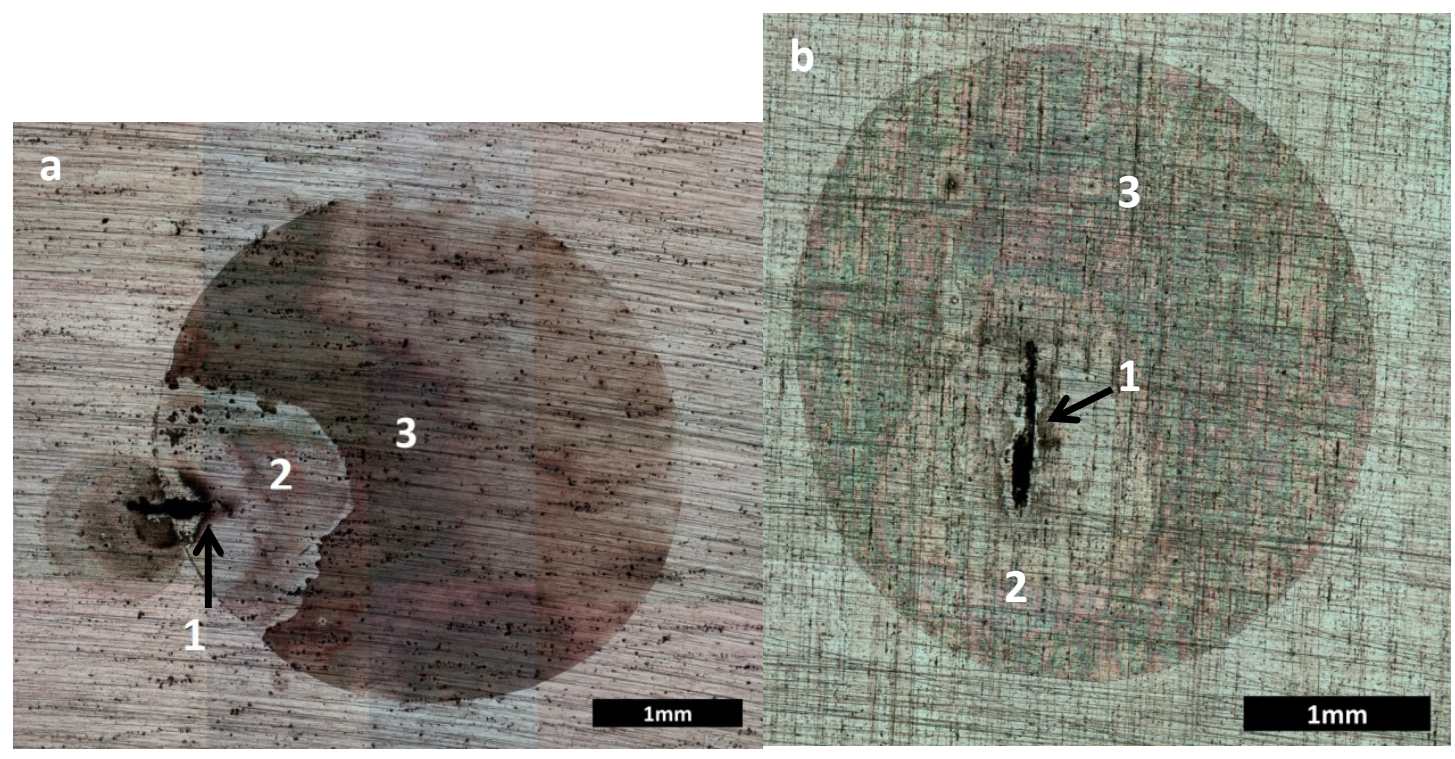

Figure 4.14. Optical microscope images of representative examples of behavior under droplets in SKP tests. a) Droplet of $3.5 \mathrm{wt} \% \mathrm{NaCl}$ with initial volume $6 \mu \mathrm{L}$. b) Droplet of $0.5 \mathrm{M} \mathrm{MgCl}_{2}$ with initial volume $6 \mu \mathrm{L}$. Regions consistently observed are identified in both images. 


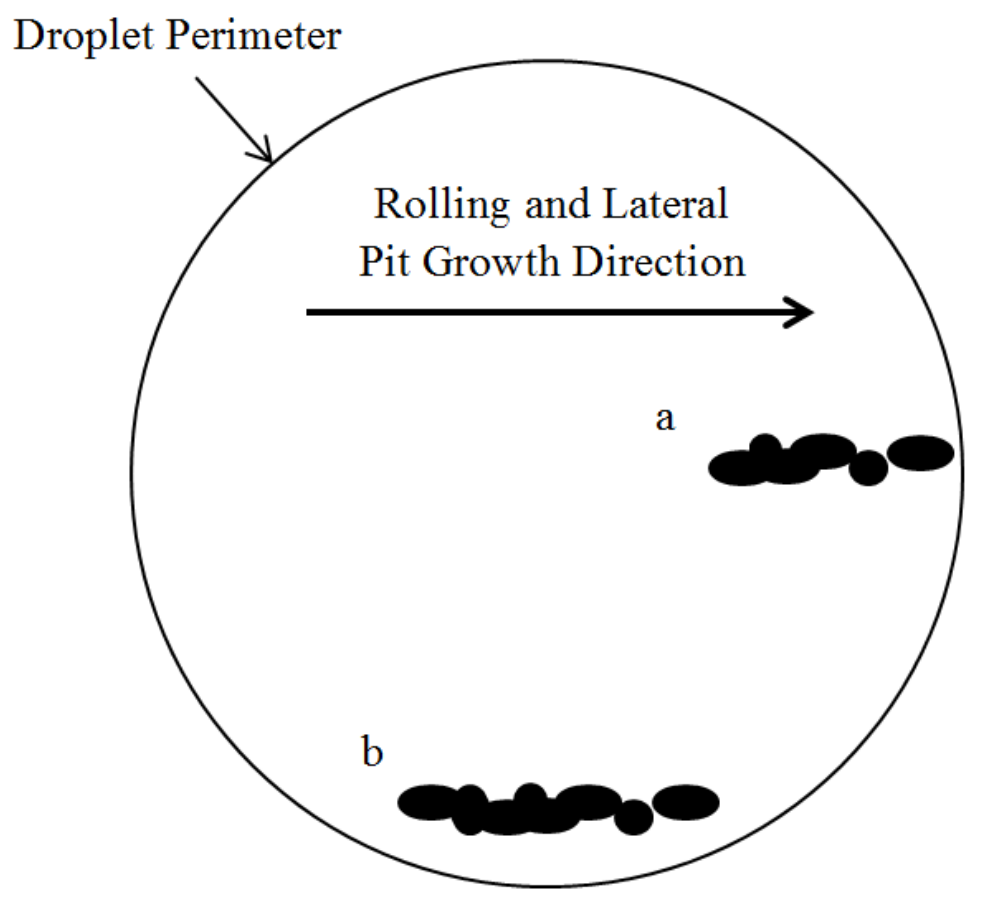

Figure 4.15. Schematic of the surface under a droplet with rolling direction (and subsequently lateral pit growth direction) identified. a) Sustained pitting growing laterally toward droplet edge. b) Sustained pitting growing laterally parallel to droplet edge. 

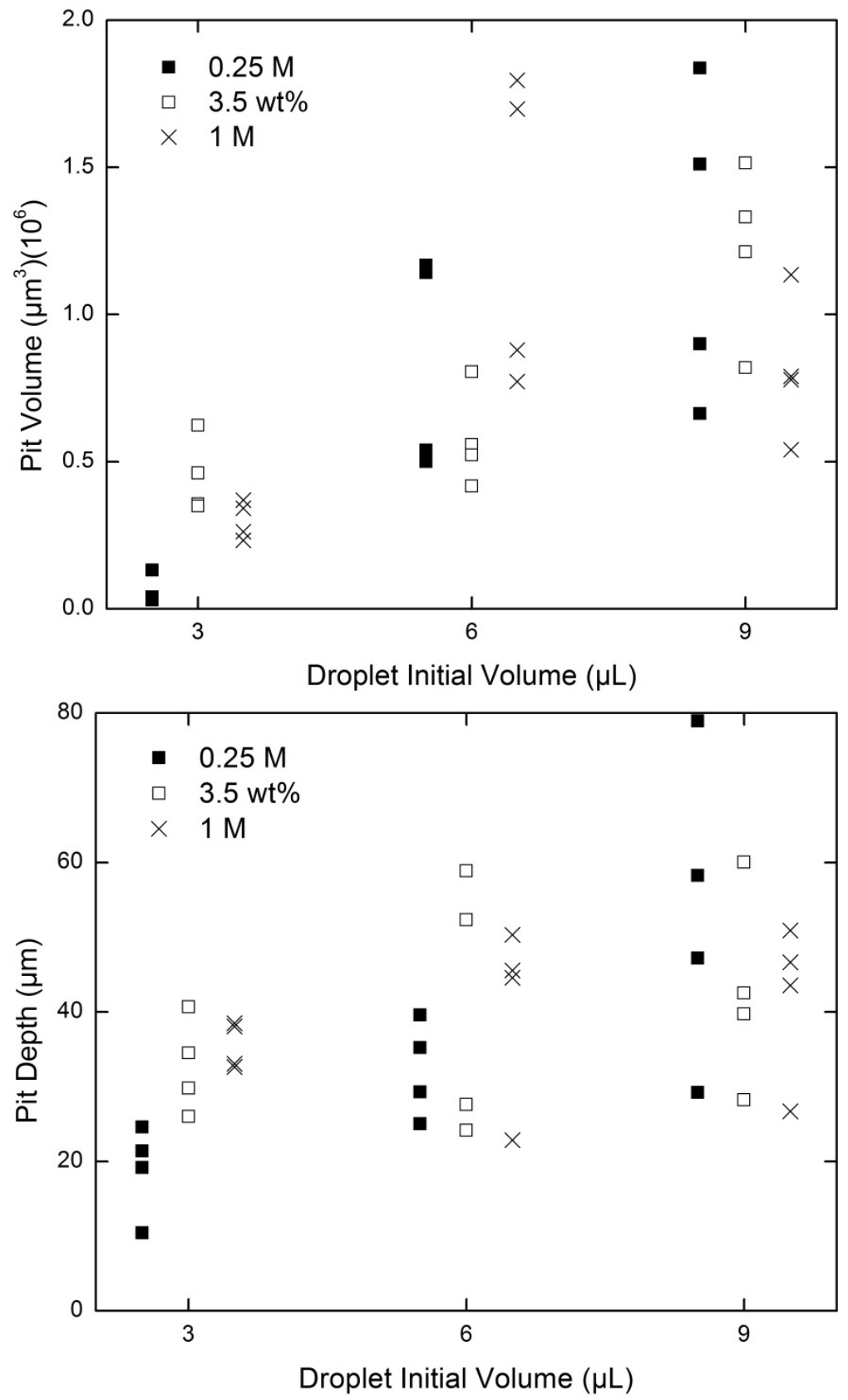

Figure 4.16. Pitting volume and maximum pit depth of sustained pitting attack regions for droplets of $\mathrm{NaCl}$ studied in SKP. Pit volume shown on top, maximum pit depth shown on bottom. Data displaced for sets at matching initial droplet volume. 

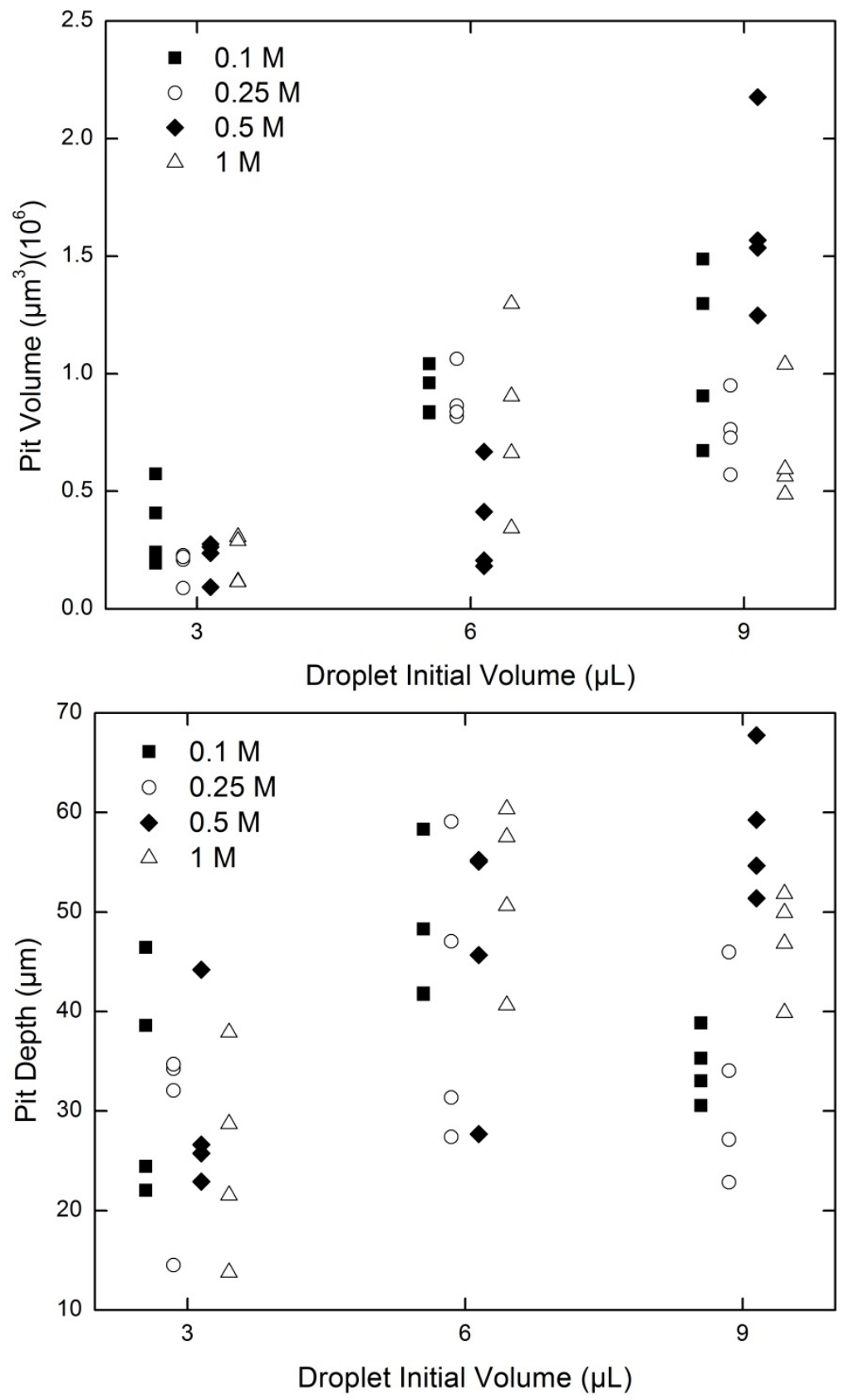

Figure 4.17. Pitting volume and maximum pit depth of sustained pitting attack regions for droplets of $\mathrm{MgCl}_{2}$ studied in SKP. Pit volume shown on top, maximum pit depth shown on bottom. Data displaced for sets at matching initial droplet volume. 


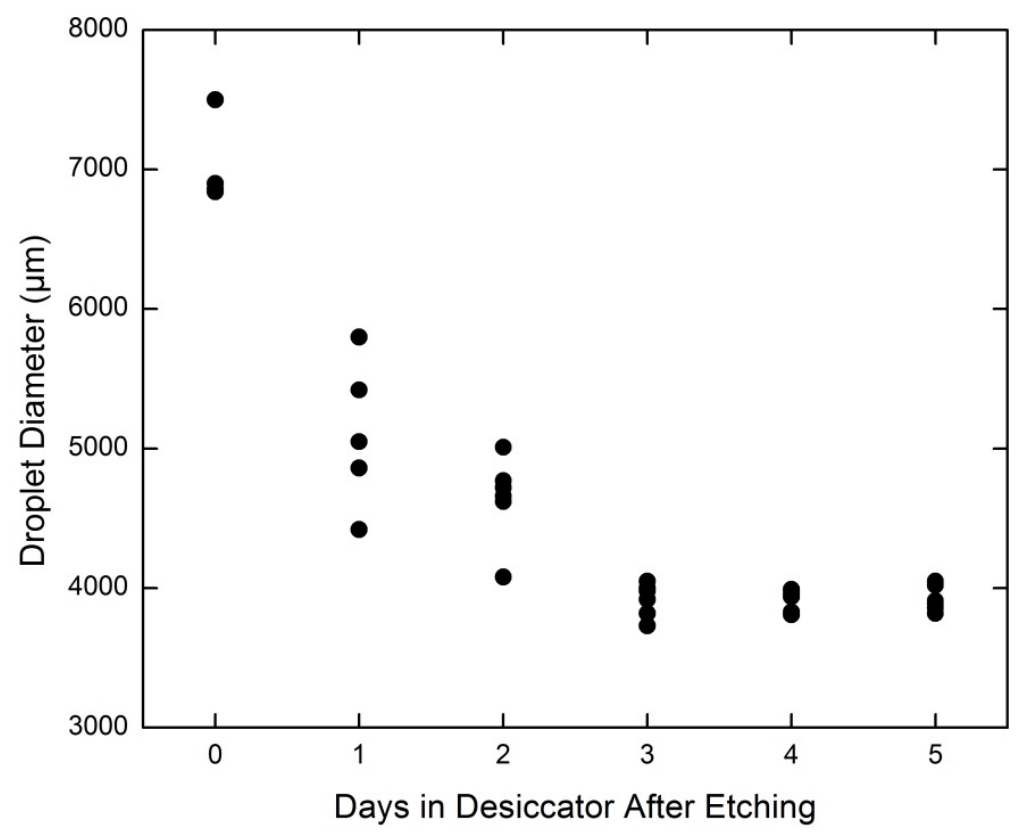

Figure 4.18. Diameter of droplets measured during aging experiments. 


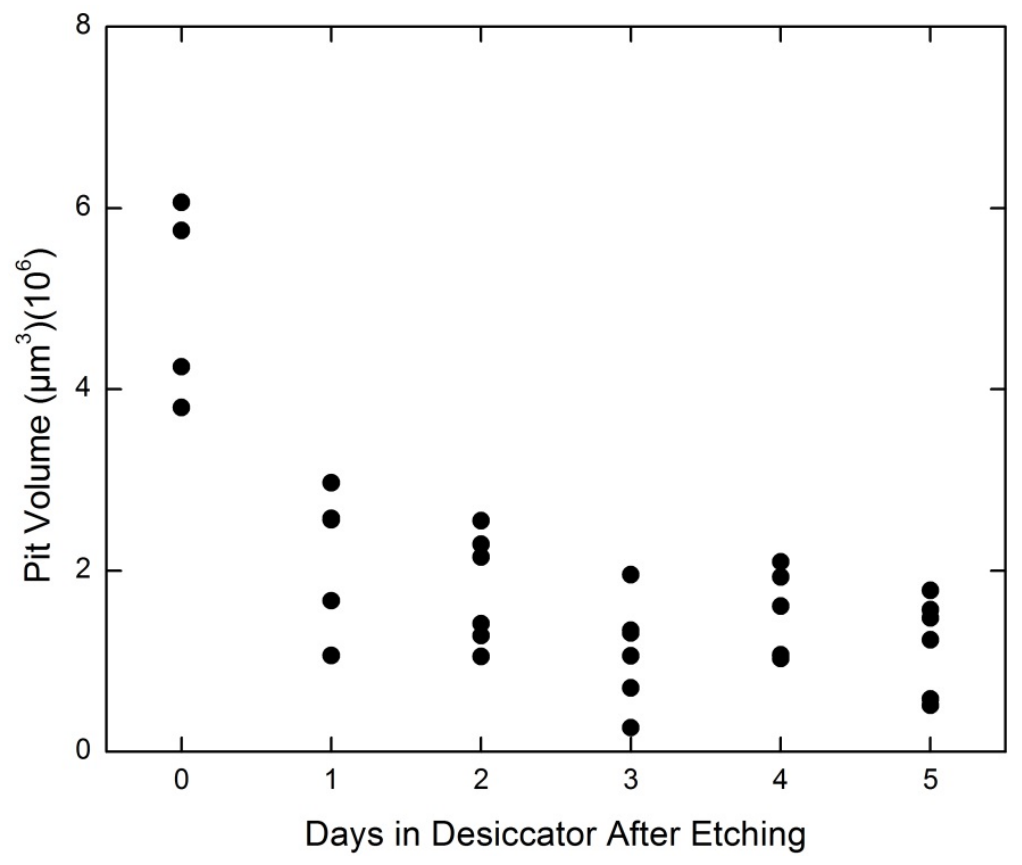

Figure 4.19. Volume of pits measured during aging experiments. 


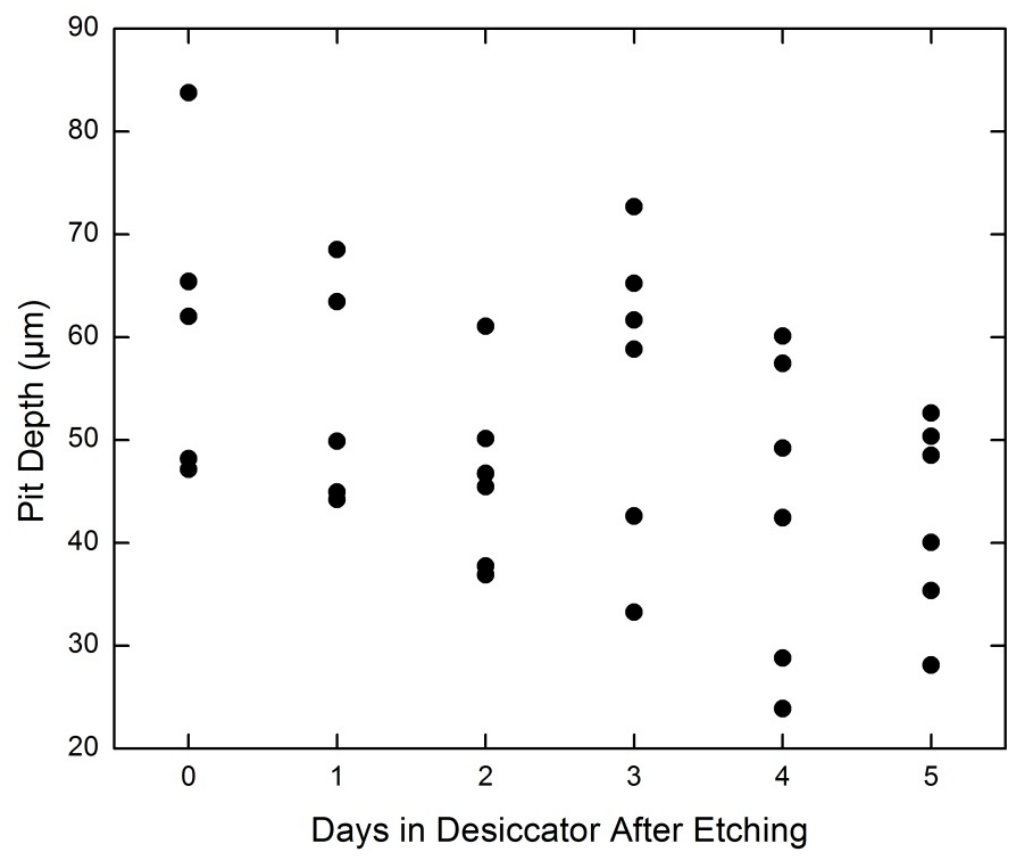

Figure 4.20. Maximum depth of pits measured during aging experiments. 

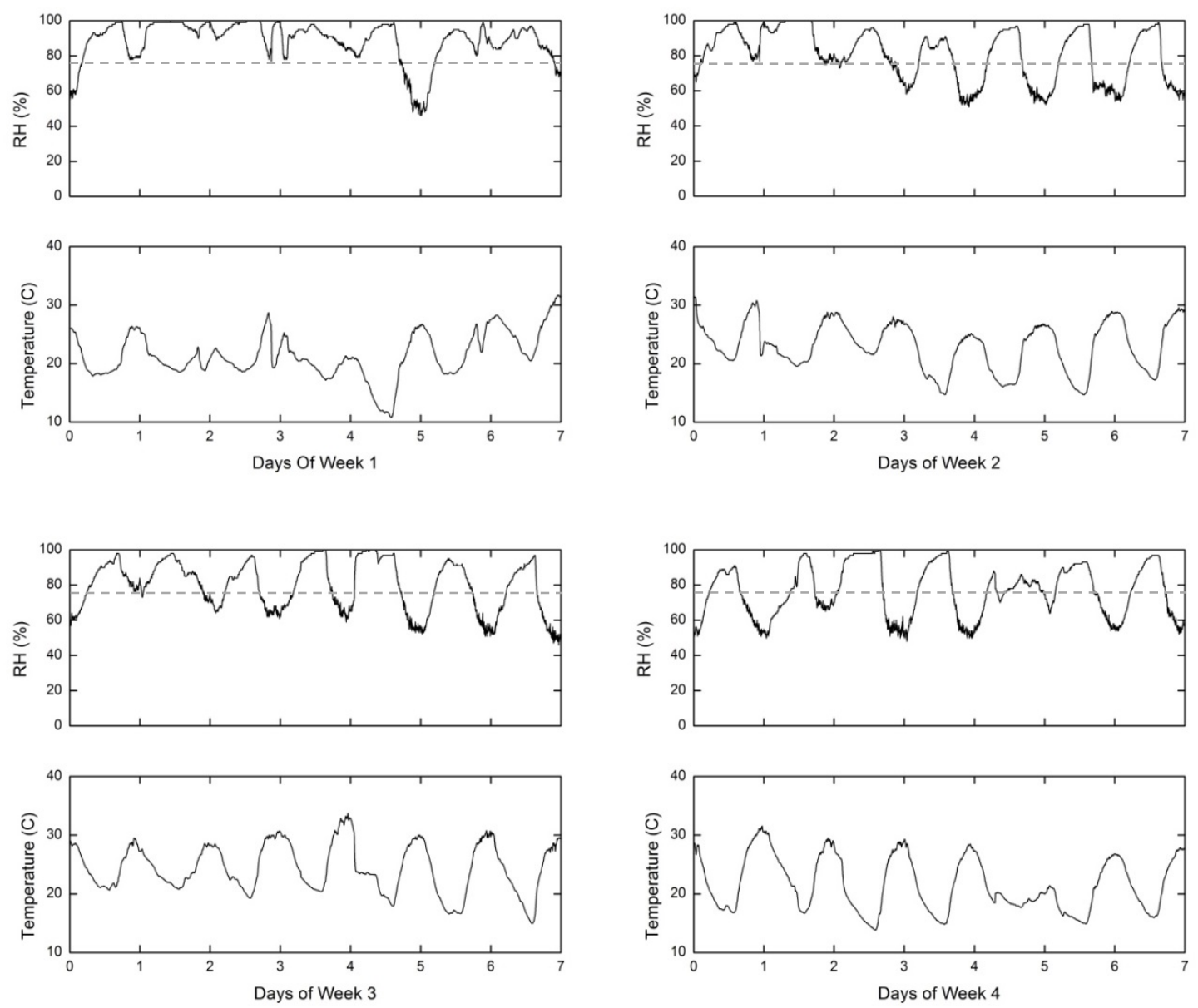

Figure 4.21. Temperature and RH measured for the four weeks outdoor tests were conducted in Dublin, OH between July 11, 2015 and August 8, 2015.Data obtained from ref 6 . 

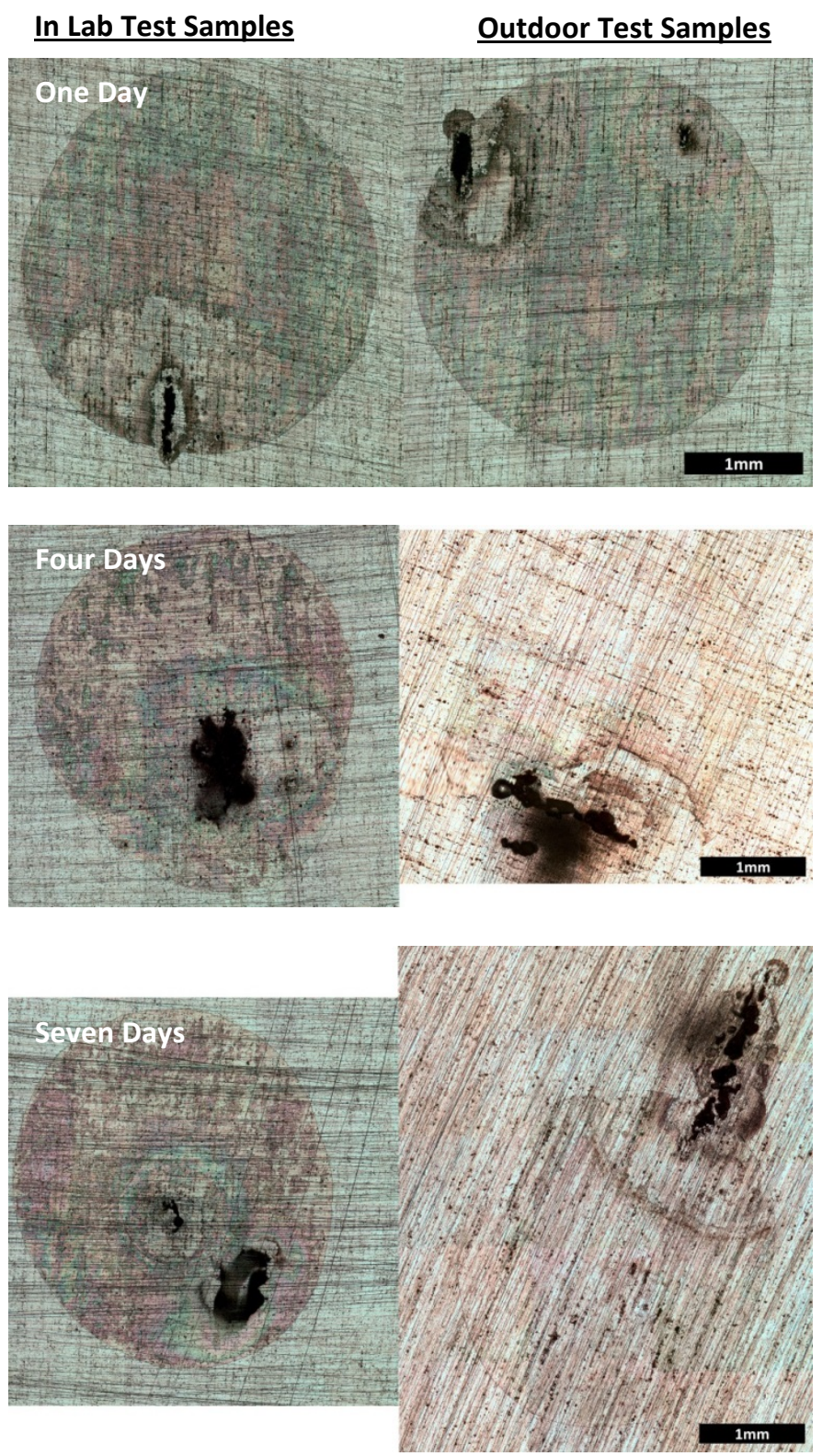

Figure 4.22. Corrosion behavior of droplets of $0.5 \mathrm{M} \mathrm{MgCl}_{2}$ with initial volume $6 \mu \mathrm{L}$. Tests conducted in the lab are shown on the left, tests conducted outdoors shown on the right. Lengths of exposure were one day (top), four days (middle) and seven days (bottom). 

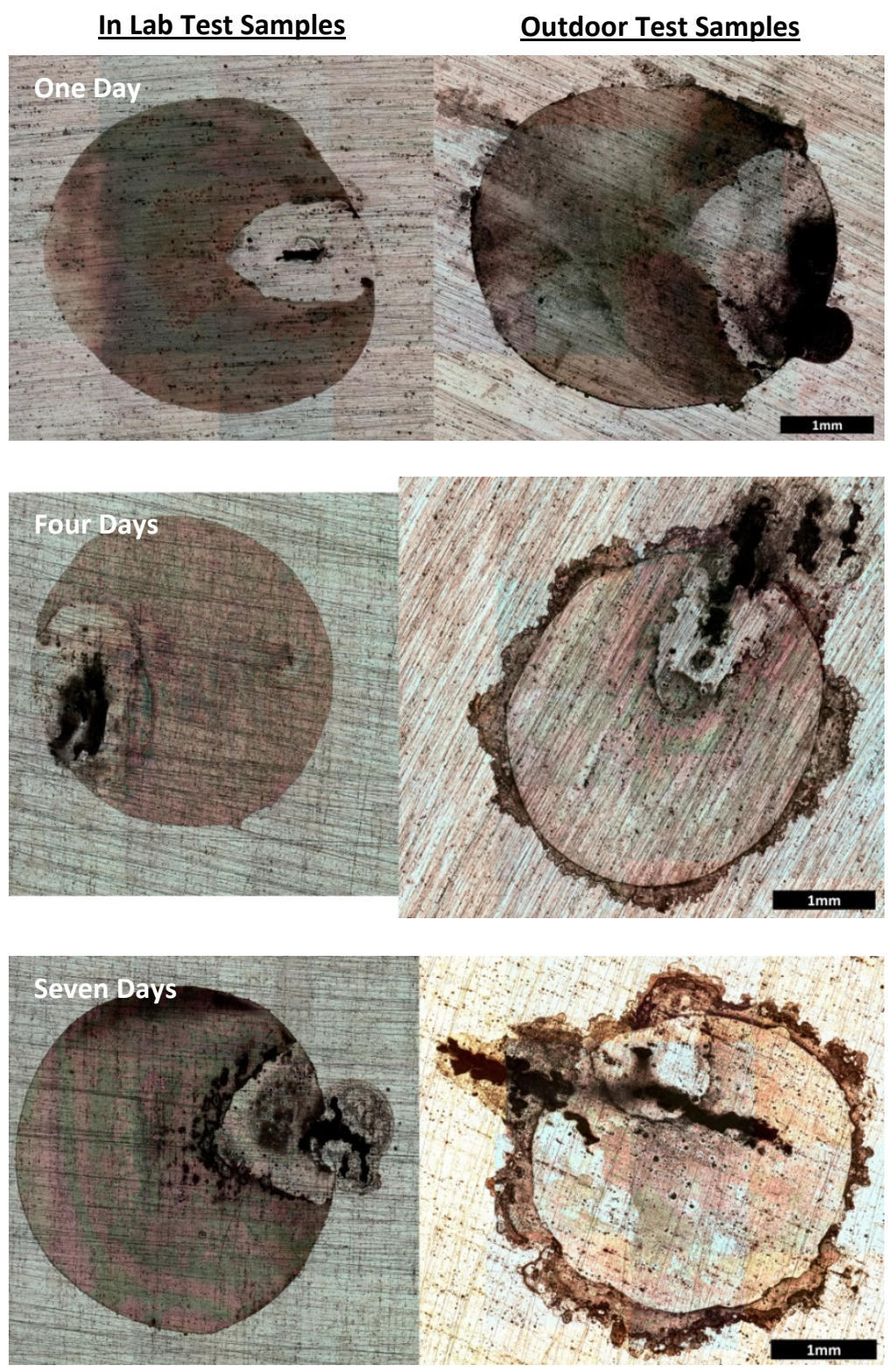

Figure 4.23. Corrosion behavior of droplets of $3.5 \mathrm{wt} \% \mathrm{NaCl}$ with initial volume $6 \mu \mathrm{L}$. Tests conducted in the lab are shown on the left, tests conducted outdoors shown on the right. Lengths of exposure were one day (top), four days (middle) and seven days (bottom). 

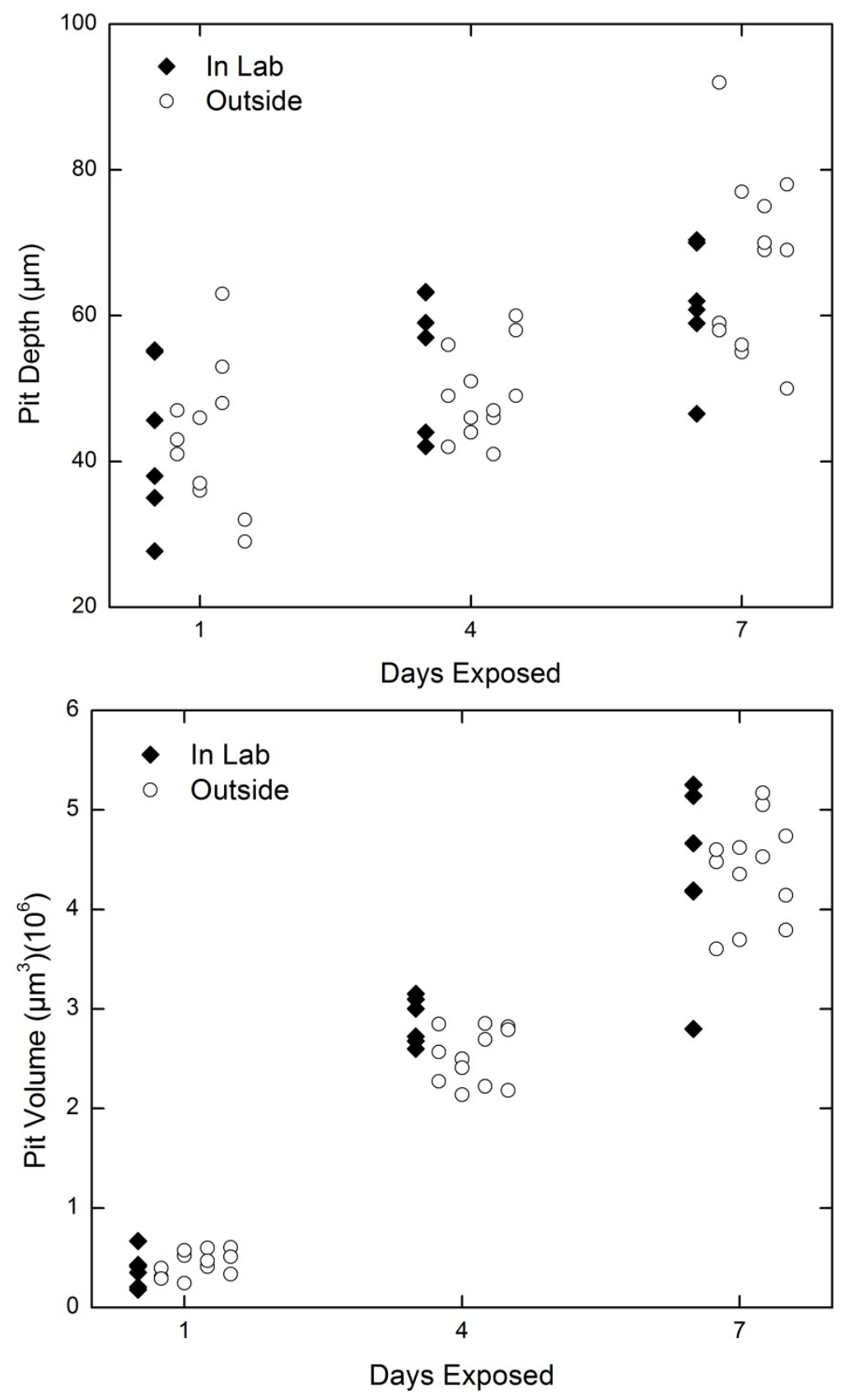

Figure 4.24. Comparison of pitting results for $\mathrm{MgCl}_{2}$ droplet tests conducted in the lab with those tested outdoors. Pitting depth shown on top, pitting volume shown on bottom. Data at each time interval displaced to separate weeks during which outdoor tests were conducted. 

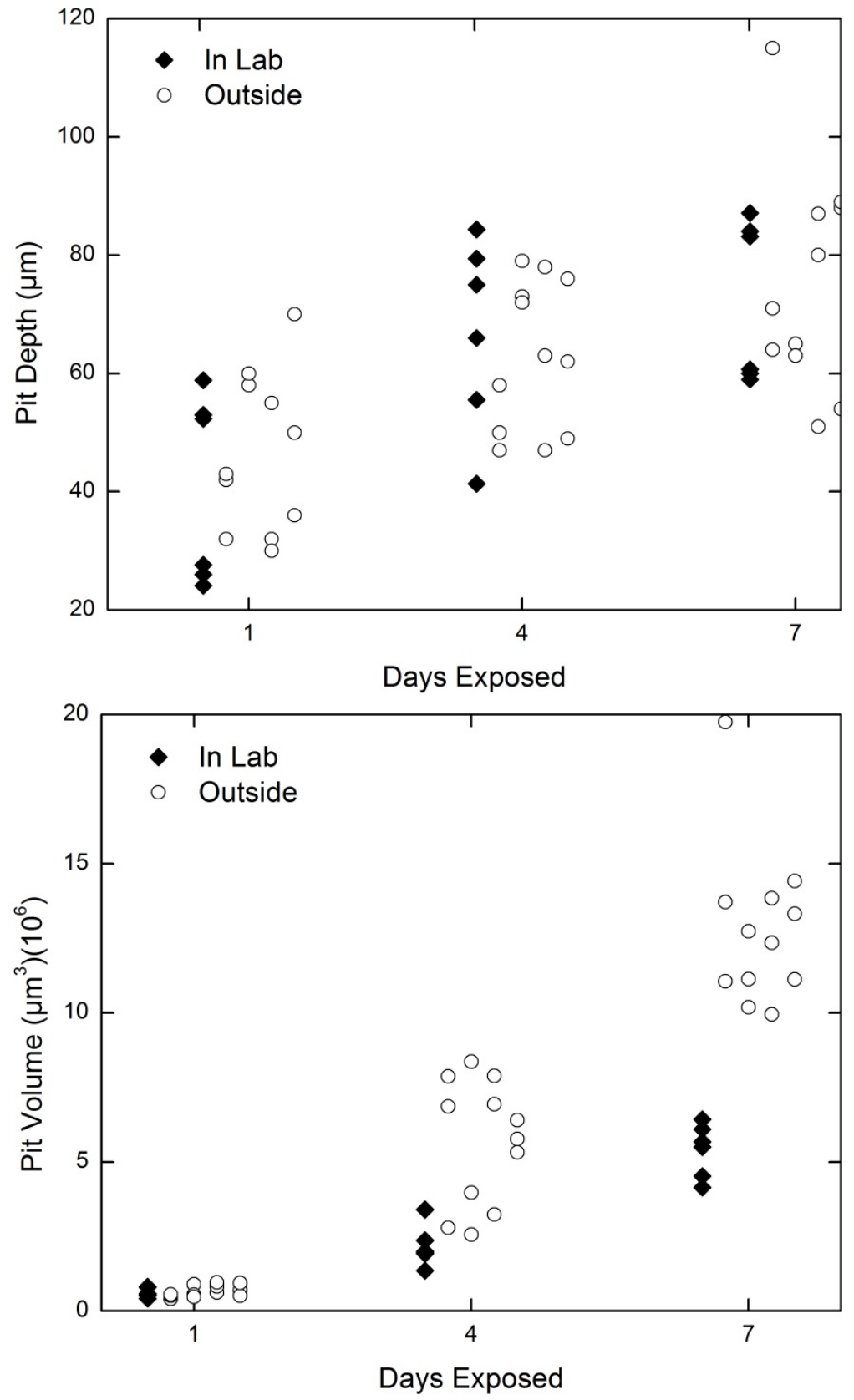

Figure 4.25. Comparison of pitting results for $\mathrm{NaCl}$ droplet tests conducted in the lab with those tested outdoors. Pitting depth shown on top, pitting volume shown on bottom. Data at each time interval displaced to separate weeks during which outdoor tests were conducted. 


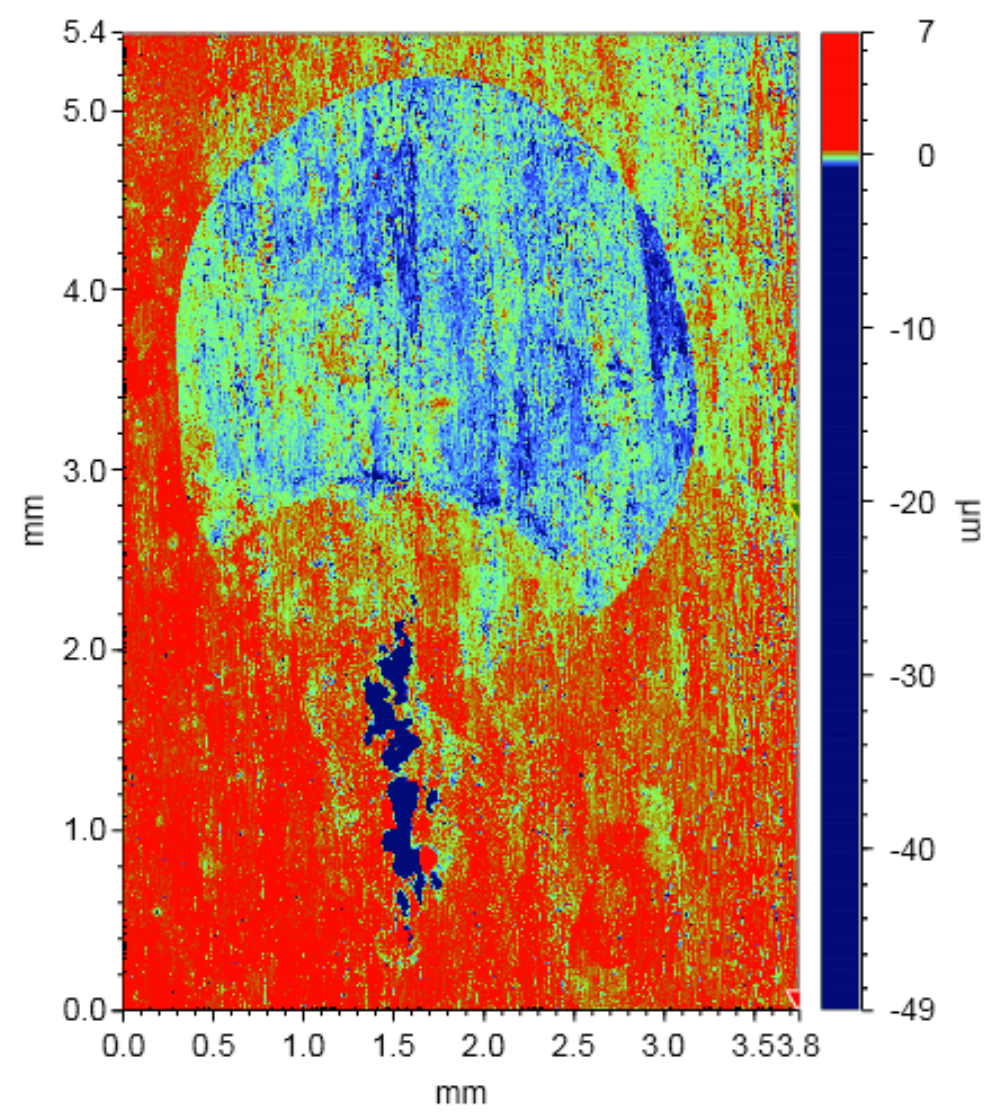

Figure 4.26. OP image of $\mathrm{MgCl}_{2}$ droplet exposed for seven days outdoors. Height of sample beneath original droplet area is lower than that of the surrounding material. 

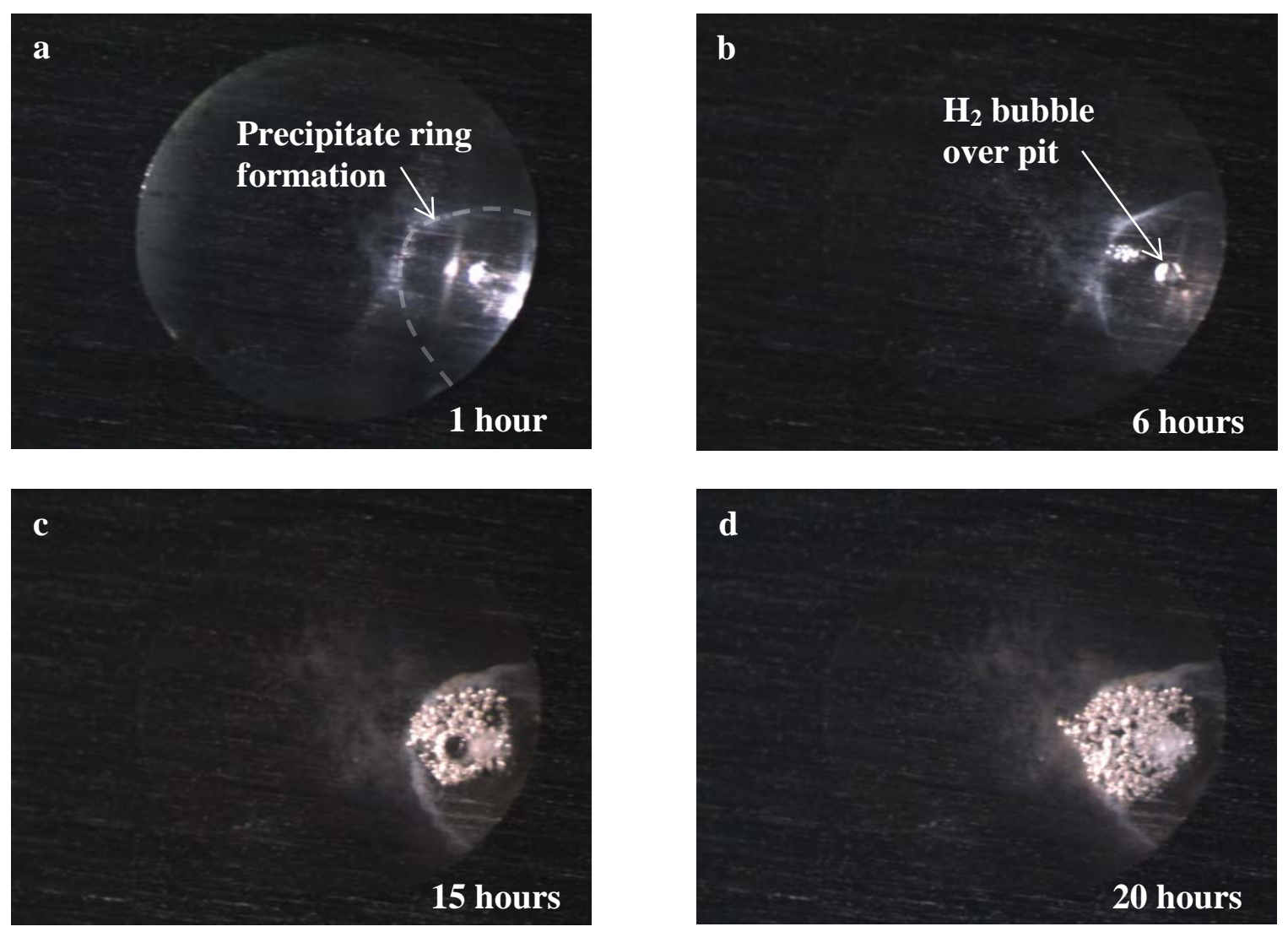

Figure 4.27. Images recorded for droplet described in Example 1. 

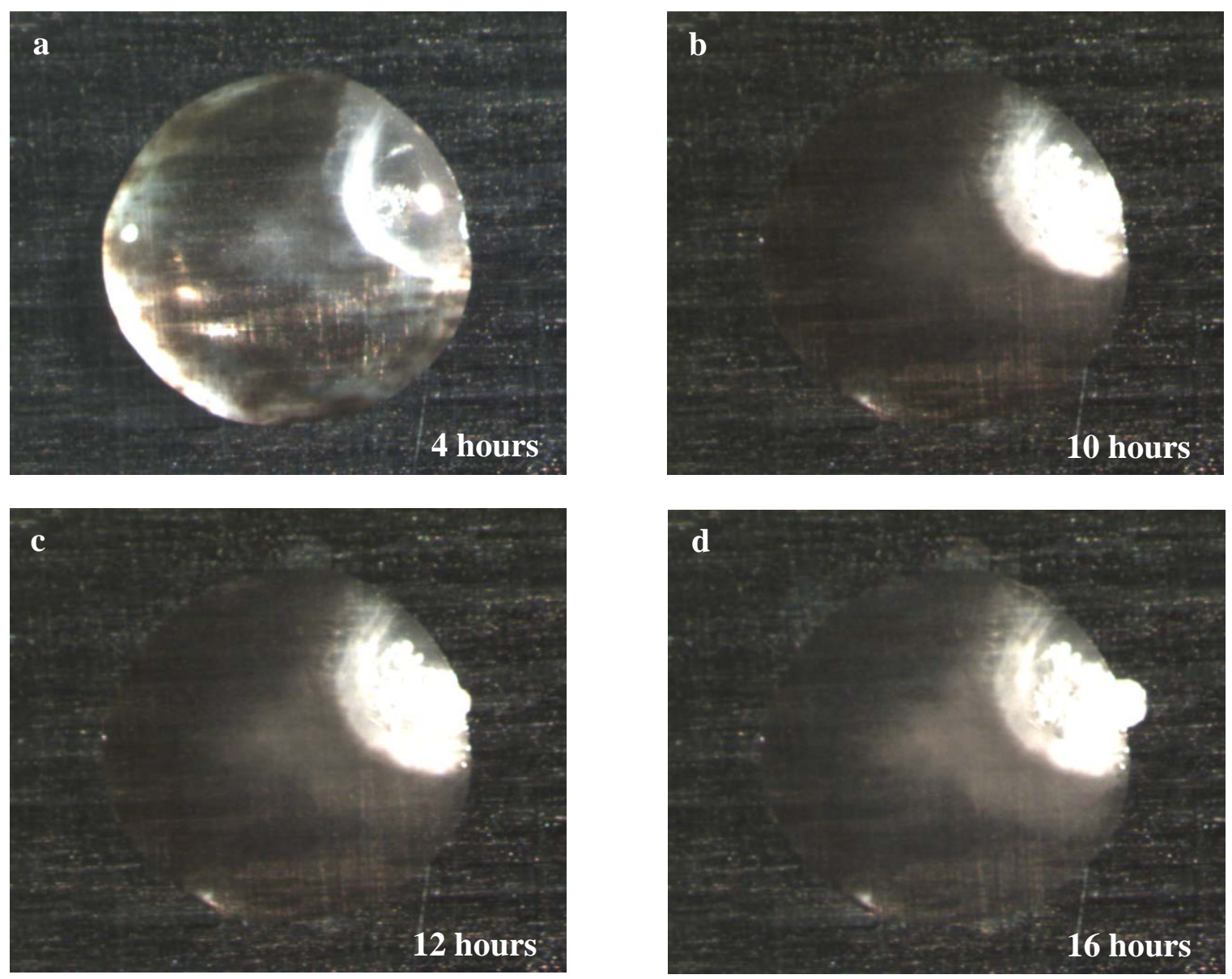

Figure 4.28. Images recorded for droplet described in Example 2. 

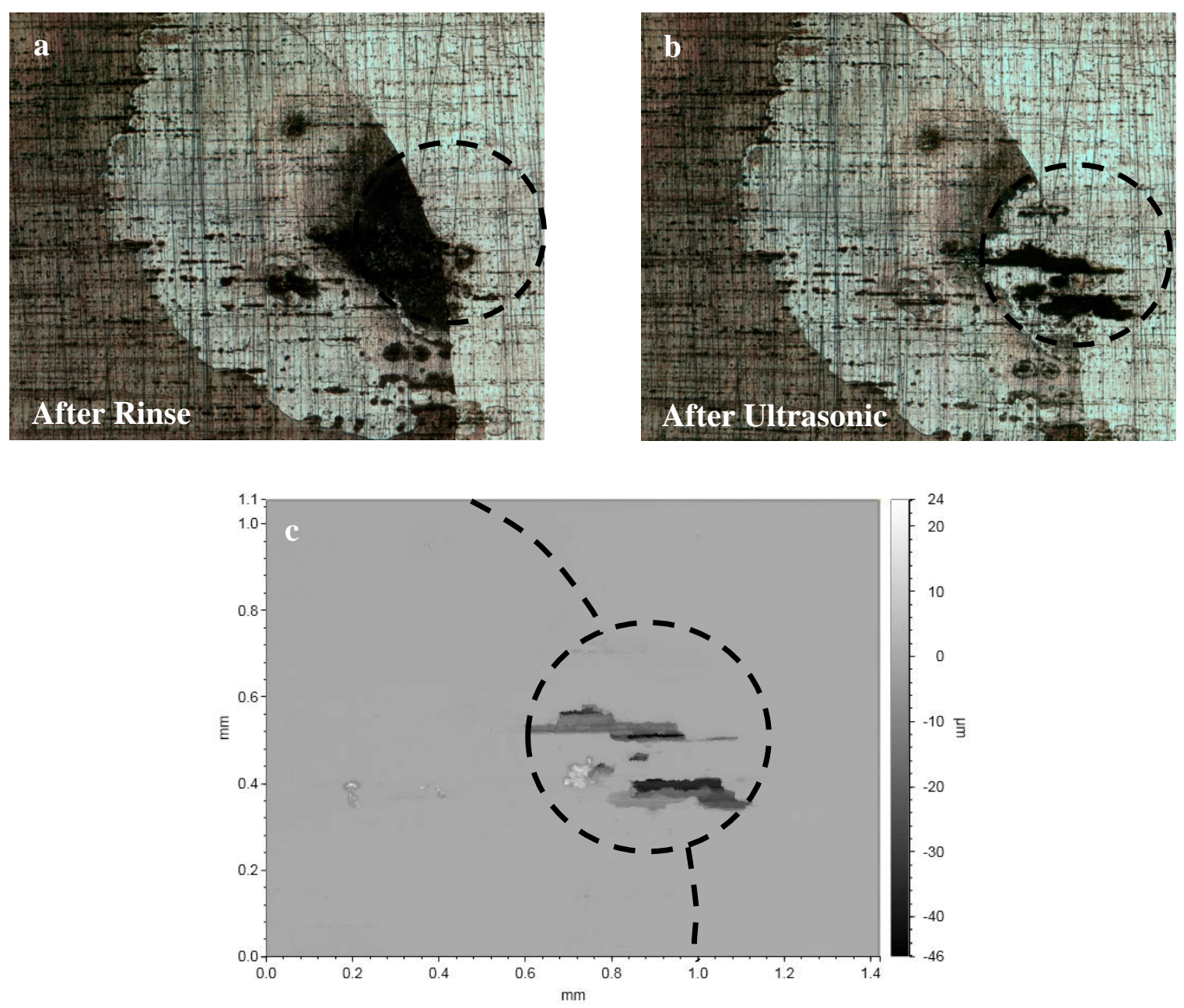

Figure 4.29. a) OM image of secondary droplet region from Example 2 after rinsing with DI water and ethanol. b) OM image of secondary droplet region after several minutes in the ultrasonicator. c) Secondary droplet region analyzed by optical profilometer. The secondary droplet regions are identified in the figures. 

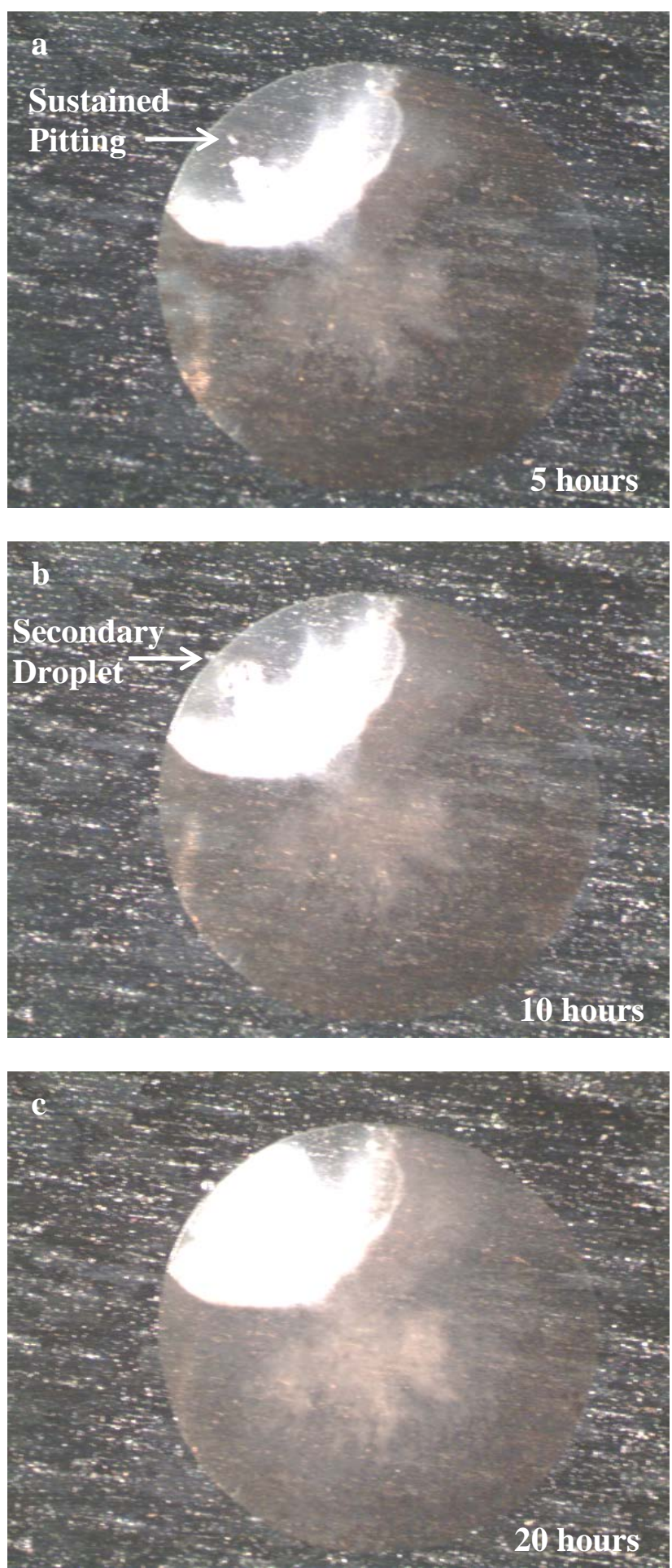

Figure 4.30. Images recorded for droplet described in Example 3. Initiation of secondary droplet identified. 

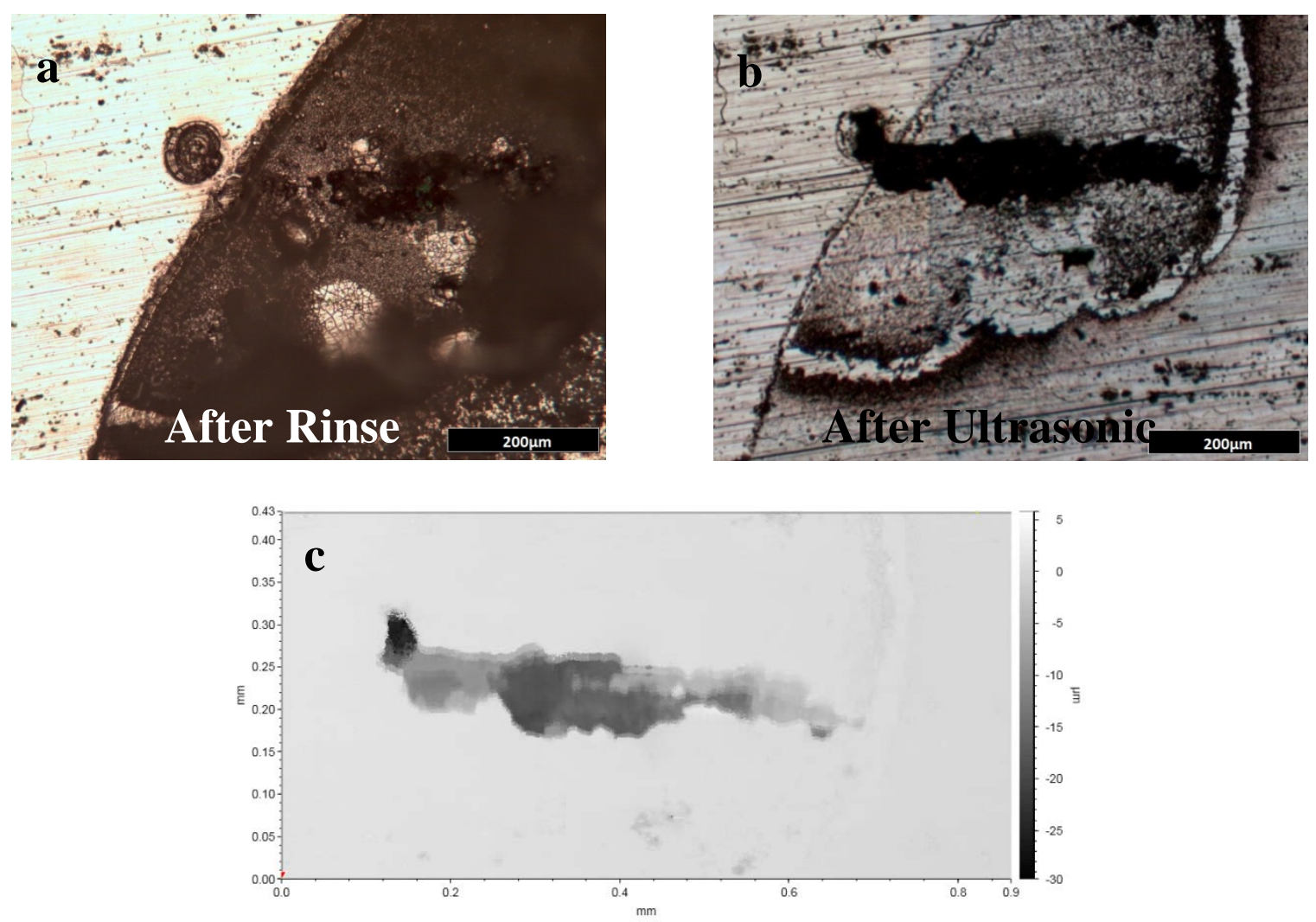

Figure 4.31. a) OM image of secondary droplet region from Example 3 after rinsing with DI water and ethanol. b) OM image of secondary droplet region after several minutes in the ultrasonicator. c) Secondary droplet region analyzed by optical profilometer. 

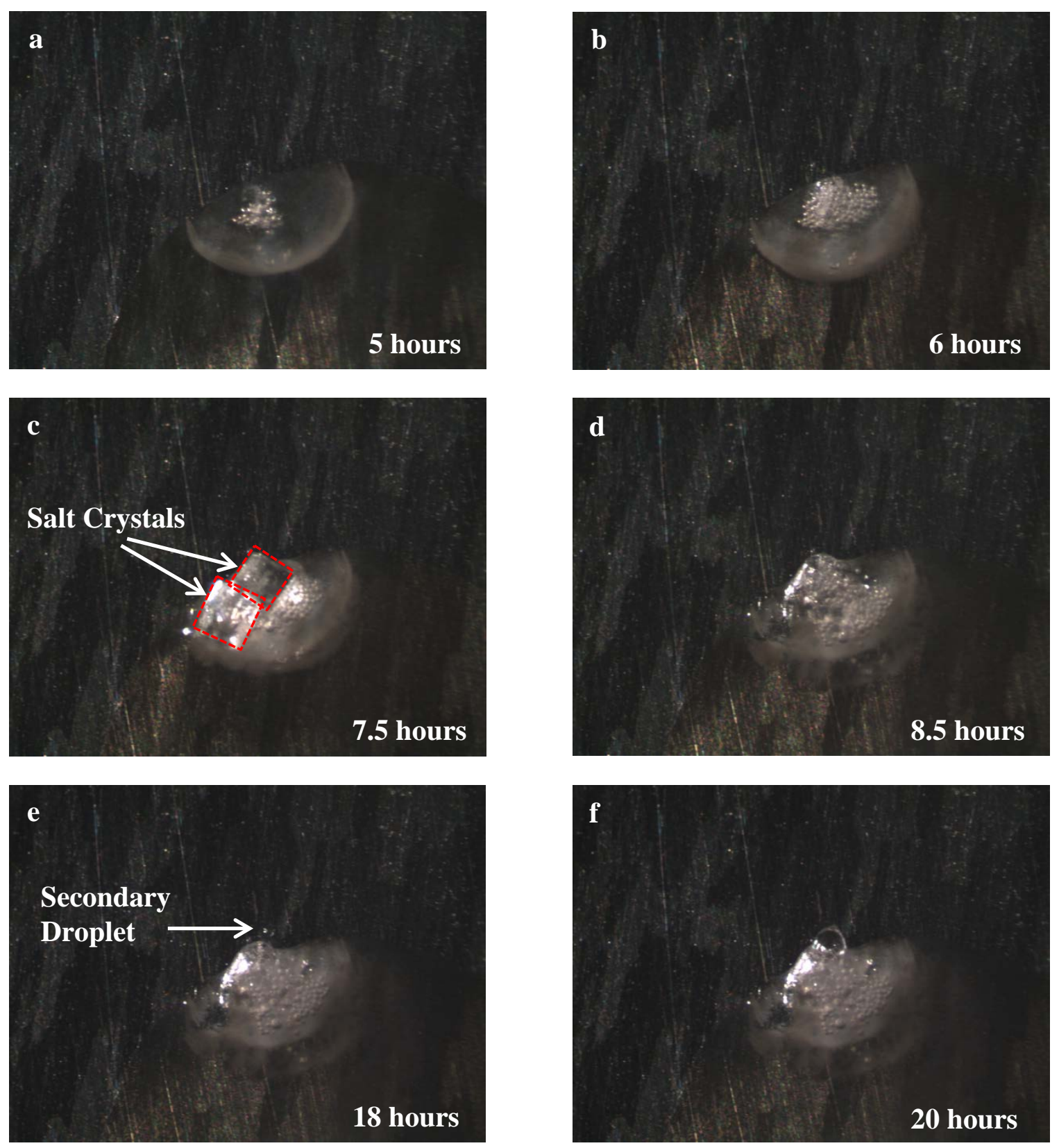

Figure 4.32. Images recorded for droplet described in Example 4. Initiation of secondary droplet identified. 

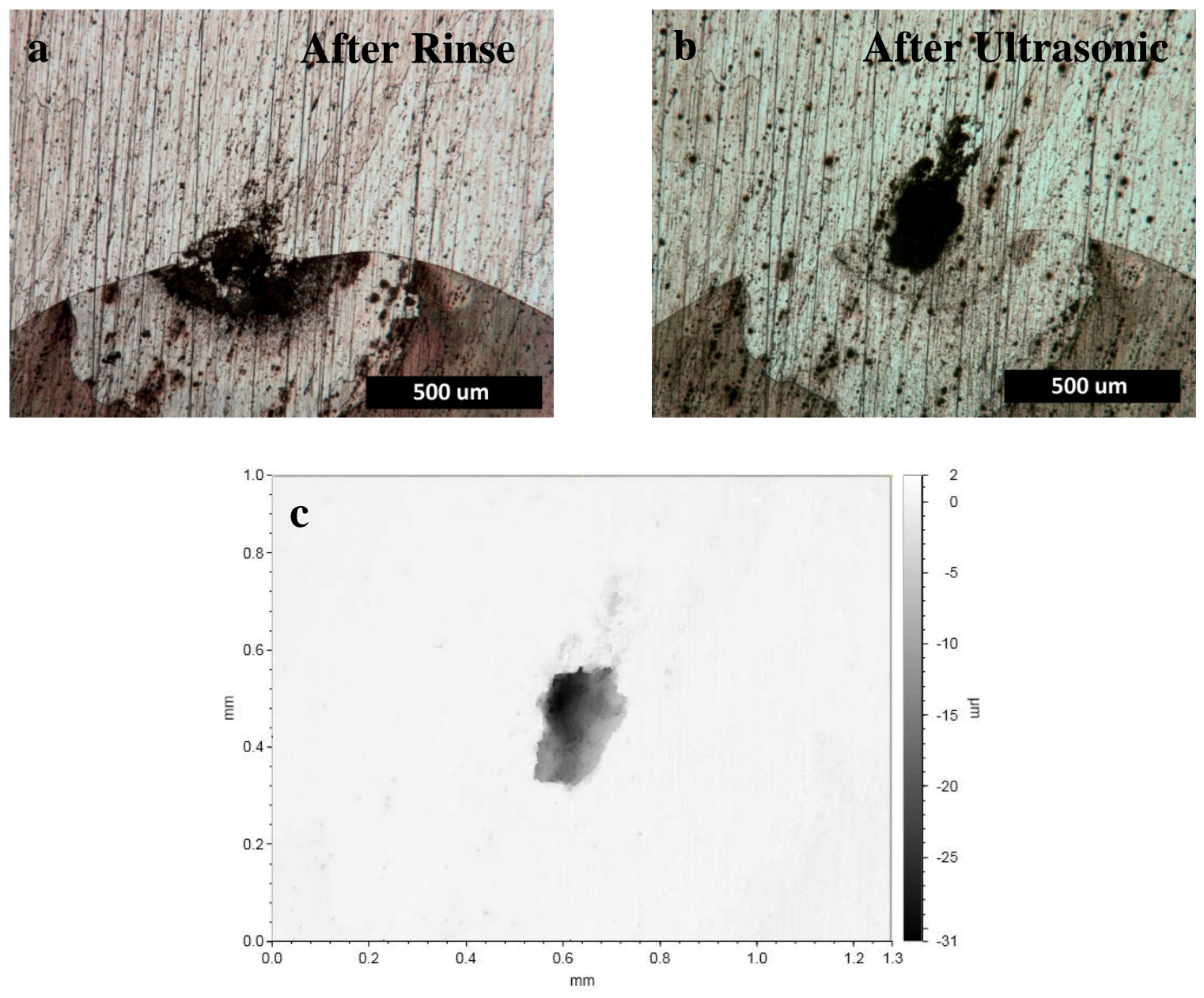

Figure 4.33. a) OM image of secondary droplet region from Example 4 after rinsing with DI water and ethanol. b) OM image of secondary droplet region after several minutes in the ultrasonicator. c) Secondary droplet region analyzed by optical profilometer. 


\subsection{References}

1. C. Vargel: 'Corrosion of Aluminium'; 2004, Amsterdam; Boston, Elsevier.

2. S. C. Morton and G. S. Frankel, Materials and Corrosion-Werkstoffe Und Korrosion, 2014, 65(4), 351-361.

3. V. Boljanovic, Applied Mathematical and Physical Formulas - Pocket Reference, Industrial Press.

4. M. Ohring, Materials Science of Thin Films - Deposition and Structure (2nd Edition), Elsevier.

5. Z. Zhao and G. S. Frankel, CS Corrosion Science, 2007, 49(7), 3064-3088.

6. WeatherUnderground. 'Weather Station KOHDUBLI3', [viewed 7/11/158/8/15]; Available from: https://www.wunderground.com.

7. I.-W. Huang: The Ohio State University, unpublished work, 2016 


\section{Chapter 5: Discussion}

\subsection{Discussion}

The monitoring of the corrosion of 7075-T6 under electrolyte droplets by SKP conducted in this study has shown many behaviors consistent with previously reported results. However, some key differences are evident. SKP line scans across the surface of droplets have shown that anodic pitting regions form near the edge of the droplets, and that the pits are surrounded by supporting cathodic regions. This behavior is similar to that described by Evans drop experiments on iron, ${ }^{1}$ but for $\mathrm{Al}$ the anode is not limited to the center of the droplet. Morton et al. monitored the potential at the center of droplets of $3.5 \mathrm{wt} \% \mathrm{NaCl}$ on AA7075-T6 and observed large jumps (as large as $500 \mathrm{mV}$ ) in some cases corresponding to the formation of secondary droplets. ${ }^{2}$ When line scans after the point measurements were completed, less drastic potential profiles were observed, often finding a potential change less than $100 \mathrm{mV}$. The smaller potential change was attributed to evaporation of the droplet caused by a humidity drop during opening of the chamber to adjust the sample position before performing the line scans. In this study, however, no such large potential jumps were observed during point measurements under any conditions. On the other hand, similar potential profiles were observed from line scans performed without opening the SKP chamber. This suggests a difference is present somewhere in the acquisition of the potential data. 
It is important to consider the resolution of the potential that is achievable by the SKP. As discussed in Chapter 2, the Volta potential measured by the SKP between the probe and the electrolyte surface is directly proportional to the corrosion potential. ${ }^{3}$ It is assumed that the Volta potential observed is essentially a reflection of the potential at the interface of the metal and solution. In the present study, it is not clear how large an area under the droplet is sensed by the probe. It is possible that if the signal is weak enough, the observed potential could be an average produced from the potential over a large area. There is precedent for this type of behavior. In previous tests conducted using the SKP in this lab, utilization of probe tips with smaller diameters appeared to collect stray signal from surrounding areas. This was particularly an issue when the probe tip was located near the edge of a droplet where signal gathered from side of the probe influenced the recorded potential. The SKP used in this study is the same used by Morton et al. ${ }^{2}$ It also underwent repairs during this investigation due to an insufficient signal, and later encountered a malfunction again that weakened the signal. It is possible that degradation of the SKP signal caused the probe to collect signal from a larger area. This could lead to an observed potential produced from the average of a larger area. This also could explain the failure to observe the spikes in potential previously observed. ${ }^{2}$ Lateral resolution of potential by the SKP is one suggestion that this study will present for future study.

Although not large, changes in the observed potential during point measurements were observed, as shown in Figures 4.1 and 4.2. By supplementing the point measurements with interval line scans, these potential changes were found to take place during expansion of the pitting region, most visibly the agglomeration of $\mathrm{H}_{2}$ bubbles, 
beneath the SKP probe tip, Figure 4.12. This, in combination with the observed growth of the cathodic region during interval line scans presented in Figure 4.14, is suggested to be the cause of the elevations in potential observed in many of the point measurement experiments. The lateral resolution described in the previous paragraph could also influence this, by blurring the boundary of the cathodic region and increasing the observed potential before the cathodic region actually extends beneath the probe. Optical analysis of the pits after testing showed that they underwent lateral growth along the rolling direction, shown schematically in Figure 4.15. This lateral expansion could cause propagation toward the center of the droplet, resulting in the observed growth of the cathodic region in that direction. The area of cathodic reaction may have also increased as a result of the increased size of the anodic pitting area, and expansion toward the center of the droplet promoted due to the limit posed by the droplet edge.

In tests conducted on samples placed outdoors, the cycling of humidity was found to have a greater influence on droplets containing $\mathrm{NaCl}$ than $\mathrm{MgCl}_{2}$ droplets, Figures 4.24 and 4.25. For $\mathrm{MgCl}_{2}$, little difference was found for any interval of time between the tests performed outdoors and those done in lab. For $\mathrm{MgCl}_{2}$ exposed outdoors for seven days, instances were observed where pitting extended laterally by the formation of a series of secondary droplets. For $\mathrm{NaCl}$ the volume of pitting was found to be consistently greater for droplets tested outdoors than those tested in the lab for four or seven days. Maximum pitting depths were found to be similar. Also, for the $\mathrm{NaCl}$ droplet tested outdoors, attack was found along the entire edge of the droplet in addition to the secondary droplet attack, Figure 4.23. It is proposed that, during the initial sustained attack taking place during the 
droplet edge, many of the dissolved salt ions migrate toward the edge pit, lowering the chloride concentration in the remaining bulk of the droplet. This would explain the limit of attack observed in the bulk region. As the humidity drops beneath the critical RH of $\mathrm{NaCl}$, evaporation of the bulk droplet causes the remaining dissolved ions to diffuse toward the droplet edge and precipitate, in a manner similar to the coffee ring effect. ${ }^{4}$ Corrosion product within the initial droplet area makes attack there less favorable, so upon rehydration of the salt at the droplet edge, attack propagates outward along the entire droplet perimeter. This type of attack is not observed for $\mathrm{MgCl}_{2}$ droplet because the humidity never dropped below the critical $\mathrm{RH}$ of $\mathrm{MgCl}_{2}$.

The greater attack in $\mathrm{NaCl}$ droplets placed outdoors is likely a result of the humidity cycling above and below the salt's critical relative humidity. This would cause chloride concentration to reach very high levels at lower humidity. Also, it is possible that some of the corrosion products may have a critical $\mathrm{RH}$ lower than that of $\mathrm{NaCl}$, allowing water to persist at lower RH and corrosion attack to continue. Also of note was the attack presented in Figure 4.21 for the $\mathrm{NaCl}$ droplet exposed outdoors for four days. During pitting attack along secondary droplets forming in sequence, new pitting regions formed near the initial pit. These regions were also oriented along the rolling direction. Assuming the pitting attack takes place at secondary particles as has been done previously, ${ }^{2}$ it appears that the additional pitting regions are separate groupings of secondary particles. It is proposed that the secondary droplet region in this test grew large enough to contact additional groupings of secondary particles that were susceptible to attack, and new regions of sustained pitting attack were formed. 
Based on the observations of droplets during SKP tests, aging tests, and outdoor tests, some conclusions can be drawn regarding the influence of the initial droplet conditions on the corrosion behavior. The area of the droplets was shown to have the greatest influence. As droplet area increased, so did pitting volume, as seen during the SKP droplet tests, but specifically during the aging tests. It seems most likely that this is caused by an increase in the chance of regions more susceptible to pitting attack being covered by droplets of a larger area. The initial salt concentration did not appear to have any significant effect on the corrosion behavior. Shown in Figures 4.16 and 4.17, pit depth and pit volume were not significantly different between droplets of differing initial salt concentration with the same starting volume. However, salt concentration could have been impactful because of the increase in droplet thickness. When a droplet equilibrates with the humidity in the chamber air, its salt concentration will be fixed by the value in equilibrium with the chamber RH. Droplets with higher initial salt concentration contain a greater amount of salt, and as such will take up a greater volume of water at equilibrium. ${ }^{5}$ Greater droplet volume with the same contact area means an increased droplet thickness. Droplet thickness affects the diffusion distance for oxygen to the sample surface, at least in regions away from the droplet edge. Therefore, droplets of greater thickness could experience pitting attack limited by oxygen diffusion. Reduction of oxygen is the primary supply of supporting cathodic reaction, so limiting the supply of oxygen could reduce the anodic reactions in the pits. Some of this effect may be offset by the increased chloride content present. Although the chloride concentration by volume does not increase, higher starting salt concentration does lead to a greater concentration 
of chloride relative to the area of sample exposed. Droplet thickness alone does not appear to be entirely controlling the severity of attack. Pit depth and pit volume do not show direct relationships to the initial salt concentration, the controlling characteristic of equilibrium droplet height. Therefore it is likely that another condition is influencing pitting, though it is as of yet unidentified.

In studies on aluminum alloy 2024, pit initiation and propagation are attributed to the clustering of intermetallics and secondary particles at the surface. ${ }^{6,7}$ Liao et al. proposed that initiation occurred by galvanic coupling between constituent particles and the alloy matrix. In this model, pit growth is caused by exposure of clusters of subsurface particles to electrolyte and proceeds by corrosion around the surface of nearby particles. In a study by Hughes et al., it was suggested instead that initiation occurred by coupling between intermetallic surface particles. ${ }^{7}$ Following initiation, intergranular corrosion was observed to reach depths similar to the maximum reported pitting depths. It was suggested that further corrosion took place by grain fall out as a result of the IGC. In both studies, a dome of corrosion product was found to form over the pitting sites, forming occluded cells where $\mathrm{H}_{2}$ is produced, similar to observations in this study. Surrounding these cells, a ring of corrosion product was found to form, typically several hundred microns in diameter. The area within the ring is absent of corrosion product aside from the domes formed, also similar to the product-free region found in the droplet tests performed here. It was assumed that these product-free regions were cathodically protected by the anodic pits. Additionally, chlorine was found to only be located in the dome regions. Due to 
similarities to this process observed in the current study, it is believed that a similar mechanism controls the pitting investigated on 7075-T6.

The following is a proposed mechanism for the pitting process investigated on 7075T6 beneath droplets of $\mathrm{NaCl}$ or $\mathrm{MgCl}_{2}$. Metastable pitting initiates across the sample surface beneath the droplet at surface particles. Eventually, pitting at a cluster of secondary phase particles transitions to sustained attack, typically near the droplet edge. Preference for attack at the droplet edge is caused by the shorter distance for oxygen diffusion, the primary supporting cathodic reaction. Chloride ions then concentrate over this pitting region. This is supported by the observation of salt crystals only precipitating over the pitting region when the humidity was lowered and nowhere else across the droplet surface. A corrosion product ring then forms surrounding the cathodic region, identified previously by its lack of corrosion product, region "2” in Figure 4.14. This region initially composes the cathodically protected region. The observation of lateral pit growth consistently extending in the rolling direction suggests that one or more characteristics of the microstructure present favorable conditions for an anodic pathway oriented in the rolling direction. Microstructure characteristics dictating the preferred pitting path could also explain the relatively low variation in pitting depth consistently observed. The pit extends along this anodic pathway, supported by the cathodic region at the surface of the sample surrounding the pit. Growth of the supporting cathodic region is observed by SKP. The cathodic region can expand beyond the initial corrosion product ring, however it does not visibly change the surface outside of the ring where corrosion product has built up. 
In cases where secondary droplets form, the proposed mechanism can be extended as an additional mechanism to the one proposed by Morton et al. ${ }^{2}$ In the previous proposal, the restricted diffusion of ions generated by the pit at the droplet edge caused the expansion of the droplet outward, forming the secondary droplet. This appears to be the case presented in Example 2 here, and a similar process occurs in Example 4. However, precipitation of salt crystals caused the expansion of the droplet perimeter in that test. It is proposed here that ions are also able to diffuse into a thin absorbed water layer that extends outside of the primary droplet area, similar to what was proposed by Tsuru et al. ${ }^{8}$ Beneath the absorbed water layer, possibly at a susceptible secondary particle at the surface, cathodic reactions can take place in the form of oxygen reduction, providing cathodic current to the nearby edge pit. The ions generated by this process, in addition to ions that migrate to this region through the absorbed water layer from the primary droplet to balance the charge, lead to the absorption of water from the humid air and secondary droplet growth. In Example 4, the pit eventually extended to this region. Depending on the proximity of this cathodic site to the droplet edge, secondary droplet formation can appear either as a bulge in the primary droplet boundary, or as the growth of an entirely independent droplet that does not overlap the primary droplet area.

The tests presented here show in greater detail the processes that AA7075-T6 undergoes during pitting corrosion under droplets of electrolyte, exploring the influence of various initial conditions. The effects of droplet area and salt cation are shown to be important factors controlling the severity of pitting attack, and the role of humidity, specifically between a fixed, elevated humidity and humidity that is cycled, is found to be 
of particular importance in controlling the corrosion behavior. The exploration of these conditions, with the increased in situ analytical capabilities presented by the SKP, expand the foundation for the development of electrolyte droplet testing as a means of accelerated lab testing of atmospheric pitting corrosion. 


\subsection{References}

1. U. R. Evans: 'An introduction to metallic corrosion'; 1982, London; Metals Park, Ohio, E. Arnold ; American Society for Metals.

2. $\quad$ S. C. Morton and G. S. Frankel, Materials and Corrosion-Werkstoffe Und Korrosion, 2014, 65(4), 351-361.

3. M. Stratmann and H. Streckel, Corrosion Science, 1990, 30(6-7), 681-696.

4. R. D. Deegan, O. Bakajin, T. F. Dupont, G. Huber, S. R. Nagel, and T. A. Witten, Nature, 1997, 389(6653), 827-829.

5. C. Schaschke, Dictionary of Chemical Engineering, Oxford University Press.

6. C. M. Liao, J. M. Olive, M. Gao, and R. P. Wei, Corrosion, 1998, 54(6), 451-458.

7. A. Hughes, T. H. Muster, A. Boag, A. M. Glenn, C. Luo, X. Zhou, G. E. Thompson, and D. McCulloch, Corrosion Science, 2010, 52(3), 665-668.

8. T. Tsuru, K. I. Tamiya, and A. Nishikata, Electrochimica Acta, 2004, 49(17-18), 2709-2715. 


\section{Chapter 6: Conclusions and Future Work}

\subsection{Conclusions}

The pitting behavior of AA7075-T6 has been investigated by application of electrolyte droplets under varying initial conditions and analysis by Scanning Kelvin Probe measurement along with video observation. Studies of the influence of droplet volume, salt cation, and initial concentration were performed, as well as the influence of the etching procedure on droplet behavior, and the difference in attack between fixed and cycling humidity. The following conclusions can be made.

1. Regarding the initial droplet conditions, the area of the droplet/sample interface had the greatest influence on corrosion behavior. Increasing the area led to increasing pitting attack, likely because areas more susceptible to accelerated attack are more likely to be covered by a larger droplet.

2. Higher initial salt concentration in droplets of the same initial volume, which resulted in greater droplet thickness at a given $\mathrm{RH}$, did not have a direct relationship with the severity of attack. It seems likely that additional variable conditions played a role, possibly in combination with droplet thickness, to influence the severity of corrosion attack. These factors, however, were not identified. 
3. Aging time after etching to remove the active surface layer was shown to affect the wetting of the sample surface, changing droplet diameters and corrosion behavior. This should be carefully monitored in future studies to ensure consistent conditions.

4. Corrosion by droplets containing $\mathrm{NaCl}$ was faster in outdoor tests than in the controlled SKP chamber. This was the result of RH cycling above and below the critical $\mathrm{RH}$ of $\mathrm{NaCl}$, creating elevated chloride concentrations. The disparity of attack compared to lab tests suggests that cyclic variation of RH during lab testing is critical to better simulate atmospheric corrosion behavior. In contrast, corrosion under droplets of $\mathrm{MgCl}_{2}$ exhibited similar corrosion behavior in tests conducted outdoors and in the SKP chamber. This occurred because the RH remained above the critical $\mathrm{RH}$ of $\mathrm{MgCl}_{2}$ in both test conditions. It is also believed that the difference in equilibrium concentration of $\mathrm{MgCl}_{2}$ for the maximum and minimum RHs observed is much smaller than initially assumed.

5. Outdoor exposure with $\mathrm{NaCl}$ droplets also exhibited attack around the entire droplet perimeter instead of attack remaining localized in the sustained pitting areas as experienced during tests in the SKP chamber. This was attributed to chloride ions flowing to the droplet edge during evaporation by a mechanism similar to the coffee ring effect. ${ }^{1}$

6. A mechanism for the process of pitting attack under electrolyte droplets on AA7075-T6 was proposed, by which sustained attack initiates at a cluster of 
secondary particles at the surface and propagation follows an anodically favorable pathway oriented in the rolling direction.

7. A mechanism was proposed for the formation of secondary droplets in which an absorbed water layer forms externally to the primary droplet. Generation of ions under this layer by oxygen reduction, as well as diffusion of ions generated by a pit at the edge of the droplet into the absorbed water layer, leads to absorption of water from the humid air and growth of the secondary droplet. This mechanism would operate in addition to a previously proposed mechanism. ${ }^{2}$ Both proposals could be accurate but represent behavior experienced under differing conditions.

8. An explanation was offered for inconsistencies in the magnitude of potential fluctuations observed here and in previous results. ${ }^{2}$ Operational issues with the SKP experienced during this study could have influenced the potential resolution of the instrument. It is possible that the potentials measured by the SKP in the current study were an average of potentials collected over a larger area.

\subsection{Future Work}

The results and proposals of this work expanded the knowledge of pitting behavior of AA7075-T6 under electrolyte droplets. However, additional work could be built upon this to expand the understanding and assist in better explaining the mechanisms identified. Regarding future work, the following suggestions are proposed.

1. Expansion of the testing performed with the SKP could improve the value of the data obtained. Specifically, area scans over the droplet would allow for the 
potential and topography of the entire droplet area to be mapped at different times during the pitting process.

2. Further investigation is needed into the behavior of the adsorbed water layer outside of the primary droplet proposed to participate in the development of secondary droplets. SKP studies could be used to determine if reactions contributing to the pitting process are taking place outside of the primary droplet area.

3. Analysis of the lateral resolution of potential measurements beneath thin electrolyte layers by the SKP is needed, possibly by the incorporation of a multielectrode array. ${ }^{3}$

4. Cycling of the humidity should be performed in the lab to better observe the behaviors discovered here. Additionally, cycling should include RH values above and below the critical $\mathrm{RH}$ of $\mathrm{MgCl}_{2}$ to look for behavior similar to that observed in $\mathrm{NaCl}$ droplets exposed outdoors. 


\subsection{References}

1. R. D. Deegan, O. Bakajin, T. F. Dupont, G. Huber, S. R. Nagel, and T. A. Witten, Nature, 1997, 389(6653), 827-829.

2. $\quad$ S. C. Morton and G. S. Frankel, Materials and Corrosion-Werkstoffe Und Korrosion, 2014, 65(4), 351-361.

3. N. D. Budiansky, F. Bocher, H. Cong, M. F. Hurley, and J. R. Scully, Corrosion, 2007, 63(6), 537-554. 


\section{Bibliography}

\section{Chapter 1}

1. J. E. Hatch, A. Aluminum, and M. American Society for: 'Aluminum : properties and physical metallurgy'; 1984, Metals Park, Ohio, American Society for Metals.

2. N. Birbilis and R. G. Buchheit, JOURNAL- ELECTROCHEMICAL SOCIETY, 2005, 152(4), B140-B151.

3. G. S. Frankel, Journal of the Electrochemical Society, 1998, 145(6), 2186-2198.

4. E. Lunarska, E. Trela, and Z. Szklarska-Smialowska, Corrosion Corrosion, 1987, 43(4), 219-228.

5. D. B. Blucher, J. E. Svensson, and L. G. Johansson, Journal of the Electrochemical Society, 2003, 150(3), B93-B98.

6. C. Leygraf and T. E. Graedel: 'Atmospheric corrosion'; 2000, New York, WileyInterscience.

7. U. R. Evans: 'An introduction to metallic corrosion'; 1982, London; Metals Park, Ohio, E. Arnold ; American Society for Metals.

8. $\quad$ S. Hastuty, A. Nishikata, and T. Tsuru, Corrosion Science, 2010, 52(6), 20352043.

9. S. C. Morton and G. S. Frankel, Materials and Corrosion-Werkstoffe Und Korrosion, 2014, 65(4), 351-361. 
10. J. F. Li, B. Maier, and G. S. Frankel, CS Corrosion Science, 2011, 53(6), 21422151.

11. T. Tsuru, K. I. Tamiya, and A. Nishikata, Electrochimica Acta, 2004, 49(17-18), 2709-2715.

12. M. Stratmann, K. T. Kim, and H. Streckel, Zeitschrift Fur Metallkunde, 1990, 81(10), 715-725.

13. M. Stratmann and H. Streckel, Corrosion Science, 1990, 30(6-7), 697-714.

14. M. Stratmann, H. Streckel, K. T. Kim, and S. Crockett, Corrosion Science, 1990, 30(6-7), 715-734.

\section{Chapter 2}

1. J. E. Hatch, A. Aluminum, and M. American Society for: 'Aluminum : properties and physical metallurgy'; 1984, Metals Park, Ohio, American Society for Metals.

2. Q. Meng, 2003.

3. C. Leygraf and T. E. Graedel: 'Atmospheric corrosion'; 2000, New York, WileyInterscience.

4. $\quad$ S. Hastuty, A. Nishikata, and T. Tsuru, Corrosion Science, 2010, 52(6), 20352043.

5. B. S. Maier: 'Electrochemical studies under thin electrolyte layers using a Kelvin Probe', Ohio State University, Columbus, Ohio, 2010.

6. J. F. Li, B. Maier, and G. S. Frankel, CS Corrosion Science, 2011, 53(6), 21422151. 
7. G. S. Frankel, M. Stratmann, M. Rohwerder, A. Michalik, B. Maier, J. Dora, and M. Wicinski, Corrosion Science, 2007, 49(4), 2021-2036.

8. M. Stratmann and H. Streckel, Corrosion Science, 1990, 30(6-7), 681-696.

9. M. Stratmann and H. Streckel, Corrosion Science, 1990, 30(6-7), 697-714.

10. M. Stratmann, H. Streckel, K. T. Kim, and S. Crockett, Corrosion Science, 1990, 30(6-7), 715-734.

11. M. Wicinski, Kelvin Probe: The Vibrating Capacitor Technique, WicinskiWicinski GbR.

12. G. S. Frankel, MSE 7818 Notes. Spring 2015.

13. B. Maier and G. S. Frankel, J Electrochem Soc Journal of the Electrochemical Society, 2010, 157(10), C302-C312.

14. J. R. Davis, Metals Handbook, Desk Edition (2nd Edition), ASM International.

15. F. Andreatta, H. Terryn, and J. H. W. de Wit, Electrochimica Acta, 2004, 49(17/18).

16. I. J. Polmear: 'Light alloys : metallurgy of the light metals'; 1996, New York; Toronto, J. Wiley \& Sons.

17. N. Birbilis and R. G. Buchheit, JOURNAL-ELECTROCHEMICAL SOCIETY, 2005, 152(4), B140-B151.

18. M. Chemingui, M. Khitouni, K. Jozwiak, G. Mesmacque, and A. Kolsi, Materials \& Design, 2010, 31(6), 3134-3139.

19. I. L. Muller and J. R. Galvele, CS Corrosion Science, 1977, 17(12), 995-1007. 
20. I. L. Muller and J. R. Galvele, CS</cja:jid > Corrosion Science, 1977, 17(3), 179,191-189,193.

21. Q. J. Meng and G. S. Frankel, Journal of the Electrochemical Society, 2004, 151(5), B271-B283.

22. M. Gao, Metallurgical and Materials Transactions. A, Physical Metallurgy and Materials Science, 1998, 29(4), 1153-1160.

23. R. Buchheit and L. Sandia National, Journal of the Electrochemical Society, 1995, 142(11), 3994-3996.

24. C. Vargel: 'Corrosion of Aluminium'; 2004, Amsterdam; Boston, Elsevier.

25. M. C. Reboul, T. J. Warner, H. Mayet, and B. Baroux, Aluminium Alloys: Their Physical and Mechanical Properties, Pts 1-3, 1996, 217, 1553-1558.

26. Z. Zhao and G. S. Frankel, CS Corrosion Science, 2007, 49(7), 3064-3088.

27. Z. Zhao and G. S. Frankel, CS Corrosion Science, 2007, 49(7), 3089-3111.

28. Z. Zhao, 2006.

29. G. S. Frankel, Journal of the Electrochemical Society, 1998, 145(6), 2186-2198.

30. R. P. V. Cruz, A. Nishikata, and T. Tsuru, Corrosion Science, 1998, 40(1), 125139.

31. D. A. Jones: 'Principles and prevention of corrosion'; 1996, Upper Saddle River, NJ, Prentice Hall.

32. S. Hu, S. Sun, A. Guo, X. Jia, and Y. Geng, Corrosion, 2011, 67(10).

33. B. S. Smith, E. J. Duxbury, B. T. Moore, S. Defence, and C. Technology Organization, 1997. 
34. Y. Tsutsumi, A. Nishikata, and T. Tsuru, Journal of the Electrochemical Society, 2006, 153(7), B278-B282.

35. J. R. Duncan and J. A. Ballance: 'Marine salts contribution to atmospheric corrosion'; 1988, Porirua, BRANZ.

36. U. R. Evans: 'An introduction to metallic corrosion'; 1982, London; Metals Park, Ohio, E. Arnold ; American Society for Metals.

37. S. Ito, M. Yabumoto, H. Omata, and T. Murata: 'ATMOSPHERIC CORROSION OF STAINLESS STEELS A2 - FROMENT, MICHEL', in 'Passivity of Metals and Semiconductors', 637-642; 1983, Elsevier.

38. M. Stratmann, K. T. Kim, and H. Streckel, Zeitschrift Fur Metallkunde, 1990, 81(10), 715-725.

39. S. C. Morton and G. S. Frankel, Materials and Corrosion-Werkstoffe Und Korrosion, 2014, 65(4), 351-361.

\section{Chapter 3}

1. A. International, ASTM Standard B211-12e1, in Standard Specification for Aluminum and Aluminum-Alloy Rolled or Cold Finished Bar, Rod, and Wire. 2012.

2. Z. Zhao, 2006.

3. S. C. Morton and G. S. Frankel, Materials and Corrosion-Werkstoffe Und Korrosion, 2014, 65(4), 351-361.

4. Anon. 'National Centers for Environmental Information (NCEI)', [viewed; Available from: $\underline{\text { http://www.ncdc.noaa.gov/. }}$ 


\section{Chapter 4}

1. C. Vargel: 'Corrosion of Aluminium'; 2004, Amsterdam; Boston, Elsevier.

2. S. C. Morton and G. S. Frankel, Materials and Corrosion-Werkstoffe Und Korrosion, 2014, 65(4), 351-361.

3. V. Boljanovic, Applied Mathematical and Physical Formulas - Pocket Reference, Industrial Press.

4. M. Ohring, Materials Science of Thin Films - Deposition and Structure (2nd Edition), Elsevier.

5. Z. Zhao and G. S. Frankel, CS Corrosion Science, 2007, 49(7), 3064-3088.

6. WeatherUnderground. 'Weather Station KOHDUBLI3', [viewed 7/11/158/8/15]; Available from: https://www.wunderground.com.

7. I.-W. Huang: The Ohio State University, unpublished work, 2016

\section{Chapter 5}

1. U. R. Evans: 'An introduction to metallic corrosion'; 1982, London; Metals Park, Ohio, E. Arnold ; American Society for Metals.

2. S. C. Morton and G. S. Frankel, Materials and Corrosion-Werkstoffe Und Korrosion, 2014, 65(4), 351-361.

3. M. Stratmann and H. Streckel, Corrosion Science, 1990, 30(6-7), 681-696.

4. R. D. Deegan, O. Bakajin, T. F. Dupont, G. Huber, S. R. Nagel, and T. A. Witten, Nature, 1997, 389(6653), 827-829.

5. C. Schaschke, Dictionary of Chemical Engineering, Oxford University Press.

6. C. M. Liao, J. M. Olive, M. Gao, and R. P. Wei, Corrosion, 1998, 54(6), 451-458. 
7. A. Hughes, T. H. Muster, A. Boag, A. M. Glenn, C. Luo, X. Zhou, G. E. Thompson, and D. McCulloch, Corrosion Science, 2010, 52(3), 665-668.

8. T. Tsuru, K. I. Tamiya, and A. Nishikata, Electrochimica Acta, 2004, 49(17-18), 2709-2715.

\section{Chapter 6}

1. R. D. Deegan, O. Bakajin, T. F. Dupont, G. Huber, S. R. Nagel, and T. A. Witten, Nature, 1997, 389(6653), 827-829.

2. S. C. Morton and G. S. Frankel, Materials and Corrosion-Werkstoffe Und Korrosion, 2014, 65(4), 351-361.

3. N. D. Budiansky, F. Bocher, H. Cong, M. F. Hurley, and J. R. Scully, Corrosion, 2007, 63(6), 537-554. 